\title{
The Localisation of Vulnerabilities: The construction of risks and hazards in the coverage of overseas earthquakes in the Seattle Times and the Vancouver Sun
}

\author{
By

\section{Thomas Jamieson}

\author{
A thesis \\ submitted to Victoria University of Wellington \\ in fulfilment of the requirements for the degree of \\ Master of Arts in Media Studies.
}

Victoria University of Wellington 


\section{ABSTRACT}

Despite an increasing willingness among academics politicians, policymakers, nongovernmental organisations [NGOs], businesses, practitioners and citizens to confront the risks posed by disasters, many attempts at implementing measures of disaster risk reduction [DRR] have been unsuccessful. Much has been written about disaster risk reduction, but none of the literature has effectively analysed the necessary conditions for disaster risk reduction to be successful in an at-risk community.

Van Belle argues that the localisation of distant disasters - the practice where a news outlet covers an external event from their own locality's point of view and interprets that event in terms of how it relates to them - is essential for DRR to become on the public agenda and create the opportunity for DRR policy to be successfully pursued (2012). This thesis adds to the understanding of the news coverage of non-local disaster events by analysing how disasters are localised by the news media to relate to the hazards faced by their communities. It was found that overseas disaster events must not only be localised, but also communalised through direct comparisons between communities in the news coverage for DRR to become on the public agenda in at-risk communities.

229 newspaper articles were analysed through a structured qualitative content analysis. Localisation occurred in the Seattle Times and the Vancouver Sun following six overseas earthquakes. It was found that the nature of the coverage changed according to the stricken country's level of development, where more direct comparisons were made between communities after the earthquakes in Japan, Chile and in Turkey in some instances. However, the coverage of the earthquakes in Turkey, Pakistan and Haiti led 
to the establishment of a paternalistic victim-saviour type relationship between communities in the newspapers.

These findings have significant implications for the implementation of disaster risk reduction in at-risk communities and for the understanding of the production of news. Additionally, the theoretical practice of localisation was developed and operationalised. This led to the formulation of five typologies of localisation that illustrated the nature of the coverage of the earthquakes in the two leading broadsheet newspapers in the Pacific Northwest. Significantly, the thesis suggests that the nature of the localisation may depend on their level of identification with the stricken community. 


\section{TABLE OF CONTENTS}

ABSTRACT

ii

ILLUSTRATIONS vi

ACKNOWLEDGEMENTS vii

INTRODUCTION 1

CHAPTER ONE: CONTEXTUALISATION 15

DEFINITIONS OF DISASTER 15

MEDIA RESEARCH INTO DIFFERENCES IN DiSASTER COVERAGE

DEFINITIONS OF DISASTER RISK REDUCTION

DISASTER RISK REDUCTION LITERATURE IN NON-GOVERNMENTAL ORGANISATIONS 22

Disaster Risk Reduction in Practice

RESEARCH INTO DISASTER RISK REDUCTION AND THE MEDIA

VAN BELLE'S MODEL

$\begin{array}{ll}\text { SUMMARY } & 38\end{array}$

CHAPTER TWO: LOCALISATION AND NEWS THEORY

DEFINING LOCALISATION

LOCALISATION AND NEWS THEORY

LOCALisation IN PRACTICE

LOCALISATION AND LoCAl NeWs ProduCERS

LOCALISATION AND TRANSLATION IN THE BBC WORLD SERVICE

LOCALISATION AND DISASTER COVERAGE

THE OTHERING EFFECT

CHAPTER THREE: METHODOLOGY

$\begin{array}{lr}\text { AVOIDING THE CONFIRMATION BIAS } & 67\end{array}$

THE TYPOLOGIES OF LOCALISATION

THE FoCAL QUESTIONS

SOURCing NewSPAPER ARTICles to Reveal the NATURe OF LOCALISATION

CHAPTER FOUR: FINDINGS $\quad 78$

$\begin{array}{ll}\text { OVERVIEW } & 78\end{array}$

COMMUNALiSATION

Partial Communalisation $\quad 91$

NEUTRAL LOCALISATION

Partial Othering $\quad 94$

$\begin{array}{ll}\text { OTHERING } & 101\end{array}$

A COMParison of Localisation between the Third Person Communities 111 
WhAT THE Findings SUgGeST

SUMMARY

CHAPTER FIVE: DISCUSSION

IMPLICATIONS FOR DISASTER RISK REDUCTION

IMPLICATIONS FOR NEWS THEORY

SUGGESTIONS FOR FUTURE RESEARCH

APPENDIX: THE NEWSPAPER ARTICLES IN THE SAMPLE

THE SEATTLE TIMES

129

THE VANCOUVER SUN 


\section{ILLUSTRATIONS}

\section{FIGURES}

1. Van Belle's Necessary Causes and the Third Person Effect Model

2. The TYPOLOGIES OF LOCALISATION.

\section{TABLES}

1. The Damage Caused by the Six Overseas EarthQuakes 6

2. IndiCATORS OF DEVELOPMENT IN THE THIRD PERSON AND STRICKEN COMMUNITIES 7

3. The Full Quantitative Findings OF THE ANALysis 79

4. A COMParison OF COMMUNALisation AND Othering IN THE ANALysis 81 


\section{ACKNOWLEDGEMENTS}

The thesis would not have been possible without the full support of my parents, my siblings, and the rest of my extended family. I have been tremendously fortunate to have them behind me every step of the way, encouraging me at every opportunity. This support network has been a real comfort throughout this process.

I owe a huge debt of thanks to my supervisors, Doug Van Belle and Peter Thompson. I could not wish for better people to work with. Doug's News Analysis paper triggered my interest in political communication in the first place, and he has continued to be an inspiring person to work with. He has been particularly influential in providing personal and professional guidance over the past few years. Peter was brilliant in providing useful critiques throughout the writing of the thesis, and was especially helpful in providing critiques of the methodology. I am grateful for their thorough reviews of numerous drafts, which were extremely helpful as I refined the thesis. I have been very fortunate to be supervised by two extremely capable, warm and sincere people.

I was fortunate enough to be granted a generous Master's scholarship by The Dominion Post. This allowed me to study full-time towards the MA thesis without the need to work part-time to make ends meet. I am very grateful for this opportunity and I truly appreciate their support.

I was also fortunate to have received the Student Allowance for 12 months during my study. I am acutely aware of the significant support this funding provided me, and I am hopeful of its return for postgraduate students. 
The staff and students at SEFTMS have been a pleasure to work alongside. It has been great to discuss ideas with like-minded students and staff. I am lucky to have been surrounded by so many friendly people in the school. I am also grateful for the opportunity to tutor undergraduate courses, which has stimulated my learning into different areas of research and developed my teaching skills.

I must also thank my friends for being patient during long-winded updates on my thesis and for being understanding when the university work encroached on time spent with them.

Finally, I would like to thank my partner, Jess, for her loving support over the course of my study. She has also been extremely patient when the study has cut into the time we have spent together. I appreciate her constant encouragement and reiteration of her belief that all of the hard work would eventually pay off. 


\section{INTRODUCTION}

Natural disasters are worthy of attention due to the threat they pose to communities all around the world. Unsurprisingly, there is an increasing amount of literature about how best to implement measures of disaster risk reduction [DRR], where the risks presented by disasters are reduced through specific actions in an at-risk community. There appears to be an increasing willingness among politicians, policymakers, nongovernmental organisations [NGOs], businesses, practitioners and citizens to mitigate the risks of hazards as much as possible. This is most evident in the United Nations Development Programme's [UNDP] recent emphasis on disaster risk reduction.

This investigation is based on the strategic model for the opportunity for successful implementation of DRR proposed by Van Belle (2012). His opportunity model involves a non-local, observing [third person] community's news media covering an overseas disaster event in terms of their own vulnerabilities, which could ultimately lead to a public discussion of disaster risk reduction where political actors can take the opportunity to campaign for disaster risk reduction policies in their own rational selfinterest. His theory is based around the principle that if there is no public will for disaster risk reduction in an at-risk community, it does not matter how much money is contributed towards its implementation, it will ultimately be unsuccessful. This matches Tierney, Lindell and Perry's argument that there has been "little acknowledgement that gains in science and technology, while important, will have little impact unless they are accompanied by changes in the way society thinks about disasters and the steps that are taken to manage them" $(2001,255)$. 
Perhaps the most perceptive analysis of the role of the news media in disaster coverage came from the proceedings of the Committee on Disasters and the Mass Media Workshop in Washington, D.C. in 1979. Gladys Engel Lang and Kurt Lang wrote about how "only when disaster strikes does the public become willing to face problems such as the lack of preparedness against natural forces known to strike with predictable frequency, the inadequacy of safety measures against known industrial or medical hazards, and the long-term damage from measures and policies that take no account of complex ecological interrelationships" $(1980,277)$. They argued that the role of the media is important due to "their potential influence on the adoption of remedial measures, strikes us as potentially the most productive area of research, an area at least as valuable as the study of media activity during the actual emergency" (Lang and Lang 1980, 278). They suggested that the news media could play a part in addressing disaster mitigation in unaffected communities, proposing that research should be conducted to compare "the reporting of a disaster within the community it directly affects and in communities where it has become a national story" (Lang and Lang 1980, 278). 33 years later, this has remained an area which has not been explored in enough depth to suggest how the news media localise non-local disaster events and how this translates into DRR policy.

Localisation is the practice where a news outlet covers an external event from their own locality's point of view, interpreting that event in terms of how it relates to them. Localisation of vulnerabilities occurred in the Seattle Times and the Vancouver Sun following six overseas earthquakes, but the nature of the localisation changed according to the stricken country's development, and in some instances the news outlets rejected the notion that the disasters were relevant to their community. The primary focus of the 
investigation was to evaluate the nature of the localisation in two broadsheet newspapers of Seattle and Vancouver in response to six major overseas earthquakes over the past two decades. The hypothesis of this study was that the respective levels of development of these countries would determine how the disaster was localised or nonlocalised in the newspapers of the cities of Seattle and Vancouver because of the news media's prioritisation of elite nations and their perception of difference between communities.

This is significant because localisation is considered to be a necessary precondition for disaster risk reduction in Van Belle's model, and if the nature of the news media coverage of the overseas disaster is affected by the development of the stricken community, this affects how lessons can be learned from the disaster in the observing third person community. However, localisation by itself is not enough for DRR to occur in the third person community - there also needs to be communalisation between communities in the news coverage for DRR to become on the public agenda. This involves direct comparisons between communities, leading to an affinity between communities, where the third person community can recognise their own vulnerability through the experience of the stricken community. This is important because if the third person community cannot relate to the threat posed by a particular hazard in another community, it would be difficult to create the necessary public willingness to bear the social costs of implementing DRR in their community.

The investigation was conducted through a structured qualitative content analysis, which involved applying a formal structure to the qualitative analysis of newspaper articles. This method involved the qualitative coding of the newspaper articles through 
a structured coding scheme. However, indicators of localisation are not easily labelled and narrowed down to a set of key words or phrases, so the qualitative, evaluative element in the analysis was useful. A result of this was that five typologies of localisation were developed after a piloting of the coding schedule to best describe the patterns of coverage evident in the analysis. These typologies were: communalisation, partial communalisation, neutral localisation, partial othering, and othering. Additionally, the number of articles which featured these types of localisation was measured, which allowed for the quantitative measurement of localisation to supplement the qualitative findings. This allowed the investigation to explore the nature of localisation in the newspaper coverage of overseas disasters.

The area and the scope of this research were selected due to a number of significant factors. Firstly, natural disasters represent an important area for research as they can be extremely destructive and they are able to strike communities irrespective of their level of development. They are an interesting phenomenon for mass communication scholars to study, as they are inherently newsworthy. Van Belle elaborated on this further, stating that:

"Natural disasters provide an excellent set of events for studying the contextual factors influencing the reporting of international events. Disasters are unusual, dramatic, and often have great impact upon people's lives. This combination makes disasters newsworthy and creates the expectation that news outlets, which are driven by commercial imperatives, will report them. Natural disasters also occur throughout the world, are unplanned, and in most cases take place independent of political control. Further, the aspects of disasters that are likely to cause variations in their newsworthiness, such as the magnitude of the event, can be roughly 
controlled for in the statistical analysis, making it easier to isolate contextual factors" $(2000,50)$.

The potential effects of disasters on large numbers of people make it a valuable area to study - disasters are worthy of scrutiny due to the potential consequences of this research [or any research] leading to disaster risk reduction, which may save lives. Earthquakes are a suitable disaster type to analyse because they occur across the world and their severity is measureable according to the Richter scale. Bilham suggested in 1995 that the annual fatality rate from earthquakes was likely to "rise by a factor 4-10 in the next 30 years, attributable partly to an increase in the fatality rate from moderate earthquakes near large cities, but principally from a few catastrophic earthquakes near supercities (populations 2-28 million)" (30). The potential impact of this study for disaster risk reduction makes research in this area particularly important. Another reason why earthquakes were the subject of this investigation was that they can affect most regions of the world, regardless of their respective wealth, levels of development, culture or language. The news media are subject to different influences that determine that the coverage of these disasters is not necessarily proportionate to the impact of the event, even though disasters occur all around the world.

The six earthquakes are similar in the type of natural disaster event, they all caused extensive damage to the affected regions in terms of human casualties or economic impact, the dates they occurred, the geographical range between the countries, and the spread across their respective levels of development. The earthquakes to be included in the data sample are the 1995 Japan earthquake, the 1999 Turkey earthquake, the 2005 Pakistan earthquake, the 2009 Italy earthquake, the 2010 Chile earthquake and the 2011 
Haiti earthquake. Each of the earthquakes caused considerable damage to their region, and together represent the majority of the most damaging earthquakes in the past 15 years (EM-DAT 2012). With the exception of the Chilean earthquake, they were also seismic events that did not generate tsunamis. Their damage was therefore similar to that predicted for the cities of Vancouver and Seattle in the event of an earthquake, as tsunamis do not present a danger to the two cities, despite coastal towns near them being at risk. The earthquakes occurred across a broad range of time over the past twenty years.

Table 1. The Damage Caused by the Six Overseas Earthquakes.

\begin{tabular}{c|cccccc}
$\begin{array}{c}\text { Stricken } \\
\text { Country }\end{array}$ & $\begin{array}{c}\text { Date of } \\
\text { Earthquake }\end{array}$ & $\begin{array}{c}\text { UN HDI } \\
\text { Value } \\
\text { (Rank) }\end{array}$ & $\begin{array}{c}\text { Magnitude of } \\
\text { Earthquake on } \\
\text { Richter Scale }\end{array}$ & $\begin{array}{c}\text { Number } \\
\text { Killed }\end{array}$ & $\begin{array}{c}\text { Number of } \\
\text { People } \\
\text { Affected }\end{array}$ & $\begin{array}{c}\text { Estimated } \\
\text { Damage } \\
\text { (US\$M) }\end{array}$ \\
\hline Japan & 17 January 1995 & $0.901(12)$ & 6.9 & 5,297 & 541,636 & 100,000 \\
Italy & 6 April 2009 & $0.874(24)$ & 6.3 & 295 & 56,000 & 2,500 \\
Chile & 27 February 2010 & $0.805(44)$ & 8.8 & 562 & $2,671,556$ & 30,000 \\
Turkey & 17 August 1999 & $0.699(92)$ & 7.6 & 17,127 & $1,358,953$ & 20,000 \\
Pakistan & 8 October 2005 & $0.504(145)$ & 7.6 & 73,338 & $5,128,309$ & 5,200 \\
Haiti & 12 January 2010 & $0.454(158)$ & 7.0 & 222,570 & $3,700,000$ & 8,000 \\
\cline { 2 - 7 }
\end{tabular}

Sources: Data from EM-DAT (2012); UNDP (2011, 127-130); US Geological Survey (2013).

These earthquakes occurred across the world - one occurred in Central Europe, one in Western Asia, one in South Asia, one in East Asia, one in the Caribbean and one in South America. Additionally, the countries struck by these earthquakes are at different points in the United Nations Human Development Index [UN HDI], with Japan [12] close to the summit, followed by Italy [24], Chile [44], Turkey [92], Pakistan [145], and Haiti [158] (UNDP 2011, 127-130). This is a useful measure of development as it is determined by the "basic dimensions of human development - a long and healthy life, knowledge and a decent standard of living" (UNDP 2011, 130). The UN HDI measures 
life expectancy, actual years of schooling, expected years of schooling and the Gross National Income per capita in each country (UNDP 2011, 166). Other indicators of development reflect similar assessments of the countries involved in this investigation. The World Bank's Gross National Income data replicates the relative standing of the countries in the HDI table (2013). Overall, the spread of disasters across a range of levels of development enables the investigation to make some preliminary suggestions from the findings about how the level of development of a stricken country affects the nature of the news coverage in a third person community.

Table 2. Indicators of Development in the Third Person and Stricken Communities.

\begin{tabular}{c|cc|} 
Country & $\begin{array}{c}\text { UN HDI Value } \\
\text { (Rank) }\end{array}$ & $\begin{array}{c}\text { Gross National Income per capita } \\
\text { [Atlas Method] in 2011 (\$US) }\end{array}$ \\
\hline U.S.A. & $0.910(4)$ & 48,620 \\
Canada & $0.908(6)$ & 45,560 \\
Japan & $0.901(12)$ & 44,900 \\
Italy & $0.874(24)$ & 35,290 \\
Chile & $0.805(44)$ & 12,280 \\
Turkey & $0.699(92)$ & 10,410 \\
Pakistan & $0.504(145)$ & 1,120 \\
Haiti & $0.454(158)$ & 700 \\
\cline { 2 - 3 } & &
\end{tabular}

Sources: Data from UNDP (2011, 127-130); World Bank Group (2013).

The cities of Seattle and Vancouver were good subjects for this investigation because of their similar statuses as regional hub cities, geography, population, and their similar levels of development. ${ }^{*}$ Seattle and Vancouver are economically very similar to each other as capital cities of their regions. They are barely 250 kilometres apart from each

\footnotetext{
* A great deal of consideration and debate went into choosing these two cities as the locations for the analysis of overseas earthquakes. A consideration that resulted in the absence of New Zealand newspapers was the fact that the majority of overseas news in the newspapers of New Zealand is produced by agencies such as Associated Press and Reuters, or it is lifted directly from overseas newspapers. This meant that it was possible that there would not be any specific localisation of overseas earthquakes for communities in New Zealand at all because the content may not have been specifically tailored for local audiences.
} 
other, so the geographical distance to the overseas disaster events is extremely similar between the two cities. Likewise, their populations are of comparable demographics, so their cultural distance to the overseas disaster events would also be extremely similar. Economically, they are important cities to the region as they both have ports. These similarities make the cities of Seattle and Vancouver good cities to study in terms of their news media's coverage of foreign disaster events because they reduce the number of variables, which could have accounted for any potential differences in their news coverage of the six earthquakes otherwise. While the news media of similar cities was the focus of this investigation, further research could compare dissimilar cities' news coverage of overseas disaster events.

There are some differences between the cities though, especially as they are located in different countries. Indeed, there are differences between the two countries as "the U.S. is far more engaged in the politics of disasters both in terms of being struck more frequently than Canada and committing far more money to foreign disaster assistance" (Jamieson and Van Belle 2013, 7). Additionally, the 2001 Nisqually earthquake in Washington may account for some difference between the two newspapers as it caused some damage, although it was "not disastrous" (Jamieson and Van Belle 2013, 7). However, the two cities share more similarities than differences. Perhaps the most significant similarity between these cities is that they are both earthquake-prone, but they have not suffered from catastrophic earthquakes in recent memory - so there is the potential for their coverage to be framed as part of a narrative emphasising the fact that 'we could be next'. This potential for them to be struck by earthquakes means that their coverage could be impacted by this. 
The extent of the identification between the local newspapers and the disaster stricken communities may depend on how much they can see themselves as potential victims. Interestingly, Seattle is Sister Cities with Kobe, Japan and Christchurch, New Zealand two cities which have both suffered from debilitating earthquakes in recent times (Seattle Office of Intergovernmental Relations 2011). A hypothesis of the investigation was that if an earthquake hits a developed nation with extensive disaster risk reduction in place, there is a greater likelihood that the news coverage in the third person community reflects the presumption that they could have been the victims themselves. Conversely, if the victims are from a developing nation with poor building standards it is less likely that the newspaper coverage would compare that event with the possibility for similar consequences for them if an earthquake struck their locality.

Newspapers are the medium of choice for this investigation because they remain largely region-specific and produce content primarily for their local audience. Because of their relatively small, targeted readership, local newspapers produce content to serve the needs of the public in their area of circulation. This has potential ramifications for the coverage of disasters, as this may reflect their own potential risks from a similar disaster event. Another reason why newspapers are worthy of investigation is that there is some evidence to suggest that they still influence policymakers. Aeron Davis conducted a series of interviews with policymakers and politicians in the United Kingdom, and he found that the "most common form" of news media consumed by them "was broadsheet newspapers, with interviewees, on average, looking at three broadsheet newspapers per day" $(2010,88)$. Similarly, Conrad Smith found in 1992 that the New York Times and the Washington Post remained the most significant sources for political actors following catastrophic events (9). Baumgartner and Jones argue that this 
is significant in their analysis of agenda setting in American politics, as they found that "media coverage does indeed correspond to official concerns" $(1993,49)$. This is important for the understanding of the interdependent relationship between news media and politicians.

Additionally, newspapers are arguably a good index of the prevailing news agenda and are broadly representative of the other news media. Davis stated that "as work on media-source relations tends to confirm, political elites automatically come to be the dominant news sources and agenda setters for news" $(2010,89)$. It is plausible to suggest that there will be local politicians who read broadsheet newspapers in Seattle and Vancouver, and that many would be conscious of the issues on their agenda. Although this does not confirm that the press influences policy, it is likely that the political elite will be at least aware of the issues covered by the broadsheet newspapers. Newspapers effectively provide the context in which policy is formed.

A third and final reason why newspapers are the subject of this investigation is their accessibility. Newspapers are the news medium of record, allowing for easy access by researchers for analysis. Newspaper articles are available on electronic databases following the digitising of content, and often articles are available on the internet at the same time as the publication of the print version. This means that news content is available for researchers on the internet, and historical records are available if one has access to a computer. These reasons have all contributed to why newspapers are the news medium for analysis in this research. 
The Seattle Times and the Vancouver Sun are the newspapers in this analysis because they are the leading broadsheet newspapers of their respective regions, and they have comprehensive coverage of overseas events. Servicing the two regional capital cities, these newspapers serve a large region, providing news for their specific audiences. The Seattle Times has an average circulation of 251,697 on a weekday, while the Vancouver Sun has a similar market share, circulating 163, 803 newspapers on average on weekdays (Associated Press and Seattle Times Business Staff 2010; Newspapers Canada 2012). If they are found to be constructing their coverage of overseas disaster events in terms of their region's own vulnerabilities, there exists the possibility that this could help to set the agenda for disaster risk reduction to become a political issue.

Significantly, broadsheet newspapers' audiences are traditionally the more educated, elite sections of society. This has implications for the implementation of effective measures of DRR. Studies in the United Kingdom have found that "those who are most engaged are also better educated, wealthier, and have higher status occupations" and that these "high engagers have more associational memberships, are more knowledgeable about politics, are more confident of their knowledge, and are more likely to read broadsheet newspapers" (Davis 2010, 148-149). If policymakers read in the Seattle Times or the Vancouver Sun that an overseas earthquake has lessons for their own community, there is the possibility that they will subsequently take the initiative as policy entrepreneurs to make political capital out of pushing for the improvement of their region's preparedness in disaster mitigation and the prevention of risk. Alternatively, political actors may simply feel obliged to respond to public opinion, and they may react to news coverage of overseas disasters due to the perception that the newspaper acts as an index for that opinion. 
The thesis is divided into five chapters. The first chapter features a literature review of research into disaster risk reduction and the news media's coverage of natural disasters. Notions of disasters and disaster risk reduction are operationalised after a discussion of the problems associated with the terms and the categorisation of disaster events. There is a critique of the developmental perspective of non-governmental organisations' reports on disaster risk reduction. This includes a discussion of examples of disaster risk reduction in practice, and consideration of the media's role in reporting natural disasters. The chapter contextualises the investigation against the background of the theory behind existing practices of disaster risk reduction and establishes how the research challenges these approaches. Van Belle's model is introduced as a way of changing the approach to disaster risk reduction in order to improve its chances of success in at-risk communities.

The second chapter reviews the news theories which contribute to the practice of localisation before examining articles which address localisation in the production of news content for local audiences. Localisation is operationalised, before it is contextualised alongside existing news theory. Ideas of newsworthiness, news values, agenda setting and the CNN Effect are discussed in relation to localisation, establishing how localisation is a result of existing media practices, although it has previously not been the focus of much academic research in itself. Existing literature which discusses localisation is reviewed in addition to its implementation in translation services. Examples of localisation in the news media coverage of overseas events are identified. The chapter concludes with a discussion of othering, where differences between communities are emphasised in the production and dissemination of news content. 
The third chapter outlines the methodology used in the investigation, describing why these newspapers and earthquakes were selected for analysis, and why these particular methods were used to reveal the processes of localisation in the news media. The typologies of localisation are operationalised in order to establish clear indicators of the practice. Communalisation is determined to be evident where a direct connection was made between the locale of the newspaper's publisher and the disaster stricken community, leading to the establishment of an affinity between the two communities. Conversely, othering is interpreted as being where differences between the locality of the newspaper and the disaster stricken community are emphasised. The focal questions are operationalised, with explanations of how those questions helped to reveal the nature of the localisation in the research sample. There is an explanation of how the combination of both qualitative and quantitative analysis was most effective at uncovering the data required to answer the focal questions. There is also a description of how the sample of newspaper articles was collated and how this represents the entire coverage of the six major earthquakes.

The fourth chapter outlines what was revealed in the structured qualitative content analysis of the newspaper articles. Four key trends in the newspaper coverage of the six overseas earthquakes are described in detail. Communalisation through the explicit localisation of vulnerabilities and the drawing of direct comparisons between communities occurred following the earthquakes in Japan, Chile and Turkey. Some indicators of partial communalisation are briefly explored before a summary of the neutral localisation in the coverage is outlined. The second major finding is that partial othering was prevalent following all earthquakes, but the nature of this changed 
depending on the level of development of the stricken country. Othering was evident in the involvement of the third person community in the provision of aid and the involvement in the response and recovery of the stricken community following their earthquakes. This was much more prevalent following the earthquakes in Turkey, Pakistan and Haiti, prompting the establishment of a victim-saviour relationship between the communities in the newspaper coverage, whereas the coverage of the earthquakes in Japan, Italy and Chile largely avoided this emphasis. There is an examination of the indicators of othering which were almost exclusively present only following the earthquakes in Pakistan and Haiti and how this served to differentiate those countries from the third person communities. This could prevent any public discussion of the local community's preparedness for a similar hazard - a barrier to effective implementation of DRR measures.

The fifth chapter examines what the findings mean for the implementation of disaster risk reduction in at-risk communities and for the field of political communication. The research is positioned against existing literature, establishing its position as contributing to the field of disaster risk reduction, confirming that Van Belle's model of implementing successful disaster risk reduction is worth exploring further. The research findings are also contextualised against news theory, confirming that localisation should be considered by political communication scholars as a significant process in the production of the news. This section concludes with a discussion of the direction that research may take in the future to build on the findings of this investigation. 


\section{CHAPTER ONE}

\section{CONTEXTUALISATION}

Natural disasters present a destructive threat to a large proportion of the world's population. However, there are significant failures in the application of knowledge about what can be done to best limit their effects. Despite the efforts of many politicians, policymakers, NGOs, academics, journalists and the general public; some efforts at disaster risk reduction have been less effective and less efficient that they could have been, due to the absence of the necessary conditions for DRR (Van Belle 2012). It is important to examine what has been written about disasters in the past in order to understand how Van Belle's model marks a critical development in the knowledge of disaster risk reduction.

\section{Definitions of Disaster}

Before examining the previous literature examining natural disasters and the media, it is important to operationalise what those terms mean, and acknowledge the inherent problems with the categorisation of catastrophic events as disasters. The Emergency Events Database's definition of a disaster notes that "though often caused by nature, disasters can have human origins", including "wars and civil disturbances that destroy homelands and displace people" as among the causes of disasters (EM-DAT 2009). It is important to note that there are human actions which may amplify the effects of natural disasters such as poor housing or overpopulation. Sociologist Enrico Quarantelli discussed the problems associated with defining the phenomena when he advocated that "we need to rethink, for research purposes, the central question of what is a disaster" $(1987,21)$. He argued that the concept of disasters is inherently a "logical and definitional matter" as it is almost impossible to define the term empirically 
(Quarantelli 1987, 22). Olson, Prieto and Hoberman also note the problems associated with defining the concept as they criticise "the fact that everyone seems to define it idiosyncratically" $(2010,5)$.

There are also difficulties in differentiating between hazards and disasters. The UNISDR defined a hazard as "a dangerous phenomenon, substance, human activity or condition that may cause loss of life, injury or other health impacts, property damage, loss of livelihoods and services, social and economic disruption" (2009b, 17). In general terms, the difference between hazards and disasters relates to potentiality - a hazard relates to the potential threat of a particular phenomenon, where a disaster relates to the effects of the realisation of that particular threat. Anthony Oliver-Smith described disasters as being socially constructed crises; meaning that they are not only the result of natural processes, but that people have some involvement in creating the necessary conditions for a disaster to occur, and they also suffer the consequences (1999, 22-30). Furthermore, Salvano Briceño laments the erroneous labelling of the phenomena as "natural disasters" as it has "led to an excessive focus on understanding the hazards themselves from a physical and natural science point of view, and does not facilitate the much-needed attention to understanding and reducing human and social vulnerability" (2012, xxx). Even with the rejection of the concept as being inherently natural, there remain differences of opinion about how to define the term.

An authoritative body in development and disaster risk reduction, the United Nations defined disaster as "a serious disruption of the functioning of a community or a society involving widespread human, material, economic or environmental losses and impacts, which exceeds the ability of the affected community or society to cope using its own 
resources" (UNISDR 2009b, 9). However, Olson, Prieto and Hoberman note that "many UN definitions appear to result from committees, where many interests and perspectives manifest" $(2011,62)$. As the most comprehensive and relevant conceptualisation of the term, Olson, Prieto and Hoberman's own definition will be adopted. They defined disaster as "a social crisis characterised by a sense of great uncertainty, significant disorder, or potential collapse in a community caused by a serious disruption in its normal functioning and involving widespread human, material, economic, or environmental losses and impacts that exceed the community's ability to cope using its own resources" (Olson, Prieto, and Hoberman 2011, 62). Borrowing heavily from both the UN definition, as well as Oliver-Smith and Hoffman's, it is a definition that encompasses the human toll of disasters, acknowledging that it requires both a hazard event and human vulnerabilities to become a disaster (Olson, Prieto and Hoberman 2011, 62). Having adopted this definition, it is important to evaluate the evolution of literature concentrating on the media coverage of disasters before using this as a base from which to explore DRR and the media.

\section{$\underline{\text { Media Research into Differences in Disaster Coverage }}$}

The news media have faced some criticism for their reporting of natural disasters whether it be for allegedly exaggerating the extent of the damage, inconsistencies in the extent of the coverage of different foreign disasters, or only reporting 'bad news' stories from particular regions (Adams 1986; de Beer 2010; Golan 2008; Gurevitch, Levy, and Roeh 1991). However the short time frames imposed on journalists make it difficult for them to verify facts and provide context - a problem which is further complicated by the chaotic nature of disasters (Davies 2009). It is important to establish what has already been written about disaster coverage and the media and gain a clearer 
understanding on the news coverage of disasters. It is clear that the news media does not cover all disasters equally or proportionally across all countries. There are different factors that determine the frequency of coverage, and these have been the subject of much academic enquiry throughout the latter half of the twentieth century through to the present time.

There have been countless investigations into the coverage of foreign disasters, with most criticising the inconsistencies in levels of coverage depending on the location of the disaster (Boyd-Barrett 1979; Dahlgren 1982; Galtung 1971; Lee 1980; Madec 1981; Meyer 1989; Schiller 1969; Singhal and Sthapitanonda 1996; Tomlinson 1991). Accusations of the western media's neglect of third world countries are encapsulated by William Adams' ratio of media coverage to the number of casualties. In 1986, Adams undertook a quantitative investigation analysing foreign disaster coverage in newspapers in the United States and he found that the "three most potent factors" were the number of U.S. tourists that visited the affected nation, the severity of the event and the distance from New York City (116-119). Extrapolating from these results, he concluded that in the United States, "the globe is prioritised so that the death of one Western European equalled three Eastern Europeans equalled 9 Latin Americans equalled 11 Middle Easterners equalled 12 Asians" (Adams 1986, 122). While Adams presents a normative critique of news values and reveals a valid pattern in the coverage of overseas disaster events, there are factors apart from nationality which affect the levels of coverage.

In a similar vein, Tsan-Kuo Chang addressed disparities in coverage of different regions in the Western news media. Tackling the reasons for this, Chang argued that "in the 
context-oriented approach, external factors carry more weight in news decision making, including political affiliation, economic relations, relevance, geographical proximity, and cultural similarity" (1998, 535). Continuing this research with two other contemporaries, he found that while it was relevant, location alone was less important than what was previously thought, and "geographical and cultural proximity does not automatically generate international flow of events or issues nor does it translate into news coverage" (Chang, Lau and Xiaoming 2000, 518). Arnold de Beer argued that "not all countries are created equal when it comes to news coverage - the core countries dominate the news flow and news about the periphery is more often than not "negative"' (2010, 596-597). He argued that Africa suffers in news coverage by either being ignored or being labelled a 'dark continent' where most news stories were negative (de Beer 2010). Still investigating news coverage of Africa, but in the U.S. television networks, Guy Golan found that Gross Domestic Product and trade with the U.S. were the key determinants that affected the amount of coverage (2008). These observations hint at an underlying set of editorial and journalistic priorities reflecting their own values, resources and sources.

Leung and Huang pointed out that while many scholars argue that news organisations in the West produce negative images of the developing world, this could be a justifiable practice $(2007,675-677)$. They noted that "the alleged emphasis on natural disasters and accidents in news from the third world may be true... because there simply is more open, armed conflict and crisis in these countries than in more developed countries" (Leung and Huang 2007, 677). In their investigation of the coverage of the SARS virus, they found that "the western media are not nearly as biased as this critical model argument would have us believe" (Leung and Huang 2007, 691). Switching the focus 
from U.S. media to Japanese newspapers, Hiromi Cho and Stephen Lacy found that there was a "negative relationship between the number of wire subscriptions and the percentage of international news in Japanese newspapers about conflict and disaster" $(2000,839)$. They suggested that "this could represent a difference in the nature of the copy from the wire services or it may represent a selection on the part of the editors to use the option of two stories to select fewer disaster and conflict stories" (Cho and Lacy $2000,840)$. It is interesting to note these differences in news values between countries.

\section{Definitions of Disaster Risk Reduction}

Just as there are several difficulties in defining the concept of a disaster, there are also problems with explaining the exact nature of disaster risk reduction. Before operationalizing DRR though, it is important to determine what is meant by the notion of vulnerability. The UNISDR defined the term as meaning "the characteristics and circumstances of a community, system or asset that make it susceptible to the damage effects of a hazard," (2009a, 30). This definition provides context for the discussion of vulnerability. Wisner, Gaillard and Kelman in their comprehensive handbook describe DRR as "the process of understanding, analysing and managing the causes and origins of disasters and the risks that accumulate and lead to disasters" $(2012,1)$.

The UNISDR definition is more specific, labelling it as "the concept and practice of reducing disaster risks through systematic efforts to analyse and manage the causal factors of disasters, including through reduced exposure to hazards, lessened vulnerability of people and property, wise management of land and the environment, and improved preparedness for adverse events" (2009, 10-11). It mentions the difference between 'disaster reduction' and 'disaster risk reduction', distinguishing 
DRR as providing "a better recognition of the ongoing nature of disaster risks and the ongoing potential to reduce these risks" (UNISDR 2009b, 11). It is important to appreciate that DRR is not a stand-alone concept, but instead most of the literature surrounding it has come from a developmental angle.

As Van Belle explains, "theories and concepts from development dominate the way that both the academic and applied policy communities approach the politics of disaster risk reduction" $(2012,3)$. Wisner, Gaillard and Kelman agree, claiming that "it is impossible and fruitless to try to distinguish between human development and DRR" as the two concepts are inextricably linked $(2012,1)$. This is reinforced in the 2004 UNDP report on Reducing Disaster Risk. It states that "the linkages between development and disaster risk are not difficult to visualize" as "any development activity has the potential to either increase or reduce disaster risk" (UNDP 2004, i). It makes the valid point that there are "development choices," as "disaster risk is not inevitable, but on the contrary can be managed and reduced through appropriate actions" (UNDP 2004, ii).

Citing the Millennium Development Goals, they refer to "eradicating extreme poverty and hunger, achieving universal primary education, promoting gender equality and empowering women, reducing child mortality, improving maternal health, combating HIV/Aids, malaria and other diseases, ensuring environmental sustainability, and developing a global partnership for development" as measures that can reduce the risk of disasters (UNDP 2004, 16). Emphasising the role that developmental processes can play in reducing disaster risk, it states that "while only 11 per cent of the people exposed to natural hazards live in countries as low human development, they account for more than 53 per cent of total recorded deaths" (UNDP 2004, 1). This is a key 
reason why it is important to compare the developmental indexes of the stricken countries, as it is clear that DRR and development have been indelibly linked up to this point in time.

However, while there is nothing inherently wrong with the developmental angle being dominant in the discussion of DRR, this could explain in part why DRR policies have been largely unsuccessful. As DRR has fallen under the governance of development in conception and funding, it has perhaps not been the priority with other pressing needs such as poverty reduction, the redistribution of wealth and the eradication of hunger taking precedence over DRR, which may appear to be not as urgent or as immediate. In other words, "DRR can be offered as an additional benefit of human development, but it is probably always going to be seen as a relatively minor side benefit" (Van Belle 2012, 5). This is particularly unfortunate because "disaster preparedness is a highly nonlinear phenomenon: small measures adopted early can leverage disproportionate benefits in risk reduction" (Woo 2011, 219). The role of local politics, the news media and social psychological theory all contribute to the ultimate success or failure of DRR. It is therefore important to review the existing literature on DRR and evaluate how its evolution and history put contemporary DRR efforts into context.

\section{DRR Literature in Non-Governmental Organisations}

Research into disaster risk reduction has continued since its inception in the 1970s, with Ian Davis' Shelter after Disaster forming a significant part of the early literature addressing DRR. His work attempted to identify the conditions that make communities particularly vulnerable to disasters, to outline strategies involved in the immediate response to a disaster, and to review some significant historical disasters (Davis 1978). 
Over the past decade there have been an increasing number of NGO reports about DRR, looking to implement measures to minimise disaster risk in at-risk communities. The World Bank has been involved in researching the links between development and DRR to determine how best to invest in at-risk communities (Global Facility for Disaster Risk Reduction 2008; World Bank 2009a; World Bank 2009b). Similarly, the UNISDR and the United Nations Development Programme have commissioned reports to highlight the risks of disasters to communities in attempts to help political leaders help themselves through implementing DRR (Olson, Prieto, and Hoberman 2010; UNDP 2004; UNISDR 2009a; UNISDR 2011).

These reports have all helped to provide information for NGOs, governments and policymakers as they look to serve at-risk communities by identifying conceptual approaches and programmes of action which could help the mitigation of disasters. Often these approaches have aimed at integrating disaster risk reduction with developmental goals, adopting these measures into the overall process of assisting developing nations. For instance, the 2009 Global Assessment Report on Disaster Risk Reduction noted "the difficulty of promoting earthquake safety in Kashmir until developmental conditions such as income, education and road networks are improved" following their earthquake in 2005 (UNISDR 2009a, 94). This approach is perhaps summarised best later in the report, where it stated that there were limitations to what could be achieved in reducing disaster risk in households and communities "without the broader infrastructure and service framework into which community provision can integrate" (UNISDR 2009a, 99). Helen Clark, Administrator of the UNDP, recently gave a speech where she advocated for "whole-of-society approaches to disaster risk reduction" as it is a "concern for everyone - from citizens who must be empowered to 
make decisions which reduce risk, to political leaders, government institutions, the private sector, civil society organisations, professional bodies, and scientific and technical institutions" (2012).

This all-encompassing approach is commendable, but there are potential issues with monitoring the efficacy of these aspirational measures, especially given the unquantifiable elements involved. While there have been success stories in countries such as Bangladesh, Mozambique and Indonesia, these methods could be more targeted and efficient in delivering disaster risk reduction without total support across all sectors of civil society (Clark 2012). Among political elites, David Alexander argues that there continues to be a general lack of action, where the "tendency is to defer measures until it is too late and disaster has struck, with consequences that are as predictable as they are lamentable" $(2012,3)$. These approaches have suffered from being implemented "in a reactive and event-focused, rather than a proactive and comprehensive, fashion" only after the disaster has already impacted a community (Tierney, Lindell, and Perry 2001, 254-255). It is also possible that well-intentioned DRR is implemented in the wrong areas as "political systems may reward preparing for the most common situations, rather than the greatest expected damage situations" (Hanson 2008, 372). DRR could conceivably be implemented in particular at-risk communities at the expense of others, resulting in greater damage there if a disaster were to impact the community which was perceived as being less at-risk.

The accountability of political leaders in the aftermath of a disaster has been considered by some scholars. This is an area of inquiry pursued by some scholars due to the fact that "successful performance in times of collective stress turns leaders into 
statesmen...But when the crisis fails to dissipate and 'normality' does not return, leaders are obvious scapegoats" (Boin and 't Hart 2003, 544). In 2010 Olson and Gawronski produced a framework for analysing the effects of a disaster on political leaders' popularity, arguing that these effects are not random, but instead come from disaster preparedness and response, and especially anticipation of the event (2010). However, Jason Enia argues that DRR may not implemented by policymakers because "the incentives associated with effective mitigation, management, and recovery have relatively little to do with the wisdom or the altruism of particular actors" $(2013,13)$. Instead, he argues that "even in a situation where the actors are both wise and altruistic, there may still be powerful incentives that move them away from cooperative or coordinated solutions" (Enia 2013, 13). If these incentives override any potential personal gains for political actors, it would be difficult to persuade them to implement DRR policy.

In recent years, Richard Olson's work with his various co-authors has provided much depth and considered analysis of DRR, and it is likely to inform future DRR research. In 2010, Olson, Prieto and Hoberman produced the Global Assessment Report on Disaster Risk Reduction, which outlined how disaster risk reduction "can provide a vehicle to reduce poverty, safeguard development and adapt to climate change, with beneficial effects on broader global stability and sustainability" (v). This comprehensive document described how DRR should be a priority for political leaders. A significant finding of the Global Assessment Report on Disaster Risk Reduction was that the news media are a powerful tool in potentially setting the agenda in third person communities following an overseas disaster. Olson, Prieto and Hoberman note the fact that in the countries similar to the stricken community, the "windows of opportunity for 
DRR innovations appear more likely than previously believed” $(2010,26)$. However, this optimism was tempered by the existence of "zones of silence", where "problems or issues that are not discussed or even posed by the media" mean that "ideas or proposals for change/improvement rarely escape" $(2010,28)$.

Van Belle's model for implementing disaster risk reduction marks a critical departure from the prevailing approaches of these non-governmental organisations by promoting a more targeted approach aimed at furthering the interests of the political elites in atrisk communities, who stand to make political gains out of coverage of overseas disasters if they campaign for popular DRR policies (2012). Effectively, political entrepreneurs could drown out the "zones of silence" and keep disaster risk reduction on the public agenda. However, for this to happen there must be public acknowledgement of the hazards faced by their community. The localisation of nonlocal disaster events in the local news media is a necessary pre-condition for this to occur, where those events are interpreted in terms of the shared vulnerabilities in the third person community.

\section{$\underline{\text { DRR in Practice }}$}

There have been two studies into DRR in specific disaster stricken communities after the event of a disaster. Stephanie E. Chang looked at the recovery of the city of Kobe in Japan, following its earthquake in 1995, which she contentiously labels "the developed world's first experience of a catastrophic urban earthquake," despite the Loma Prieta earthquake of 1989 (2010, 313). Looking at pre-disaster conditions, Chang argues that the earthquake served to "accelerate pre-disaster trends" in de-population of the inner city and the growth of the suburbs surrounding the city $(2010,314)$. Chang indicated 
that recovery planning can be undertaken on the basis that practitioners "can to some degree anticipate characteristics of the 'new normal' [the new status quo in a stricken community after the initial temporary instability following the disaster] to which the community would stabilise after a major disaster, and should plan for post-disaster change" $(2010,323)$. However, the 'new normal' situation is particularly difficult to predict and it is unlikely that any planning can comprehensively anticipate the effects of a disaster event on the local community. Chang advised that "decision makers at all levels should consider the possibility of long-term [economic, social and population] losses when making decisions about whether, how and to what extent they take predisaster risk reduction actions" (Chang 2010, 323). These recommendations are potentially influential as they shift the emphasis onto acceptance that the city is not going to be able to revert to its pre-disaster existence. Chang argues that policymakers should adopt this thought process when evaluating how best to reconstruct the city. This is not necessarily a popular approach though, as the New Zealand government has found in its attempts to reconstruct Christchurch after its 2011 earthquake (Wright 2012; Mathewson 2013).

Bimal Kanti Paul and Rejuan Hossain Bhuiyan undertook a study of earthquake preparedness in Dhaka City, Bangladesh. They found there to be a general lack of awareness of the risk in the city, where educational programmes introduced by the government have not been successful (Paul and Bhuiyan 2010, 356-357). They note that "hazard research, from its inception in the human ecology tradition, has emphasised the importance of public perception concerning extreme natural events," as "increased preparedness along with hazard awareness significantly reduces individual and community vulnerability to environmental hazards (Paul and Bhuiyan 2010, 342). Part 
of the role of the media in the vision of their position in society as the fourth estate should be providing information to their specific audience about risk and setting the agenda for issues which are in the public interest. Theoretically, the media have a part to play in increasing awareness and preparedness for potential disaster events. However, the media have competing interests and priorities, and advocacy of a cause such as DRR is not necessarily going to be pursued if it affects their other imperatives. It also must be acknowledged that information is insufficient by itself to create the necessary conditions for DRR - political elites also need to be involved in order for change to occur.

\section{$\underline{\text { Research into DRR and the Media }}$}

The role of the news media in introducing DRR to the public agenda has been reviewed and critiqued by many scholars. The media are potentially influential in setting the agenda for DRR, as indicated by Cass Sunstein, who suggested that "if a threat is made salient through social interactions, media attention, or other means, mitigation and preparatory measures are more likely" (Sunstein 2007, 56). In an early investigation, Barbara Combs and Paul Slovic found in an analysis of newspaper coverage of different causes of death, that "violent, often catastrophic causes of death such as homicides, natural disasters and accidents were overreported" compared to their incidence (1979, 843). They explained this phenomenon as happening "not only because it sells more newspapers, but because these hazards represent sources of societal vulnerability about which people need to be informed so that they can take precautions or institute appropriate controls" (Combs and Slovic 1979, 843). As such, they concluded that the over-representation of disasters in coverage "may serve some useful function by alerting society to the need for corrective action against hazards that, if neglected, might 
cause the premature death of many persons" (Combs and Slovic 1979, 849). As such, the media arguably fulfilled this public service function, even if the levels of coverage were disproportionate to other causes of death

There are some academics who argue that this skewed amount of coverage is harmful however; as they argue that it breeds fatalism about the prospect of disasters to the extent that no risk reduction is undertaken. Paul Simpson-Housley and Fred A. Curtis undertook an investigation into the awareness of the earthquake risk in Wellington, New Zealand, an area which is prone to earthquakes. They found that at the time, "the absence of a recent major earthquake augments the nonchalance towards the hazard" and that "most respondents did not consider earthquakes troublesome" despite a general high level of awareness of the potential for earthquake damage (Simpson-Housley and Curtis 1983, 465-467). This suggests that the media was effective in educating the public about the risk of earthquakes, but the lack of a recent personal experience of a major earthquake among respondents meant that there was a lack of urgency to their DRR efforts. It is important to note that this has changed since the 1970s in Wellington, with the city enjoying a comprehensive building inspection programme (Wellington City Council 2013).

There have also been several social psychology-oriented and sociological studies into public perceptions of earthquake risk and the role of the media in Wellington. Jodie Cowan wrote of how there is the danger of unrealistic optimism about disaster events, where people may believe that "they are they are more likely than the average person to have a happy future and less likely than the average person to suffer various misfortunes, therefore creating an illusion of personal invulnerability" (1998, 6-7). 
Significantly, she found in her study that "if people are made aware that earthquake damage is often selective [in terms of where the damage occurred] they are more likely to see damage as preventable" (Cowan 1998, 59). She determined that "directing people's attention to the selectivity of earthquake damage can enhance their perceptions of control over their own circumstances shown by attributions for earthquake damage to controllable causes" (Cowan 1998, 59). However, there is only a limited amount of control people can exert as many people are not in a position to choose to move into a safer house or workplace.

A similar study conducted by Cowan, McClure and Wilson highlighted the role of the media in promoting awareness. They asserted that because most people had not lived through a major earthquake, "mass media comprise a primary source of information about disasters and play an important role in shaping citizens' knowledge of natural disasters" $(2002,171)$. They use this information to imply that the news media's coverage affected the respondents' attitudes towards the risks presented by earthquakes. They wrote that "when reports portray damage as selective and refer to the lessons learned from patterns of damage, people tend to see the damage as preventable and attribute it to controllable causes" (Cowan, McClure, and Wilson 2002, 182). Similarly, research by Turner, Nigg and Paz found that "fatalism is most widespread toward the prospect of large-scale and impersonal disaster but is less prevalent when the question is personal survival or help for those at greatest risk" (1986, 422-423).

Robert A. Stallings suggests that the earthquake threat needs to be "personalized", where "personalizing risk would also personalize victimization" $(1995,206)$. He argues that "as human agents begin to replace nature, fate, and the luck-of-the-draw as 
explanations for why some people die in earthquakes and others do not, the belief that 'nothing can be done' becomes harder to sustain" (Stallings 1995, 206-207). Likewise, McClure, Sutton and Sibley argue that "agencies should spell out to citizens that the buildings that typically suffer the worst damage in earthquakes are those that have poor building designs, whereas those that withstand earthquakes usually have good designs" (2007, 1971). Arguing against fatalism in the coverage of earthquakes, these scholars suggest that by attributing damage to building design and affirming that damage is preventable, news coverage will lead to a greater public resolve to support DRR measures (McClure, Sutton, and Wilson 2007, 240-241). It makes sense that this would arguably increase the motivation for DRR, as if damage is perceived as controllable through building design and measures of preparedness which can be undertaken by citizens of at-risk communities, there may be greater social and political urgency to increase DRR for a future disaster event.

The City of New Orleans was not prepared for the destruction of Hurricane Katrina in 2005, and has been the subject of an article by Tierney, Bevc and Kuligowski. They looked at the dispelling the myths surrounding the disaster, especially in the media coverage of the event. They argue that "it was widely understood well before Katrina that New Orleans could not be successfully evacuated in the face of a major hurricane, but few concrete actions had been taken to address the needs of these most vulnerable residents" (Tierney, Bevc, and Kuligowski 2006, 76). The lack of DRR, despite this knowledge, is particularly significant as many other urban areas in the United States are similarly at risk from disasters (Tierney, Bevc, and Kuligowski 2006, 76). 
Olson, Prieto and Hoberman produced a framework for DRR advocates to follow in order to induce political will, including conducting 'pristine investigations', speaking truth to power, publicly making people aware of the disaster risk, creating 'guilty knowledge' and authority accountability, and being aware and prepared for the consequences of one's actions in promoting DRR (2011, 65-67). Radford and Wisner argued that it is journalists' professional best interests to aggressively promote DRR in their work through advocacy journalism, despite the risks involved in potentially losing the perception of objectivity through an association with a cause (2012).

There has been a lot of recent literature from NGOs too, providing rich material for DRR advocates in their pursuit of DRR in communities. However, there have even been problems in getting DRR implemented in communities which have already suffered from disaster events, as if may be difficult for the public to be willing to bear the social and economic costs of implementing DRR (Van Belle 2012). This may be reflected in the news coverage, with Olson, Prieto and Hoberman finding that "risk reduction as a theme" appeared in 15 per cent of the stories in Jamaica following the Haiti earthquake and 34 per cent of the stories in Peru following the Chile earthquake in 2010 (2010, 22). This is a marked contrast from the coverage of the earthquakes in the stricken communities, with the Haitian news media having "only $2 \%$ of the stories focusing on risk reduction, and Chile 4\%" (Olson, Prieto, and Hoberman 2010, 22). This is a natural response to the crisis, as long-term measures which require strategy and planning may not complement more immediate recovery measures. 


\section{Van Belle's Model}

\section{DRR in Disaster Stricken Communities}

Van Belle has produced a model which explains how DRR may be possible in thirdperson communities, but he acknowledges the difficulty in implementing DRR in communities which have already suffered the effects of a disaster event. Van Belle suggests that there is a missing link between an at-risk community and the implementation of effective DRR measures. He argues that for meaningful DRR to become a reality, there first has to be some localisation of the news coverage of distant disasters, a process where the media in a third person community cover that event in terms of their own vulnerability to the same natural hazard (Van Belle 2012). Van Belle develops this notion further, arguing that the "third person effect is generalizable to any situation in which news media coverage of a non-local event, or coverage of someone else's policy crisis highlights a risk or threat to something valued locally" $(2012,6)$. Through this localisation in the news media, the foreign event can trigger public debate about how well the third person community is prepared for a similar disaster (Van Belle 2012). This discussion will theoretically provide the opportunity for policy entrepreneurship, a process where political actors grasp the opportunity to pursue DRR in the third person community, leading to successful measures of disaster risk reduction to be implemented (Van Belle 2012). 
Figure 1. Van Belle's Necessary Causes and the Third Person Effect Model.

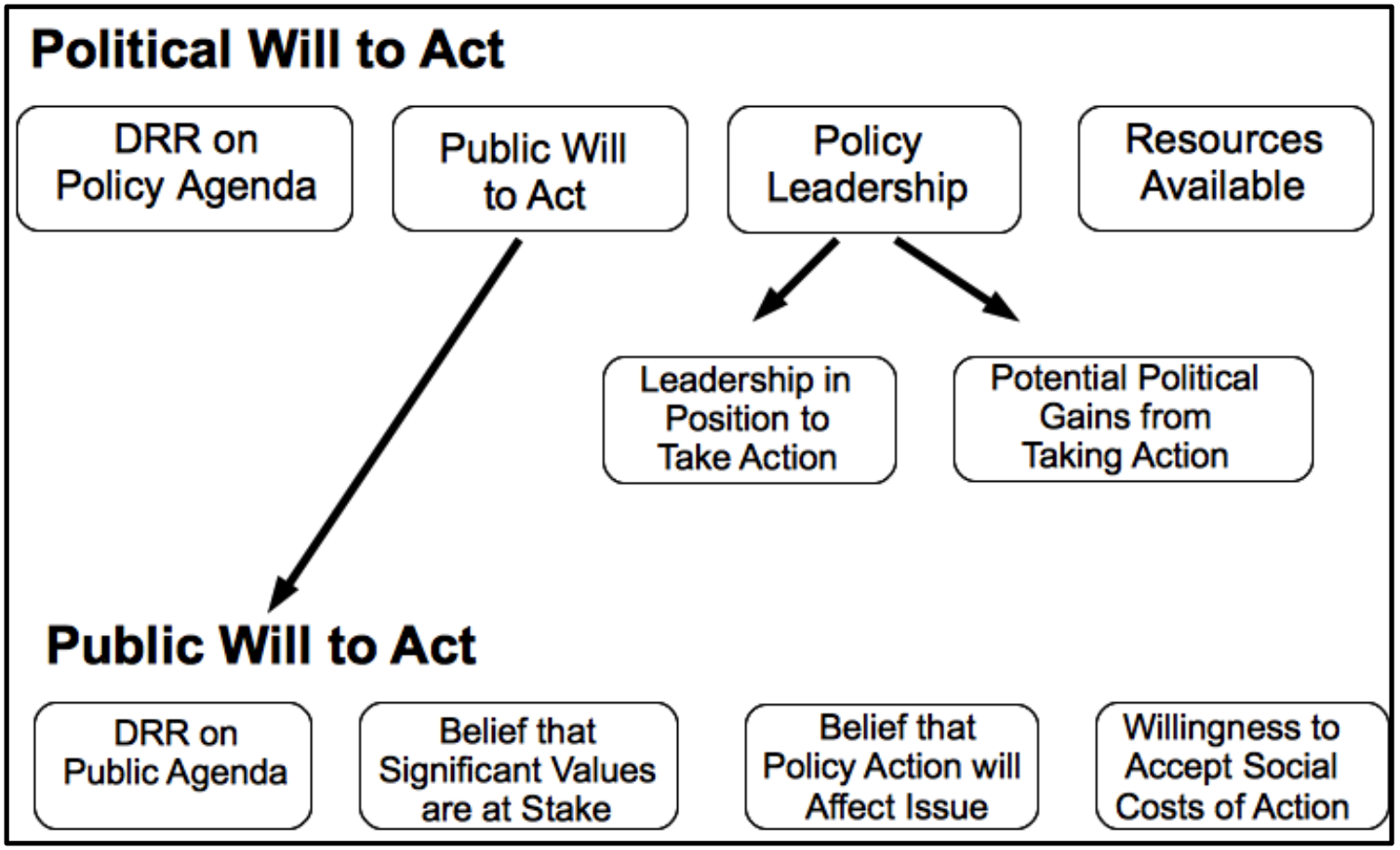

Source: Diagram from Van Belle $(2012,21)$.

The first part of the model concerns the lack of public will to act in disaster stricken communities, despite them having already suffered the consequences of a lack of DRR combined with a natural hazard. In essence, they "just do not seem to learn" as "around the world and across cultures, disaster stricken communities almost never seem to pursue or enact policies that will significantly reduce their risk of future losses" (Van Belle 2012, 2). An explanation for this is that stricken communities do not have the time or effort to pursue DRR, or even to engage with the thought of it. In the aftermath of a disaster, with the burden of their initial response and recovery already weighing heavily on victims, they simply "need to recoup all the time they just diverted into the social response to the disaster instead of private action," which could help mitigate against future disasters (Van Belle 2012, 8). In such an atmosphere, it is difficult for stricken communities to muster up the energy required to consider DRR - they are 
essentially stuck in the moment as victims and have little ability to consider anything beyond the immediate future.

As it is unlikely that the victims have come to terms with their losses, after a disaster "a significant proportion will become intent if not obsessive about returning to the previous status quo and they will react negatively, if not with hostility, to any effort to direct the recovery effort toward something different, even if the alternative is clearly better" (Van Belle 2012, 10). This could be a result of the emotional trauma in addition to material losses suffered in the disaster. An example of this was in the Indian village of Vondh following the 2001 Gujarat, where a new, rebuilt village was left uninhabited as residents preferred to live in the old village because of its history and personal significance to them (Sanderson and Sharma 2008, 179-180; Powell 2011, 282). This is an example fulfilling Kahneman and Tversky's Prospect Theory, where "the failure to adapt to losses or to attain an expected gain induces risk seeking" in individuals (1979, 287). Admittedly their research is focused on individuals rather than normative behaviour, and on economic decisions rather than DRR. However, this behaviour may help to explain why measures to implement DRR in the wake of a disaster have met obstinate resistance from residents in the disaster stricken community.

\section{DRR in Third Person Communities}

If DRR is not necessarily possible in a stricken community, it raises the question of whether it is possible elsewhere. Although there need to be the "necessary conditions for DRR," it is possible for other communities to successfully pursue DRR (Van Belle 2012, 3). The "third-person effect model" presents a case for this occurring, "where the mediated observation of an event occurring elsewhere is combined with local 
conditions and local political actions to create opportunities for DRR in the third-person (observing) location" (Van Belle 2012, 3). The third person effect is created where “news media coverage of a non-local event, or coverage of someone else's policy crisis highlights a risk or threat to something valued locally" (Van Belle 2012, 6). Van Belle points to the fact that "most of the disaster risk reduction we see occurs or is initiated when just such a window for social and political action is opened by disasters occurring elsewhere" $(2012,15)$. An example of this is Sacramento's levees being urgently repaired after Hurricane Katrina struck Louisiana (Van Belle 2012, 15-16). Olson, Prieto and Hoberman's study of the respective coverage of the Haiti and Chile earthquakes in Jamaica and Peru also suggested that third person communities could learn lessons from non-local disaster events (2010). This opportunity for DRR comes from the localisation of the coverage of foreign disaster events.

\section{Localisation of Vulnerabilities and Policy Entrepreneurship}

For DRR to become a reality in third person communities, Van Belle argues that two essential conditions have to be met. The first is that there has to be the localisation of coverage, where the news media of a particular location interpret and report on an overseas disaster in terms of their own vulnerabilities to a similar disaster. This condition is supported by anecdotal evidence that this exists, but the practice has not been the subject of much research. Van Belle argues that the localisation of coverage in response to disasters is a "natural result of the business imperatives that drive the news media" as "at the most fundamental level all news media outlets are driven to attain and sustain an audience" $(2012,17)$. By relating coverage back to their own audience, especially if there are similar risks in that community, news outlets are able to present the news in a manner that's relevant and resonant with their audience. For example, 
Ralph H. Turner argued in 1980 that "the Los Angeles Times has dealt with the need for earthquake preparedness, has supported the legislative measures to implement safety procedures, and has presented careful reports of significant advances in earthquake prediction," although it is unclear how much of this coverage was in response to nonlocal disasters (Turner 1980, 289-290). This localisation as part of the news production process may prove extremely useful in setting the agenda for DRR if it is evident following non-local disasters.

A second necessary condition is that there must be some policy entrepreneurship, where political actors use the opportunity to campaign for DRR in their community following an overseas disaster in their own rational self-interest. This involves the process where “someone or some group must see potential political gains from pursuing disaster risk reduction policy action" in addition to simply pursuing a policy in the public interest (Van Belle 2012, 19). Thomas A. Birkland defined policy entrepreneurs as "participants who are constantly involved in the policy community because of their technical expertise in their field, because of their political expertise and ability to broker deals that lead to new programs and policies, and because of their connection to the problem as representatives of a particular constituency" $(1997,18)$.

Crucially, Birkland's policy entrepreneurs "press for policy change that favors their interests during normal, non-event-driven politics" but he acknowledges that there has been a notable "failure of all-hazard mitigation policy to gain much attention in public policy" (1997, 18-19; 2006, 126). Birkland's definition assumes that the policy entrepreneur would already be involved in campaigning for DRR prior to a disaster, but this is not a precondition in Van Belle's model. Instead, Van Belle posits that 
opportunistic political actors may seize the opportunity to campaign for DRR after a disaster simply because it is politically beneficial for them to do so - they do not have to be active in promoting DRR beforehand.

Policy entrepreneurship could be apparent in a number of responses to the non-local disaster. It could include campaigning in both public and private political channels, but the news media are an important vehicle which can be exploited by a political actor to keep DRR in the public consciousness. With both the localisation of coverage and policy entrepreneurship, the theory is that DRR is possible in third person communities following an overseas disaster event. This model does not guarantee the successful implementation of DRR if these conditions are met, but it will be almost impossible for DRR to be successful if the conditions are absent (Jamieson and Van Belle 2013, 5).

\section{$\underline{\text { Summary }}$}

There has been some valuable research into the media's coverage of disasters, and especially in recent years, there have been many important studies into the implementation of DRR in at-risk communities. Building on these, Van Belle's model provides a basis for scholarly research into the phenomenon of unsuccessful DRR in stricken communities, with the hope that localisation of coverage and policy entrepreneurship will result in successful implementation of DRR in third person communities. Firstly, there needs to be an investigation into the nature of localisation in third person communities in the news coverage of foreign disasters. 


\section{CHAPTER TWO}

\section{LOCALISATION AND NEWS THEORY}

Van Belle's model for the effective implementation of DRR in third person communities relies on the assumption that localisation of foreign disaster events occurs in the news media of those communities. While there have been few investigations into the nature of localisation, anecdotal evidence has suggested that the process itself is evident in the news. It is reasonable to assume that a news media organisation would cover a non-local disaster event and relate it to their community in order to make it meaningful for their audience. Indeed, there have been instances where this is evident in the news coverage of a particular event. For instance, there have been a number of articles in the Dominion Post which have compared Wellington's vulnerability to earthquakes to Christchurch in the aftermath of their fatal earthquake in February 2011 (Anon. 2012a; Anon. 2012b; Chapman 2011; Chapman 2012; Hubbard 2013; Hunt 2011). However, there have been few studies where localisation has been investigated as its own process, even though news theories have been developed that hint at why localisation may occur, with Galtung and Ruge's news values and Gatekeeping theory being particularly insightful. Media research into the differences in coverage of foreign events between nations has led to some hypotheses suggesting that economic, geographical, development, geopolitical, and cultural affinities between countries may affect the level of coverage, meaning that the location of the news media involved may be significant. There is also some fledgling evidence that localisation does occur, with journal articles supporting this notion coming from a variety of different subject matters and perspectives. 
This chapter moulds these different viewpoints into a coherent whole, combining the different elements into a coherent framework to contextualise the practice of localisation in the news media. The concept of localisation is defined by using several influential news theories to establish where ideas of localisation exist in current literature and identify areas where localisation and the news theory overlap. Localisation in practice is examined, beginning with a theoretical perspective before progressing to how local news operations and translation services localise content for their audiences. The process of localisation is identified and assessed in the analysis of news coverage of disasters conducted by various scholars. However, localisation in the news may still have an othering effect if the news outlet emphasises differences between the non-local community and their own locality. This effect is briefly examined, where the dismissal of the relevance of foreign events to the third person community may result in that community missing the chance to propel DRR onto the public agenda. The practice of localisation is placed against existing news theory and media practice, operationalising the concept before analysing the nature of the practice in the newspapers of the Pacific Northwest.

\section{Defining Localisation}

Localisation is a process where a newsworthy disaster event occurs and the news media interpret that event in terms of their own local vulnerabilities. This practice of localisation is a result of best practice in the news media. As it is imperative for news organisations to achieve and sustain an audience, they will produce content which is relevant and important to that audience. Localisation occurs where events occurring outside the region of the news media organisation's target audience are produced in a manner so they appear relevant to their audience through a variety of different 
processes. Localisation transpires through processes of gatekeeping, where stories are included or excluded due to the newsworthiness of the event for the news media organisation's audience. News values of personification and meaningfulness are evident as events are judged to be worthy of inclusion in bulletins according to how relevant and meaningful they are to the audience (Galtung and Ruge 1965).

Although the effects of 24-hour television news channels' influence over affecting changes in foreign policy were perhaps exaggerated, the theory of the CNN Effect illustrates how overseas events can become local issues through news coverage if there is policy dissensus. Through framing foreign disaster events in terms of local vulnerabilities, news media may be able to set the political and public agenda, promoting productive discussions of DRR. To better understand how this may occur, it is important to evaluate how these processes affect the production of news, and contribute to the practice of localisation. Surprisingly, the practice of localisation has not been the subject of much academic analysis. However it is worthy of further scrutiny as it is an important aspect in the production of news, while being consistent with existing news theory.

\section{Localisation and News Theory}

\section{Gatekeeping}

In the latter stages of the newsgathering process, the news media act as a control in determining what is to be included and excluded from news bulletins - in effect they act as a 'gatekeeper'. David Manning White pioneered research into this process when interviewing the editorial decisions of 'Mr Gates', a wire editor who routinely determined which stories were newsworthy and which were not (1950). The news 
bulletin is produced through a conscious decision-making and editing process to eventually produce the final copy, which is broadcast or distributed to the audience. As a result, "the typical conception of the media's role... as reporter-reflector-indicators of an objective reality 'out there"” is a falsehood (Molotch and Lester 1974, 105).

Instead, the news is produced through a series of processes which construct a version of reality, reflecting "the practices of those having the power to determine the experience of others" (Molotch and Lester 1974, 111; Tuchman 1978). As W. Lance Bennett put it, "Gatekeeping is a term often used to refer to whose voices and what messages get into the news" (Bennett 2007, 5). The gatekeeper "must winnow down a larger number of potential messages to a few;" making decisions that "directly affect the media content that reaches the audience" (Shoemaker and Reese 1996, 105). The gatekeepers are therefore significant in determining what news stories are newsworthy enough to be included in the bulletin, and it is not unreasonable to presume that knowledge of the local audience will be included as a factor in their decision-making. If there is a community at risk of experiencing the effects of a particular disaster event, it is likely that a similar event overseas will pass through the gates and make its way into the news bulletin for that community.

\section{Localisation and News Values}

The concept of localisation is perhaps best understood as being an additional element to two of the news values outlined by Galtung and Ruge in their seminal work in 1965 on the matter. Firstly, the news value of personification is relevant to the notion of localisation. Galtung and Ruge suggested that "the more the event can be seen in personal terms, as due to the action of specific individuals, the more probable that it 
will become a news item" $(1965,68)$. Conversely, the authors propose that "the less personal the news, the more negative will it have to be" as "when something positive happens it is more likely to be attributed to people, whereas something attributed to non-people will have to be negative to hit the news" (Galtung and Ruge 1965, 83). In the coverage of foreign disasters, news media may refer to the number of people affected who originate from their own locality - New Zealand media outlets routinely do this when covering a foreign disaster (Van Belle 2012, 17-18). There are additional factors which can influence the salience of disasters in a given community particularly cultural, economic, geographical, political or religious proximity to the stricken community. Without these connections, the disaster is arguably less newsworthy to a third person community, potentially affecting the levels of coverage of that event in that locality.

Similarly, another of their news values concerns meaningfulness, which is directly relevant to localisation and the prospect of implementing effective DRR in at-risk communities. Galtung and Ruge proposed that "the more meaningful the signal, the more probable that it will be recorded as worth listening to" (Galtung and Ruge 1965, 65). Significantly, they refer to meaningfulness as being important "in terms of relevance: an event may happen in a culturally distant place but still be loaded with meaning in terms of what it may imply for the reader or listener" (Galtung and Ruge 1965, 67). This is particularly applicable for third person communities in the coverage of foreign disasters - the event may have significance for them as they interpret that event in terms of their own local vulnerabilities, despite of the geographical distance between the two places. It is important to note that the uncritical repetition of Galtung and Ruge's news values has been criticised, as arguably they "should be regarded as 
open to question" (Harcup and Neill 2001, 277). Indeed, several scholars have suggested more contemporary lists of news values (Harcup and Neill 2001; McGregor 2002). However, these contemporary suggestions involve minor augmentation of the news values introduced by Galtung and Ruge, and their original findings remain relevant and authoritative in discussions of newsworthiness. As a result, the news values of personification and meaningfulness are applicable to the discussion of localisation.

\section{Localisation and the CNN Effect}

There have been some suggestions that the domestic media coverage of foreign events may be able to influence foreign policy in that state. The CNN Effect is one such theory, which "refers to the effect of a worldwide array of print and broadcast media capable of instantaneous, real-time coverage of breaking events" (Livingston and Eachus 1995, 413). In such an environment, the immediate local news coverage of a humanitarian crisis abroad, for instance, can theoretically lead to a shift in foreign policy in order to assist those affected. Diplomat George Kennan believed that the news media were the catalyst that led to American troops landing in Somalia in 1993, writing that "there can be no question that the reason for this acceptance lies primarily with the exposure of the Somalia situation by the American media" (1993, A25). If this occurred, this effect would be significant in the field of DRR as the news media could have meaningful effects in terms of influencing government policies, both in relation to providing aid foreign disasters and for preparing communities for local impacts of disaster events. 
However, measuring the news media's influence on policymakers is problematic, and the theory has been critiqued by academics. There is evidence of the news media having some influence on foreign policy, but conditions such as policy uncertainty and elite dissensus need to be present (Drury, Olson, and Van Belle 2005; Livingston 1997; Livingston 2011; Robinson 1999; Van Belle 2008). Instead of the news media being perceived as the main drivers of any shift in foreign policy, it is now widely understood that they are not influential enough to cause any change in policy without the issue being adopted by elite figures.

\section{Localisation and the Elite Influence on the News}

Another relevant theory and possible impediment to the practice of localisation is the elite dominance of the news in setting the agenda. The construction of news is the result of an external set of conditions and conventions which dictate how the news is produced. One of these conditions is the interdependent relationship between journalists and the political elite, as "journalists, in attempting to fulfil public interest aims and present authoritative accounts, purposively seek out those who already appear knowledgeable, authoritative or representative" (Davis 2007, 40). At the same time, political elites require the media to communicate policies with the voting public. The result of these "symbiotic relationships" is that the news "reflects the strange mutual dependencies (punctuated by occasional bursts of antagonism) between reporters and officials" (Bennett, Lawrence, and Livingston 2007, 3). Because "reporters overwhelmingly turn to officials as sources for stories and for framing the content of stories," these political actors hold some influence over how the story is constructed (Bennett 1994, 177). Consequently, elite sources arguably come to "dominate the reporting of political as well as most other news sources" (Davis 2010, 69). This effect 
of the use of elite sources in the news media has been derided by several political communication scholars.

The elite manipulation of the news media through their calculated use of the media has caused much angst. This process led to arguments that the American press was "in crisis" in 2007 with the argument made that "the press has grown too close to the sources of power in this nation, making it largely the communication mechanism of the government, not the people" (Bennett, Lawrence, and Livingston 2007, 1). This arguably presents a significant obstacle to realising the ideal democratic process where the media function as a fourth estate and challenge the centres of power. W. Lance Bennett lamented that "as long as the distribution of power is narrow and decision processes are closed, journalists will never be free of their dependence on the small group of public relations experts, official spokespersons, and powerful leaders whose self-serving pronouncements have become firmly established as the bulk of the daily news" (1988, xii). However, the media may still be able to fulfil their ideal democratic function of campaigning on behalf of civil society through the interdependent relationship with political actors. Aeron Davis noted the fact that "there are several documented cases of elites being influenced in their decision-making by media campaigns" (2007, 60). Even more influential could be a mutually beneficial relationship between the media and political actors in discussions of policy entrepreneurship. If the political elite realise the potential benefits for them in campaigning for disaster risk reduction as per Van Belle's model, the elite dominance of the news media could be exploited to foster the public will for DRR.

\section{Localisation and Agenda Setting}


Agenda setting theory is relevant to the process of localisation as if news media do have the ability to 'set the agenda', then framing the coverage of foreign disasters in terms of local vulnerabilities may have the effect of generating local debate on issues of DRR. It is a particularly valid news theory as it does not assume any effects of persuasion over the audience's actual political values or opinions. Instead, it proposes that the news media may hold influence in determining what issues are worth debating. As Bernard C. Cohen wrote, the news media "may not be successful much of the time in telling people what to think, but it is stunningly successful in telling its readers what to think about" $(1963,13)$. In this they are theoretically effective as they are able to "force attention to certain issues" by "constantly presenting objects suggesting what individuals in the mass should think about, know about, have feelings about" (Lang and Lang 1966, 468).

McCombs and Shaw conducted research which supported the agenda-setting theory, concluding that "interpreting the evidence from this study as indicating mass media influence seems more plausible than alternative explanations" $(1972,185)$. Likewise, Iyengar and Kinder performed an investigation into the theory in television news, finding that "our evidence decisively sustains the agenda-setting hypothesis" (1987, 33). They deduced that "when television news focuses on a problem, the public's priorities are altered, and altered again as television moves on to something new (Iyengar and Kinder 1987, 33). This evidence supporting agenda setting theory is significant for DRR as if the news media does localise coverage of foreign disasters, it is logical that they would be successful in getting the issue into the public agenda, providing a platform for policy entrepreneurs to make political gains by advocating DRR. 


\section{Localisation in Practice}

The practice of localisation is imperative for news producers as they make content to suit the needs of their audiences. Arguably, in locally-produced news media, "the media's cultural and economic imperatives of audience appeal are amplified" (Reese and Buckalew 1995, 41). This could be because "stories that are easily recognisable and of relevance to the local audience are more likely to appear than other items" so it is logical that "global stories are often made more relevant to a local audience by giving them a local spin" (Rolston and Mclaughlin 2004, 191). Theoretically, audiences will respond well to content which directly affects them, but once the bulletins stray from this they may be less willing to engage with the wider context of the topic. Roy Krøvel found this to be the case in environmental news in Norway, where the focus of the stories had to be on specific local issues, as NGOs "found it hard to compete for media attention as the media interest turned from pollution, roads, dams and local matters to the very complex question of global climate change" $(2012,272)$.

Because of this, events are portrayed differently in different regions, as "mainstream mass media around the world sometimes construct an identical media agenda, but they frame events according to their own home-grown narratives" (Hafez 2011, 486). Kai Hafez argues that this means that "international exchanges of images and information... are no guarantee for global intertextuality in news, for a growing awareness of the others' stories and perspectives or for more complexity in the mass media's world views" (2011, 486). Instead, "the media are by origin, practice and convention very much national institutions and respond to domestic political and social pressures and to the expectation of their audiences" (McQuail 1994, 121). Although the flow of 
information in a globalised world is international, the character of news media is largely still national, perhaps reflecting an international political system which is still organised around nation-states (Hafez 2011, 493). Indeed, Dimitrova et al. found that "national media are influenced by the overall political environment in which they exist" when analysing international news coverage of the beginning of the second Gulf War in 2003 (Dimitrova 2005, 35).

Lisbeth Clausen researched the differences in news production in television news stations in Japan and Denmark, and found there to be both similarities and differences between the two countries. She argues that the "ability of both knowing international affairs and knowing the receiving audience was found to be essential in the framing of international news information and an important element in the process of presenting events to a national audience" (Clausen 2004, 25). This would involve the news producer interpreting the overseas event and constructing their coverage to emphasise the parts of the story which make it meaningful for their specific audience. This duality had been previously described by Roland Robertson as the process of the "interpenetration of the universalism of particularism and the particularization of universalism," where news producers produce international news for a local audience (1992, 100). In effect, "international news is presented within frames of interpretation of local audiences in each nation, which makes global news particular to each country" (Clausen 2004, 27).

This localisation, in a counter-reaction to globalising forces in international news flows, is essential for producing content for local audiences. Gurevitch, Levy and Roeh summarised this idea by stating how "media maintain both global and culturally 
specific orientations - such as by casting far-away events in frameworks that render these events comprehensible, appealing and relevant to domestic audiences; and second, by constructing the meanings of these events in ways that are compatible with the culture and the dominant ideology of societies they serve" $(1991,206)$. News producers produce content for local audiences as "although no nation would oppose inflows of foreign cultures and information per se, it would like to keep it under a certain level or under its control” (Ito 1990, 441). News producers achieve this by actively framing articles for their local audience, demonstrating a degree of autonomy in doing so, even if the news story had an international focus.

Hillel Nossek argues that this localisation is a negative practice in the coverage of political violence, as 'the more 'national' the report is, the less 'professional' it will be, i.e. the closer the reporters/editors are to a given news event in terms of national interest, the further they are from applying professional news values" $(2004,343)$. He refers to normative professional theory, where journalists are required to direct their content towards the specific audience they are addressing in a "domestic filter" (Nossek 2004, 347). He suggests that "journalists and editors 'wear a pair of domestic glasses' when dealing with foreign news" which means that "only when the event is defined as either 'ours' or 'theirs', can the journalist decide whether to apply a professional or a national-patriotic 'frame' when covering the event" (Nossek 2004, 349-350). This national perspective on the news helps "explain the domestication and localisation of stories," where the national frame "precedes all other frames and dictates which line the coverage will take" (Nossek 2004, 363). This arguably affects the objectivity of the news as national perspectives trump professional journalistic values, acting to distort the coverage, although these might align in the instance of disaster risk communication. 


\section{Localisation and Local News Producers}

Looking specifically at local news producers, it is informative to review how they localise stories in order to make their news relevant and meaningful for their audiences. It is important to note that there is a history of the glorification of local news media organisations. Walter Lipmann exhorted the qualities of local newspapers in a speech in 1949 because they were accountable to the communities "where they are written, where they are edited, and where they are read" (quoted in Overholser 1999, 49). Reviewing a local radio reporter's performance during the second World War, Chris W. Allen admired how "when he could he talked about conditions or events by relating them to Iowa or the Midwest," demonstrating a healthy "respect for his audience" while tailoring his coverage to make it meaningful to them $(2000,49)$.

Supporting this notion of the local news producer as providing a service to communities, Stephen D. Reese and Bob Buckalew argue that "local television strives to be seen as an involved member of the community and wants to appear supportive to local community institutions" $(1995,47-48)$. This leads them to "seek means of establishing a sense of community through common symbols and interests" (Reese and Buckalew 1995, 53). This may lead to differences between local and national news producers, as they "differ on occasion with respect to what is newsworthy, and their differences obviously reflect different concepts of responsibility and differing degrees of sensitivity to local concerns" (Turner 1980, 285). These differences are especially salient in their coverage of non-local disasters, as an at-risk community is likely to interpret the disaster differently to the national news outlet with a broader audience, most of which may not be in an at-risk community. 
The notion of the 'local' is not strictly confined to geographical proximity however, as outlined by John J. Pauly and Melissa Eckert. They contend that "it can also reference citizenship, social status, religious belief, or economic situation" depending on the target audience of the medium (Pauly and Eckert 2002, 314). Indeed, Michael Conniff argued that "Local' is who you are, and what you care about" and that "it can have very little to do with where you happen to live" (qtd. in Pauly and Eckert 2002, 320). Bill Rolston and Greg Mclaughlin looked at coverage of the 2003 Iraq in Northern Ireland and found that localisation of the conflict occurred along their enduring sectarian divide, "with unionists broadly in support of the war effort and nationalists fervently opposed" $(2004,196)$. They found that "for the first time in decades, people in Northern Ireland had come together to voice their opposition to events remote from their own 'local difficulties"' (Rolston and Mclaughlin 2004, 194-195). Localisation occurred through interviews with troops from Northern Ireland which delivered "good news values for reporters and editors: they provided local drama and colour, and a vital connection between readers and the distant conflict in the Gulf' (Rolston and Mclaughlin 2004, 199). However, the authors also saw "stories and items that strained the local connection, sometimes to a barely credible extent" as the newspapers sought to highlight the conflict as being relevant and meaningful to their readers (Rolston and Mclaughlin 2004, 199). This demonstration of forced and unsuccessful localisation is perhaps indicative of the emphasis placed on it by editors and journalists.

\section{Localisation and Translation in the BBC World Service}

An interesting example of the localisation of news stories in a globalised news environment is the process of translation, especially in an international news producer 
such as the British Broadcasting Corporation (BBC). The British Broadcasting Corporation World Service [BBC WS] produces news for a variety of different regions in different languages, which resulted in "an irreducible tension between the World Service as a translation factory and the same World Service functioning as a relativizing agency, serving each audience with something approaching with something approaching their own terms and standards" (Podkalicka 2011, 144).

In recent years there has been an ideological shift in the World Service with technological advances as it was now "not good enough to broadcast global news for [a] global audience but we [at the BBC] had now local audiences listening to us on FM so it was impossible to ignore regional or national stories in those countries" (Sohohubenko qtd. in Podkalicka 2011, 146). In effect, "after globalizing (i.e.delocalizing) news stories, BBC WS language services localize them again" according to “assumptions made about the knowledge, comprehension and cultural reference points of the target audience" (Cheesman, Nohl and the BBC WS US Elections Study Group 2011, 219). This results in the fact that even for global news events like the US elections, "within BBC WS there is still potential for different accents to be placed and heard" (Cheesman, Nohl and the BBC WS US Elections Study Group 2011, 231). This has helped the BBC to develop "strong connections with their communities" as "appropriate and sensitive procedures of translation in globalising or localising news" become increasingly important (Podkalicka 2011, 149).

\section{$\underline{\text { Localisation and Disaster Coverage }}$}

There are some journal articles which add to the knowledge of localisation, each providing some insight into how news coverage may differ according to how relevant 
an event is perceived by a new consumer to their own circumstances. $\mathrm{H}$. Denis $\mathrm{Wu}$ found that "a mixture of forces that shape international news coverage worldwide economic interest, information availability, and production cost of international news are apparently at work in determining the volume of information from abroad," but it "centres on the powerful" $(2000,126)$. In a similar investigation, Folker Hanusch examined the reporting of death in news media, and how and why the extent of the coverage and the nature of the coverage vary $(2008,342-343)$. He proposed that how the people died may be important to the coverage "in that if the audience can relate with the circumstances, they might identify more easily with the event" (Hanusch 2008, 342$343)$.

Likewise, Claire Wardle claimed in her analysis of child murders in the US and UK press that "a personally threatening angle to a story also increases newsworthiness, and the 'it could happen to you' element of certain stories undoubtedly fuels interest" (2006, 518). Identification of the audience with the victim is important, as Hanusch concluded that cultural, political, economic, geographical and linguistic proximity to the affected country determined the amount of coverage of their deaths $(2008,354)$. In effect, the levels of coverage were determined by the ability of the audience to empathise and identify with the stricken community's suffering.

This factor is potentially important to the analysis of news coverage of overseas disaster events. Tierney, Bevc and Kuligowski contribute to this discussion by contending that “decisions about what and how much to cover with respect to specific disaster events are often rooted in judgements about the social value of disaster events and on conceptions of social distance and difference" $(2006,62)$. Looking beyond the practices 
of the newsroom, they argue that "media treatments of disasters both reflect and reinforce broader societal and cultural trends, socially constructed metanarratives, and hegemonic discourse practices that support the status quo and the interests of elites" (Tierney, Bevc, and Kuligowski 2006, 62).

Christine C. M. Leung and Yu Huang note that this is manifested in accusations that "western media, influenced by their ideological position and/or national interest considerations, will use their hegemonic power systematically to construct negative images and media representations of underprivileged others: usually the less-developed countries" $(2007,676)$. They also outline the popular conception that "journalists, when describing foreign contexts, routinely use binary oppositions that essentialize the complex and contradictory reality into core attributes of a nation and history to construct a reductive ideological contrast between 'us' and 'them' (Leung and Huang 2007, 676). This is particularly instructive in the process of localisation - through constructing this narrative, journalists can either relate the event they are covering to their audience, or dismiss it as being irrelevant, as if the plight of those 'others' is not applicable to their circumstances. This is significant to the discourse of DRR - the journalistic separation of the victims as either 'us' or 'them' affects the event's pertinence to their audience, and influences the ability of DRR to become on the public agenda in the third person community.

\section{The Othering Effect}

The distinct differentiation between communities in the news media is an example of othering, where one group's differences are emphasised in "the process of attaching moral codes of inferiority to difference" (Krumer-Nevo and Sidi 2012, 300). This 
notion is evident in the news coverage of overseas disasters where the stricken community is depicted as almost deserving their suffering because of issues such as their lack of preparedness, poverty, poor construction, poor government, corruption or overpopulation. Peter Teo's observation of "discursive strategies that blame the victims for their circumstances on their own social, economic and even cultural disadvantage" can be taken and applied to the news coverage of overseas disasters $(2000,8)$ Tzvetan Todorov outlined three dimensions of the relationship between the self and other, which are applicable to the news coverage of overseas disasters. These dimensions included value judgements, where the other is perceived as being either inherently 'good' or 'bad'; social distance, where the other is perceived as either psychologically or physically distant; and knowledge, where the other is perceived as being unknown either historically or culturally (Todorov 1984).

Indeed, despite the notions of objectivity in the news media, anecdotal evidence suggests that this othering is commonplace in the field. For instance, Stuart Allan wrote of a journalistic "culture of othering" where women and some ethnic groups were routinely discriminated against in the news (2010). Amir Lupovici's framework for teaching International Relations in terms of "Me and the Other" can be applied to the construction of the 'me' and the 'we' in news, especially as these relationships change in the aftermath of a natural disaster - the 'other' may become the 'we' in a disaster event depending on the level of identification between the two communities (2012). Krumer-Nevo and Benjamin determined that "the oppressive power of the news derives from the impassable barrier it draws between 'us' and 'them' and the social distancing it creates" $(2010,695)$. This is especially significant in the reporting of overseas 
disasters as this perception that the other is unlike the audience of the newspapers could prevent lessons being learned from other disasters.

Therefore, just as it is possible for news media to localise overseas disaster events and frame them in terms of their own vulnerabilities, they are similarly able to dismiss these events as irrelevant to their situation through othering. Tierney, Bevc and Kuligowski noted in the aftermath of Hurricane Katrina in Louisiana that "many of the nation's large urban agglomerations, and their populations, are at risk from future extreme events", including "New York City, Los Angeles, the Bay Area of Northern California, and Miami" $(2006,76)$. However, despite this, there remains the danger of future disaster events impacting "highly vulnerable urban places" which are "home to highly diverse populations, including many who are forced to live in poverty" (Tierney, Bevc, and Kuligowski 2006, 76). The victims of Katrina in New Orleans could have been 'othered' in coverage of the disaster by being presented as being somehow different from the audience because of their poverty, race or ethnicity.

Another example of othering involved Fabienne Darling-Wolfe examination of Le Monde and the New York Times' coverage of Hurricane Katrina and the Parisian race riots. She found that both sides were more willing to point the finger at the other nation's racial problems than confront issues of race in their own backyard (DarlingWolf 2008). Their coverage of their domestic issue was remarkably different from their coverage of the foreign event:

"while both newspapers were at times quite critical of the respective contexts in which they operate, their coverage of 'local' events followed patterns familiar to 
media scholars: the linkage of poverty to race, the subtle 'blaming of the victim', the tendency to link African-Americans to crime and violence, the failure to fully address or 'explaining away' of the structural underlying causes of the problems at hand" (Darling-Wolf 2008, 367).

In contrast to the newspapers' coverage of their own domestic events, "the other nation's 'race problem' was interpreted as indicative of a total system failure" (DarlingWolf 2008, 367). Likewise, in a comparison of coverage of the 2003 Iraq War in the United States and overseas news media, Dimitrova and her colleagues found that “international media were much more likely to discuss and analyze issues such as blame and responsibility for the war" than American online media (2005, 35-36). This could potentially be because it is easier to criticise from a detached perspective than it is from inside a state experiencing the trauma of a war effort. This could also be applied to a disaster stricken community in the aftermath of a disaster event.

Coverage of the continent of Africa is also susceptible to accusations of othering. It has been labelled as a troubled continent where "every bit of bad news - civil wars, military coups, refugees, and displaced persons, drought and disease - has sadly reinforced a mood of fatalism or, still worse, callous unconcern"” (Adams 1986; Dahlgren and Chakrapani 1982; de Beer 2010; Golan 2008; Merrill 1995, 2004). As such, it is hard for Western news media to empathise with African communities, meaning it is almost impossible for localisation to occur in their coverage of the continent.

Susan Weill and Laura Castañeda coined the term 'empathetic rejectionism' when analysing the editorial policies of African American newspapers in the American South towards stories of significance to the Latino community. They defined the term as the 
newspapers' "editorial empathy for a topic coupled with rejection of press coverage based on fear of social, financial or political consequences" (Weill and Castañeda 2004, 539). While the latter half of the definition may not be applicable to the coverage of overseas disaster events, the concept of empathetic rejectionism is relevant to the process of othering in the news coverage of disasters. This could involve empathetic coverage of the event, sympathising with victims while rejecting the significance of the event in terms of their own vulnerabilities due to the stricken community's ineffective preparation, lack of building standards, political corruption or poor warning systems. If this occurs, it would be difficult for DRR to become on the public agenda. If so, third person communities may miss their opportunity to learn from overseas disaster events.

Localisation is a process worthy of further study as it has the ability to provide insight into how local and national news organisations operate. Therefore it is important to ascertain how localisation is occurring in third person communities. Localisation is a result of the process of gatekeeping in determining the newsworthiness of stories and in potentially setting the agenda in the news media's location. It is potentially an influential practice in the production of news, and more research is necessary to determine its impact on that process. There are some examples of local news operations localising material to make stories more relevant and meaningful to their audiences, just as there has been a new emphasis on localising content in translation processes in the BBC World Service, but more research of this is necessary to bridge the gaps in understanding between these theories.

However, stories can also be determined to be irrelevant and not meaningful to audiences through the process of othering. This is especially worthy of academic 
consideration, and will also be investigated in the structured qualitative content analysis of the Seattle Times and the Vancouver Sun's coverage of overseas earthquakes. For Van Belle's model for implementing effective DRR measures to successfully occur, there needs to be localisation of a foreign disaster event in the third person community's news media. The localisation of vulnerabilities has the potential to set the agenda and help to generate public debate over DRR, so that the third person community may eventually be better prepared for natural hazards. However, it is also possible for othering to occur and for the overseas disaster event to be dismissed as irrelevant or to the community. This would make it extremely difficult to use the event as a catalyst for DRR to become on the public agenda in the third person community. 


\section{CHAPTER THREE}

\section{METHODOLOGY}

This chapter provides an overview of the methodology used in the content analysis of the coverage of six overseas earthquakes in the Seattle Times and the Vancouver Sun. The typologies of localisation are described and operationalised in order to explain how the findings of the investigation were obtained. The focal questions are introduced as central points to focus the evaluation of how localisation occurred in the person communities. An explanation of the methodology clarifies why elements of both content analysis and discourse analysis were used to reveal the nature of localisation. The risk of encountering confirmation bias is addressed with an explanation of the steps taken to avoid it occurring. The structured qualitative content analysis provided the best methodology to reveal the nature of the news coverage of the overseas earthquakes.

The hypothesis of the thesis proposed that the nature of localisation in the news coverage of the six overseas earthquakes in the Seattle Times and the Vancouver Sun would change depending on the level of development of the stricken community. For instance, communalisation would theoretically be more pronounced in the coverage of earthquakes in Japan, Italy and Chile, where comparisons are made between communities to establish an affinity between them. Conversely, othering would theoretically be more apparent following the earthquakes in Turkey, Pakistan and Haiti, where differences between communities are emphasised. The nature of the localisation is crucial for DRR to become on the public agenda. If the third person community cannot see themselves as potential victims of a similar hazard, it is unlikely that they will learn lessons from non-local disasters. 
The hypothesis was developed on the assumption that it would be easier for journalists, editors and their audiences to relate to the more developed communities than it would be to relate to the lesser-developed disaster stricken communities. It was theorised that a disastrous earthquake in Japan was theoretically more likely to resonate with the Pacific Northwest as they would potentially share many of the same DRR measures and be similarly prepared for the earthquake, prompting more localisation. However, an earthquake in Haiti would be likely to be dismissed as irrelevant to the third person communities as there are many developmental and economic differences between the Pacific Northwest and Haiti. If this was to be the case, it would suggest that there are opportunities for DRR advocates to use this coverage to help create the public will for the implementation of DRR in Olson, Prieto and Hoberman's "mirror countries" (2011). However, this form of localisation could prevent a public debate from occurring in third person communities who do not identify with the stricken community. A better understanding of the differences in coverage of non-local disasters would provide DRR advocates with the opportunity to better capitalise on overseas disaster events to campaign for DRR in third person communities.

A key consideration was to establish a framework that could be repeated so that another researcher could use the same methodology and find similar results. For this reason, this research was carried out as a structured qualitative content analysis, which combines the holistic attention to detail of qualitative methods with a formalised structure borrowed from quantitative research methods. This method would be used to test the hypothesis using a system of qualitative coding, allowing scope for evaluative analysis at the same time. As this was an exploratory study to some extent, and the nature of 
localisation itself is difficult to narrow down to a series of phrases or key words, the structured qualitative content analysis suited the needs of the investigation. While quantitative analysis may be useful as "a means of revealing patterns in news content", it can sometimes also have limitations in that it can contribute to the simplification of complex issues by leading to overarching conclusions of an entire concept (Ericson, Baranek, and Chan 2009, 132). The qualitative content analysis meant that the news coverage could be interpreted through close reading of the articles, and subtle patterns across the coverage could be identified. The limited scope of the investigation meant that a small sample size was required, but it was sufficient to reveal the nature of the localisation of overseas disasters in the newspapers in the two third person communities.

To establish a consistent approach to the research and the process of coding, the focal questions were developed to ensure that the same elements are identified in every newspaper article. In order to find answers to these questions in the sample of newspaper articles, a customised methodology was developed. Maxfield and Babbie's work highlights how qualitative methods are best suited to this investigation, as "in addition to greater detail, nonnumerical observations seem to convey a greater richness of meaning than do quantified data" $(2009,23)$. Moreover, the depth of analysis available to qualitative researchers is complemented by a process of gathering and evaluating data in the pursuit of "plausible relationships proposed among concepts and sets of concepts" (Strauss and Corbin 1994, 278). The typology of localisation and the focal questions helped to establish some consistency to make the findings more systematic and comparable. Because the process of localisation cannot be easily converted into numerical form, it was not well-suited to be evaluated through quantitative measures alone, but instead lent itself to analysis through qualitative 
interpretive methods. While some quantitative measures were used to assess the total number of stories that demonstrated the different types of localisation, the nature of the coverage was better understood through qualitative interpretation of the newspaper articles to determine how the two communities were constructed in the coverage.

To maintain the replicability of the research process, the investigation involved the use of a coding schedule with the focal questions in order to uncover evidence of the five types of localisation in each newspaper article. This would help to avoid the possibility of inconsistent coding across different examples. The investigation utilised the threepronged practice of memoing as outlined by Babbie to make sense of the data and identify patterns and trends within it. This involved the writing of code notes to identify key "code labels and their meanings"; theoretical notes as "reflections of the dimensions and deeper meanings of concepts, relationships among concepts, theoretical propositions, and so on"; and operational notes to "deal primarily with methodological issues" (Babbie 2010, 404-405). This system allowed for the typology of localisation to be developed and refined in order to categorise the patterns discovered in the content analysis.

The structured qualitative content analysis was adopted because it involved elements of both quantitative and qualitative research methods to answer the focal questions. The quantitative elements were useful because they helped to provide a means to answer the focal questions through the data sample in measures of frequency and volume of newspaper articles demonstrating localisation. Quantitative analysis generally "assumes repetition is the most valuable indicator of significance," so "the emphasis is on what can be reasonably classified so that it can be counted" (Ericson, Baranek, and Chan 
2009, 132). This form of analysis was useful as it enables direct comparison across cases, as the quantification "often makes our observations more explicit, [and it] makes it easier to aggregate and summarize data" (Maxfield and Babbie 2009, 23). The quantitative results of the investigation helped to show trends and patterns which provide some perspective on how the nature of the news coverage of overseas disasters changes differs according to the level of development of the stricken country.

However, it is important to acknowledge that these methods alone were not enough to reveal the nature of this coverage. Roger D. Wimmer and Joseph R. Dominick identified four key limitations of content analysis. They outlined how the "findings of a particular content analysis are limited to the framework of the categories and definitions used in that analysis", how a researcher may need to evaluate a large body of data to be able to sustain and validate conclusions made on the basis of their content analysis (Wimmer and Dominick 1997, 115). It is vital that quantitative researchers ask the right questions - there remains room for distortion and misrepresentation of the data if the focus of the investigation is skewed. Unfortunately this standard content analysis was not enough by itself to uncover the nature of the content, which required a degree of interpretation. Because of the difficulties involved in labelling indications of localisation as a certain set of phrases or key words, it does not lend itself easily to a quantitative content analysis alone.

Qualitative research offered a means for the researcher to view the data in fine detail, combing through the newspaper articles to uncover nuances and trends which would not necessarily be apparent in a broader investigation (Wimmer and Dominick 1997, 84). The qualitative elements of the investigation helped to establish a method that 
"involved a continuing interplay between data collection and theory...where data collection, analysis and theory are more intimately intertwined" than in quantitative analysis (Babbie 2009, 394). This type of analysis provided the means for the typology of localisation to be developed, which identified how the newspapers localised their coverage for their local audiences. This meant that there was a stronger potential for the theory and the method to construct the object of analysis than in in a solely quantitative analysis. The methodology included "the key process in the analysis of qualitative social research data" of coding each newspaper article, and the process entailed "classifying or categorising individual pieces of data" so that trends across the sample would become apparent (Babbie 2010, 400). This methodology helped to identify that while othering occurred in the newspaper coverage of all six earthquakes; it tended to attribute blame for the scale of the disaster on the countries with the lower HDI rankings. This was done through descriptions of the stricken country's amount of social disorder, its troubled history of the country, their degree of poverty and the perception of the country's inability to cope with the disaster without international assistance.

As "some research situations and topics require elements of both [methodological] approaches," this investigation required elements of both quantitative and qualitative methods (Maxfield and Babbie 2009, 24). An advantage of this was that the qualitative elements helped to uncover meaningful trends in the data. Maxfield and Babbie wrote that "in addition to greater detail, nonnumerical observations seem to convey a greater richness of meaning than do quantified data" (Maxfield and Babbie 2009, 23). However, this also presents a potential problem for replicating the analysis and establishing the validity of the findings. While "the aim of data analysis is the discovery of patterns among the data, patterns that point to theoretical understandings 
of social life," there was the danger that these patterns may only be apparent to the researcher (Babbie 2010, 400). Indeed, Earl Babbie argued that:

\footnotetext{
"The most difficult task for social scientists lies in producing powerful analyses of qualitative data...qualitative analysis depends more on the individual insights of the researcher than on the tools available to support the analysis. Qualitative analysis remains today as much of an art as a science" (Babbie 2010, 391).
}

There were issues of validity at stake here, as because the investigation involved the researcher's own perception of the reality, there are potential problems of validation for researchers forming conclusions solely from any kind of data. For this reason, the analysis of newspaper articles in this investigation was undertaken against the focal questions using the different typologies of localisation, which gave a consistent structure to the coding process and ensured the replicability of the analysis. This analysis establishes validity through the patterns manifest in the content which demonstrated quantitative patterns of localisation which support the qualitative findings.

\section{Avoiding the Confirmation Bias}

One dangerous trap to avoid was that of the analysis simply confirming the hypothesis of the investigation, reaffirming what was believed to be the case in the data. Raymond S. Nickerson interpreted the confirmation bias as "the seeking or interpreting of evidence in ways that are partial to existing beliefs, expectations, or a hypothesis in hand" $(1998,175)$. This process is sometimes manifest in situations where "persons biased towards their own hypotheses do not properly consider alternative hypotheses and disregard factors that might disprove their ideas - a mechanism that systematically impedes the possibility to reject the hypothesis to be true" (Hergovich, Schott, and 
Burger 2010, 189). Babbie wrote, "researchers face an obvious risk of seeing what they are looking for or want to find...experienced qualitative analysts avoid this pitfall through a deliberate awareness of their own values and preferences as well as adherence to established techniques for data collection and analysis" $(2010,418)$. There was a risk that the analysis of articles could have been unintentionally weighted towards confirming Van Belle's model. The consistent application of the coding criteria ensured focus, removed ambiguity and helped ensure that the analysis was based on patterns in the data and not the researcher's own biases.

Figure 2. The Typologies of Localisation.

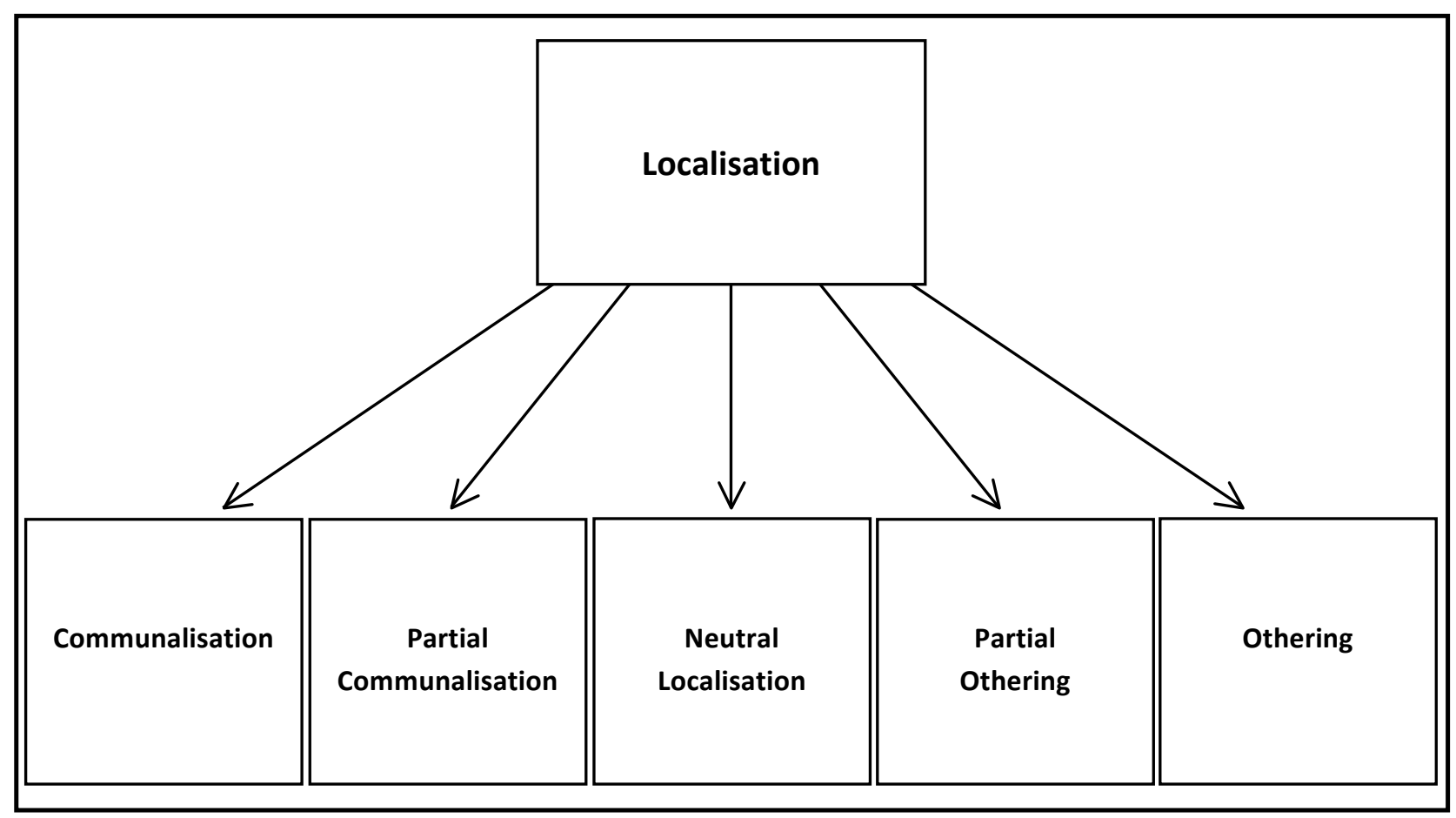




\section{The Typologies of Localisation}

A set of typologies of localisation were established which could illustrate the nature of the localisation. After piloting of the coding schedule, it became evident that there were five different types of localisation, generally in keeping with a five-point spectrum [see diagram]. It is important to note that some articles did not feature localisation at all. This was a relatively frequent occurrence, especially in the immediate aftermath of the earthquake where there are neither direct nor indirect comparisons made between the locality of the newspaper and the stricken community. However, during the piloting of the coding schedule it was noticeable that localisation did occur, but that there were some differences in how the overseas earthquakes were related to the audience in the third person community. Accordingly, the newspaper articles were coded against these five types of localisation in this investigation. The different types of localisation were explicit communalisation, partial communalisation, neutral localisation, partial othering and explicit othering. This constitutes a critical theoretical development of Van Belle's model with the introduction of typologies of localisation as the coverage localised the overseas disasters in different ways. The introduction of this set of typologies to illustrate the nature of localisation is a significant finding of the investigation.

The first of these types of localisation was communalisation, where a direct connection was made between the locale of the newspaper and the disaster stricken community, establishing an affinity between the two communities. This could include explanations or statements indicating why the overseas earthquake is significant to the locality of the newspaper. This could involve the direct comparison between the two areas, citing the common vulnerability to seismic activity. The hypothesis suggested that this form of localisation would occur more regularly with the countries at the top of the HDI table. 
All of these would constitute an attempt on behalf of the newspaper to make the overseas earthquake meaningful and relevant to their readership.

Another category of localisation was partial communalisation. There are several indicators which would demonstrate how this type of localisation occurred in any given newspaper article. This could include the mention of vulnerabilities in the disaster stricken community that are shared by their locality without explicitly comparing the two communities. Examples of this include descriptions of the technology used in the construction of buildings, the science surrounding the prediction of earthquakes, the type of fault, the natural features that proved to be significant in the tremor, or the measures taken to prepare for the eventuality of the earthquake. Additionally, partial communalisation could include the reporting of facts which may affect the third person community, including the impact of the earthquake on the global insurance industry or the global economy.

The third type of localisation was neutral localisation, where there was a connection made between the stricken community and the third person community which featured neither communalisation nor othering. This could be indicated by references to the presence of citizens of the third person community living in the stricken community. It could also been seen in the citation of people in the third person community with friends or relatives in the stricken community or the mention of people from the stricken community who were living in the third person community. For instance, if a newspaper article states that no citizens from their locality had been affected by the event in question; this would be an example of neutral localisation. 
The fourth category of localisation was partial othering. This could involve the citation of factors in the disaster stricken community, which are implied to have contributed to the scale of the disaster, which would not apply to the third person community. These could include poor government decision making, the effectiveness of the response and recovery in the stricken community, poor construction, economic policies and poor leadership. Additionally, it could involve such things as describing different cultural or religious practices of the stricken community such as the process of burial, living arrangements, gender roles, community arrangements. This process serves to other the disaster stricken community, presenting them as noticeably different to themselves, often implying that they contributed towards the consequences of the earthquake. Factors implicitly othering the stricken community were frequently present in the newspaper articles.

Othering was the fifth type of localisation, involving the practice of emphasising differences between the locality of the newspaper and the disaster stricken community. The othering could be through explicit references to differences such as the inadequate enforcement of building codes, social disorder, the lack of measures of preparedness, a troubled history, poverty, corruption or poor public infrastructure. This content places blame on the stricken community through citing their disaster risk reduction as being inadequate, especially compared to those measures in the third person community. Additionally, othering could take place in the citation of the third person community's involvement in the earthquake recovery and response or the provision of aid to the stricken community. There was the potential for a greater proportion of this form of localisation to occur in those countries in the bottom of the HDI table. This narrative establishes a paternalistic victim-saviour relationship between the communities, where 
the burden is on the third person community to assist the stricken community. This presence of this type of localisation is significant as it could prevent a discussion of the measures of DRR of the third person community, meaning that it could be more difficult to conjure up the public will for improved DRR.

\section{$\underline{\text { The Focal Questions }}$}

To test the hypothesis, there were three primary areas of interest to explore. In order to test whether the nature of localisation in the news coverage of the six overseas earthquakes in the Seattle Times and the Vancouver Sun reflected the relative development of the disaster stricken country, three focal questions were developed. These questions focused the investigation and the collection of data uncovering the nature of localisation in the newspaper coverage of overseas earthquakes. The focal questions were:

1) How is the news story about the overseas earthquake constructed for the audience in the third person community?

2) How is the earthquake stricken community constructed in relation to the third person community?

3) How are the measures of disaster mitigation and prevention of the earthquake stricken community represented against those in the third person community?

Question One - How is the news story about the overseas earthquake constructed for the audience in the third person community?

The first question addresses how the newspaper interpreted the non-local disasters and related it to the local audience. The question sought to gain information about how each 
story signalled the salience of the earthquake for the local audience or highlight dominant themes or ideas for the local community. The article could involve an effort from the newspaper to make the article relevant and meaningful for audience. An important aspect of this question is that it addressed the fact that each newspaper article was aimed at the local audience in some way and was deemed newsworthy enough to publish, so it must have been considered relevant to the local audience at some level.

It is an important question to ask as it addressed the fact that newspaper articles are constructed to grab the audience's attention. The question allowed scope for the narrative of the event to be evaluated. It seeks to determine how the newspaper constructed the story for the local community through the dominant themes of the article. In practical terms, the question required the researcher to write a brief description of the type of article, determine how it was pitched at the local audience in terms of headline, prominence of the story, and whether it alludes to local issues or local people in an attempt to make it meaningful for the local audience. For instance, if the article alluded to a specific local highway which was constructed using similar materials and technology to a highway which suffered severe damage in the stricken community, this would constitute communalisation in the discussions of the local community's vulnerability to a similar seismic event.

\section{Question Two - How is the earthquake stricken community constructed in relation to the third person community?}

This question sought to address how the people of the stricken community are compared to the people in the third person community. It also looked to reveal the nature of the relationship between the two communities. The question seeks to discover 
if the stricken community is constructed as being similar to the local community or as vastly different; in other words, whether the people in the stricken community are portrayed as equals or as 'others', as 'us' or as 'them'. The question seeks to determine whether there are differences between the stricken community and the third person community outlined in the newspaper sample. For instance, if the article referred to similarities between the two communities in terms of economic prosperity, this would constitute communalisation and provide an example of links being drawn between communities. Alternatively, othering occurs when an article alludes to specific cultural, social or religious differences that distance the local community from the stricken community. It is important to analyse the local experience of the event, their reaction to it, as well as how the victims of the stricken community are constructed. An important aspect of this question is that it looks at how the stricken community is represented and how their plight is described.

This is a particularly important issue to analyse as it illustrates the nature of the localisation of vulnerabilities in the third person community. How the community is constructed will help to determine whether lessons are to be learned from the overseas earthquake in the third person community, or whether the experiences of the stricken community are to be ignored and disregarded because the local community does not identify with them. If the people in the stricken community are represented as equals who have suffered from a disaster event, there is potentially more capacity or inclination for people in the local community to identify with the victims, making the impact of the disaster even more resonant. If the third person community can imagine themselves as the community struck by the earthquake, it is much more likely to implement measures to prevent similar consequences from occurring if a similar event 
was to hit them. Likewise, if the people in the stricken community are constructed as others, it will become harder for people in the third person community to identify with them and see themselves as potential victims in much the same way. If the local community cannot see themselves as being similar to those in the stricken community, the promotion of DRR as policy would be more difficult.

\section{Question Three - How are the measures of disaster mitigation and prevention of the earthquake stricken community represented against those in the third person community?}

This question sought to compare the measures of preparation for natural hazards in the stricken community against those in the third person community. This is significant for the field of DRR because if localisation is occurring, the description of these preparations for natural hazards in the stricken community could lead to the discussion of local vulnerabilities in the third person community. Similarities and differences in these measures between communities could be discussed in the articles produced by local newspapers. Indicators of this comparison could include mention of DRR like legislation or regulation drafted in the third person community to mitigate their vulnerability to a similar event. At the same time, if the connection between DRR in the stricken community and those in the third person community is not made or dismissed outright, it would be difficult to learn lessons from the disaster event. For instance, if an article mentioned the fact that there are DRR measures in place in the third person community which were absent in the stricken community, it would be difficult to avoid the implication that the third person community is already prepared and did not need to discuss their own DRR. 
This was an important question to ask as the comparative analysis could provide the impetus for public discussion of whether they are prepared for a similar event to take place at home. If this comparison of DRR between communities is taking place, it could potentially trigger discussion among policymakers and the public about the level of preparedness in the third person community for a similar event. This investigation hypothesised that there would be fewer of these comparisons in the news in the third person communities following the earthquakes in the less developed countries. If there is a correlation between the level of development in the stricken country and the extent of the comparisons about DRR measures, this could have an effect on the ability for the third person community to learn lessons from the non-local earthquake. If the comparison of risk mitigation between communities is not occurring, the public awareness and motivation for DRR may not be strong enough to implement it effectively.

These questions provided the framework for the structured qualitative content analysis. The questions ensured consistent themes of analysis and helped maintain a coherent set of standards for the analysis of the newspaper articles in the sample. Having established the focus of the investigation, it was important to outline which methodology was best suited to answer the focal questions. Accordingly, the evaluation of the nature of localisation in newspaper articles was undertaken through a content analysis with qualitative elements.

\section{Sourcing Newspaper Articles to Reveal the Nature of Localisation}

In order to be able to make valid and credible conclusions from a set of data in any investigation, it is necessary to establish selection criteria for the newspaper articles as 
consistent and replicable as possible. The articles were selected in order to be able to answer the focal questions and test the hypothesis, so an emphasis was placed on articles which had the capacity to demonstrate localisation. This was done to enhance reliability and help to explore variations and contradictions in the nature of localisation.

Due to time limitations, only twenty articles per newspaper per earthquake were selected for analysis. An initial search was conducted using the search terms "(name of country affected, e.g. 'Japan')" and "earthquake" in the Proquest Newsstand database for the Vancouver Sun, and in the Seattle Times' own online archive at SeattleTimes.com for their articles. These results were limited to those with full text available between the initial date of the earthquake and its corresponding date the following year. This still produced hundreds of results for some of the earthquakes, so it was important to narrow down the search further.

Eventually, the twenty longest articles were chosen for each disaster from each newspaper, with repeated articles and stories which only mentioned the earthquakes in passing excluded from the sample. Unfortunately, a shortfall in articles in the Vancouver Sun following the Italy and Turkey earthquakes resulted in a sample of 229 newspaper articles. Still, this presented the best chance of uncovering the nature of the localisation in the newspaper articles because it was assumed that the longer articles would provide enough depth for this to be analysed and shorter articles may not have had the space for contextual reflection. Subsequent studies may be able to shed light on the proportional use of localisation in news content, but as this was not the focus of this study, the methodology was suitable. 


\section{CHAPTER FOUR}

\section{FINDINGS}

\section{Overview}

The structured qualitative content analysis of the 229 newspaper articles demonstrated that the nature of the localisation generally changed according to the level of development of the stricken community. In terms of number of stories, there was a clear but imperfect trend in the data that showed that that communalisation was evident following the earthquakes in the more developed stricken countries. However, there was an unexpected finding that more stories featuring communalisation in the third person communities [TPC] occurred after the earthquakes in Chile and Turkey than Japan and Italy. Conversely, there were much more stories indicating othering following the earthquakes in Pakistan and Haiti. This quantitative data suggests that the nature of the coverage changed according to the level of development of the stricken country. Significantly, this was reinforced by the qualitative findings, which suggested that the two newspapers in the Pacific Northwest identified with stricken communities in some instances, but at other times distanced themselves from them, differentiating the hazards faced in their locality from those endured by the stricken community. This chapter outlines how these differences in the nature of coverage appeared in the investigation. 
Table 3. The Full Quantitative Findings of the Analysis.

\begin{tabular}{|c|c|c|c|c|c|c|}
\hline Indicators of Localisation & Japan & Italy & Chile & Turkey & Pakistan & Haiti \\
\hline \multicolumn{7}{|l|}{ Communalisation } \\
\hline Localisation of Vulnerabilities in TPC & 13 & $\mathbf{0}$ & 33 & 12 & 0 & 1 \\
\hline $\begin{array}{l}\text { Direct Comparisons between SC and } \\
\text { TPC }\end{array}$ & 8 & 0 & 15 & 8 & 0 & 0 \\
\hline $\begin{array}{l}\text { TPC economy affected by SC } \\
\text { earthquake }\end{array}$ & 4 & $\mathbf{0}$ & 2 & 1 & 2 & 2 \\
\hline Contextualisation of TPC against SC & 2 & $\mathbf{0}$ & 2 & 0 & 0 & 4 \\
\hline Relationship of TPC to SC & 1 & $\mathbf{0}$ & 0 & 1 & 3 & 0 \\
\hline \multicolumn{7}{|l|}{ Partial Communalisation } \\
\hline $\begin{array}{l}\text { Shared vulnerabilities between } \\
\text { communities }\end{array}$ & 5 & 0 & 7 & 5 & 0 & 0 \\
\hline Effects of SC earthquake on TPC & 5 & 1 & 1 & 2 & 2 & 0 \\
\hline \multicolumn{7}{|l|}{ Neutral Localisation } \\
\hline TPC citizens in SC & 11 & 0 & 2 & 0 & 0 & 3 \\
\hline $\begin{array}{l}\text { TPC involvement in SC before the } \\
\text { earthquake }\end{array}$ & 2 & 0 & 2 & 1 & 0 & 5 \\
\hline $\begin{array}{l}\text { TPC citizens with relatives/friends in } \\
\text { SC }\end{array}$ & 1 & 0 & 0 & 2 & 2 & 2 \\
\hline SC citizens in TPC & 1 & 0 & 0 & 0 & 0 & 1 \\
\hline \multicolumn{7}{|l|}{ Partial Othering } \\
\hline Poor decision-making of Government & 16 & 7 & 9 & 9 & 8 & 17 \\
\hline $\begin{array}{l}\text { Effectiveness of the response \& } \\
\text { recovery }\end{array}$ & 15 & 0 & 4 & 5 & 8 & 8 \\
\hline Poor construction & 10 & 11 & 3 & 7 & 3 & 6 \\
\hline $\begin{array}{l}\text { Cultural differences between TPC and } \\
\text { SC }\end{array}$ & 11 & 4 & 1 & 0 & 8 & 9 \\
\hline $\begin{array}{l}\text { Religious differences between TPC and } \\
\text { SC }\end{array}$ & 0 & 4 & 0 & 1 & 5 & 7 \\
\hline Poor hygiene & 1 & 0 & 0 & 0 & 4 & 2 \\
\hline Foreign policy & 0 & 0 & 0 & 0 & 3 & 0 \\
\hline Economic policies & 1 & 1 & 0 & 0 & 0 & 0 \\
\hline Deforestation & 0 & 0 & 0 & 0 & 0 & 1 \\
\hline Poor leadership & 0 & 0 & 0 & 0 & 0 & 1 \\
\hline \multicolumn{7}{|l|}{ Othering } \\
\hline $\begin{array}{l}\text { TPC involvement in the SC response \& } \\
\text { recovery }\end{array}$ & 3 & 0 & 1 & 11 & 25 & 26 \\
\hline $\begin{array}{l}\text { TPC involvement in the provision of aid } \\
\text { for the SC }\end{array}$ & 0 & 4 & 2 & 8 & 23 & 13 \\
\hline Social disorder in the SC & 0 & 0 & 7 & 1 & 8 & 15 \\
\hline Preparedness & 13 & 3 & 0 & 0 & 0 & 5 \\
\hline Troubled history of SC & 0 & 0 & 2 & 0 & 0 & 19 \\
\hline Inability of the SC to cope with the & 2 & 0 & 3 & 1 & 2 & 9 \\
\hline
\end{tabular}




\begin{tabular}{|l|c|c|c|c|c|c|}
\hline earthquake by themselves & & & & & & \\
\hline Poverty & 0 & 0 & 0 & 0 & 1 & 15 \\
\hline Corruption & 2 & 3 & 1 & 2 & 0 & 6 \\
\hline Lack of enforced building codes & 0 & 1 & 2 & 3 & 0 & 3 \\
\hline Othering (continued) & Japan & Italy & Chile & Turkey & Pakistan & Haiti \\
\hline Public infrastructure & 1 & 0 & 0 & 0 & 0 & 7 \\
\hline Hazards & 2 & 0 & 2 & 2 & 1 & 1 \\
\hline Education & 0 & 0 & 0 & 0 & 3 & 5 \\
\hline Desperation of citizens & 0 & 0 & 0 & 0 & 2 & 6 \\
\hline Treatment of children & 0 & 0 & 0 & 0 & 1 & 6 \\
Overpopulation & 2 & 0 & 1 & 0 & 0 & 3 \\
\hline Stability of SC government & 0 & 0 & 0 & 1 & 1 & 3 \\
\hline Inequalities of Wealth & 1 & 0 & 3 & 0 & 0 & 1 \\
\hline TPC adoption of SC children & 0 & 0 & 0 & 0 & 0 & 4 \\
\hline Insurance & 2 & 1 & 0 & 0 & 0 & 0 \\
\hline Treatment of women in SC & 0 & 0 & 0 & 0 & 3 & 0 \\
\hline Organised crime & 0 & 2 & 0 & 0 & 0 & 0 \\
\hline Xenophobia of SC residents & 1 & 1 & 0 & 0 & 0 & 0 \\
\hline Level of development in SC & 0 & 0 & 1 & 0 & 0 & 0 \\
\hline
\end{tabular}

Answering the first focal question, it was found that news stories were constructed differently for the audience in the third person community after each of the six overseas earthquakes. Following the earthquakes in the more developed countries, there was a theme in the coverage which reminded the local community that they were susceptible to a similar seismic event. 59 stories [25.8 per cent] indicated the explicit localisation of vulnerabilities; while a further 31 [13.5 per cent] included direct comparisons between the third person community and the stricken community. 89.5 per cent of these stories followed the earthquakes in Japan, Turkey, and Chile. Interestingly, the earthquake in Italy did not prompt the newspaper to communalise their coverage for their local audience. However, communalisation was conspicuously absent from the coverage of the earthquakes in Pakistan and Haiti, where there were only a few tenuous examples where the newspaper attempted to suggest what the impact of a similar tremor on their own community might be. It was evident that the construction of the earthquakes in the 
two newspapers differed according to the level of development of the stricken country, although the pattern did not quite manifest itself as clearly as hypothesised.

Table 4. A Comparison of Communalisation and Othering in the Analysis.

\begin{tabular}{|l|c|c|c|c|c|c|}
\hline & $\begin{array}{c}\text { Japan } \\
\text { (UN HDI Rank 12) }\end{array}$ & $\begin{array}{c}\text { Italy } \\
\mathbf{( 2 4 )}\end{array}$ & $\begin{array}{c}\text { Chile } \\
\mathbf{( 4 4 )}\end{array}$ & $\begin{array}{c}\text { Turkey } \\
\mathbf{( 9 2 )}\end{array}$ & $\begin{array}{c}\text { Pakistan } \\
\mathbf{( 1 4 5 )}\end{array}$ & $\begin{array}{c}\text { Haiti } \\
\mathbf{( 1 5 8 )}\end{array}$ \\
\hline Communalisation & 28 & 0 & 52 & 22 & 5 & 7 \\
\hline Othering & 29 & 15 & 25 & 29 & 70 & 147 \\
\hline
\end{tabular}

Source: Data from UNDP (2011, 127-130).

The second focal question focussed on how the earthquake stricken communities were constructed in relation to the third person community. Again, it was found that the relationship between the stricken community and the third person community differed according to the level of development of the stricken country. Significantly, the quantitative data suggests that there was a general trend where the extent of the othering steadily increased as the level of development of the each stricken country decreased. The nature of the othering varied according to the development of the stricken community, but with the notable exception of Japan, they were portrayed as different to the third person communities. The coverage of the earthquakes in Pakistan and Haiti was conspicuously different from those of more developed countries, with the emphasis of the newspaper articles placed on local involvement in the provision of aid for those communities.

50 stories [21.8 per cent] included the local involvement in the provision of aid to the stricken community; while a further 66 articles [28.8 per cent] involved the local community in the response and recovery efforts in the stricken community. This served to establish a narrative where the stricken community was constructed as being victims 
unable to cope with their earthquake without this assistance from the third person communities. Furthermore, the poor decision making of the stricken community's government was reported 66 times [28.8 per cent], a poor response and recovery in the stricken community was cited in 40 stories [17.5 per cent], 33 stories [14.4 per cent] emphasised cultural differences between communities, and poor construction was noted 40 times [17.5 per cent] in the coverage of the stricken community. However, the nature of this othering varied according to the stricken community - for instance, the indicators of othering in Japan were present because of a higher expectation of competence in the country by the newspaper compared to when the same indicator was evident in the coverage of the earthquake in Haiti. Furthermore, othering was evident in several stories which described the stricken communities in Chile, Turkey, Pakistan and Haiti as being different to the third person community. 31 stories [13.5 per cent] featured social disorder in the stricken community, ten articles [ 4.3 per cent] described poor hygiene, poverty was mentioned in 16 stories [ 7 per cent], and the troubled history of the stricken country was noted in 21 stories [9.2 per cent]. These descriptions served to distance the stricken community from the third person community.

The third focal question helped to uncover how the measures of disaster mitigation and prevention of the stricken community were represented against those in the third person community. The 59 stories [25.8 per cent] which exhibited communalisation through the explicit localisation of vulnerabilities demonstrated similarities between the communities in the measures of preparedness, methods of construction, warning systems, public infrastructure, disaster relief and soil types in Japan, Chile and Turkey. There were several articles which noted that lessons could be learned from these 
disaster events for the third person community, providing the opportunity for policy entrepreneurship.

However, it was much more frequent that the DRR in the stricken community was negatively compared to those in the third person community. For instance, the effectiveness of the measures of response and recovery in the stricken community were negatively discussed in 40 stories [17.5 per cent], poor construction featured in 43 articles [18.8 per cent], and 20 stories [8.7 per cent] featured the stricken community's inability to cope with the earthquake by themselves. These negative comparisons occurred following all of the earthquakes, despite there being vast discrepancies between the six stricken countries in the extent of the disaster risk reduction in place. Generally, there appeared to be an expectation that Japan and Chile would be prepared for their earthquakes, but their shortcomings prompted some negative coverage and comparisons with the relative third person communities. However, it was commonly noted that the DRR in Italy, Turkey, Pakistan and Haiti was inadequate.

The five different types of localisation were apparent in the coverage of overseas earthquakes in the Seattle Times and Vancouver Sun. Most significantly, there was communalisation through the localisation of vulnerabilities and direct comparisons between communities when the stricken community was relatively wealthy, with the earthquakes in Japan, Chile and Turkey triggering the majority of the comparisons. However, the finding that the earthquake in Chile prompted more of these comparisons than any other country suggests that more factors influence the extent of communalisation than the level of development of the stricken country alone, for instance Chile is not a member of the Organisation for Economic Co-operation and 
Development [OECD]. There was some partial communalisation evident in the discussion of shared vulnerabilities and the effects of the earthquake on the third person community following the earthquakes in Japan, Chile and Turkey especially. There were also some stories which featured neutral localisation, where the stricken community was neither communalised or othered.

Importantly, there was partial othering across all stricken communities, where the newspapers referred to differences between themselves and the affected areas in government decision making, the ineffective measures of response and recovery, cultural othering, and poor construction. The finding that Japan and Haiti prompted the majority of these instances of othering was particularly surprising, although the tone of this coverage was significantly different between the two countries as Japan were criticised against a higher standard of expectation than Haiti. There was clear othering in the involvement of the third person community in the provision of aid and the response and recovery efforts primarily following the earthquakes in the countries of Turkey, Pakistan and Haiti. It was also found that the stricken countries with poorer HDI rankings were othered through negative descriptions of social disorder, a lack of preparedness, the inability to cope by themselves, poverty, the fact that the country had endured a troubled history, and corruption.

\section{Communalisation}

The content analysis revealed that communalisation through the localisation of vulnerabilities and direct comparisons between the stricken community and the third person community occurred almost exclusively after the earthquakes in the countries with higher rankings in the HDI table. However, the pattern was not as clear as 
expected, and the communalisation occurred most frequently following the earthquake in Chile, with the country responsible for 45.6 per cent of the cases of communalisation. Evidence was uncovered of the localisation of vulnerabilities following the earthquakes in Chile, Japan, and Turkey. This involved the two newspapers using the overseas earthquake to ask questions of their own locality's preparedness for a similar event.

Interestingly, the earthquake in Chile prompted the greatest amount of articles featuring communalisation with 52 stories, as well as more direct comparisons between the stricken community and the third person communities of the newspapers. This could potentially be explained by the fact that the Chilean earthquake occurred along the Pacific coast, and that the Chilean earthquake occurred just six weeks after the Haiti earthquake, so earthquakes were already on the news media agenda to some extent. The earthquakes in Italy, Pakistan and Haiti did not prompt many instances of communalisation through the description of shared seismic vulnerabilities. The communalisation manifested itself in different forms - including using the overseas disaster event to analyse their locality's own hazards, personal and public preparedness, methods of construction, warning systems, and technology.

One indicator of communalisation exhibited in the sample of newspaper articles was the explicit reference to hazards in the local community compared to the stricken community overseas. This occurred in the coverage of the earthquakes in Japan, Chile and Turkey exclusively in both of the newspapers. The coverage of the Japan earthquake related that event to the potential for a similar disaster in the Pacific Northwest. This was exemplified in a Seattle Times article that used the premise of the Kobe earthquake to remind readers of the hazards faced in their own area: "The 
earthquake that devastated Kobe, Japan, yesterday was a grim reminder - as if we needed another one - that the entire Pacific Rim is earthquake country" and that "Seismologists regularly remind us that the Puget Sound region is overdue for a major quake of its own” (Anon. 1995).

This communalisation was repeated more frequently in the coverage of the Chilean earthquake in 2010. This was clearly expressed in an article which focused on the hazards faced by the Seattle area and how they are similarly vulnerable to earthquakes such as that which struck Chile:

\footnotetext{
"We cannot be complacent. We have a threat and a real risk. Collectively, all the faults in the region give us a 7 per cent chance of a experiencing a Haiti-style earthquake in a 50-year time window and the chance of a Chile-like earthquake along our subduction zone is slightly greater — very hefty likelihoods in most of our lifetimes" (Le Duc, Schelling, and Ash 2010).
}

A further comparison of the hazards faced by the region occurred with a local fault described as being "capable of producing the same type of mega earthquake and inflicting heavy damage on bustling cities like Seattle, Portland and Vancouver" (Chang 2010a). Sam Steidel, a Cannon Beach City Council member was quoted in another article as saying that "Chile really showed what would happen to communities like Cannon Beach" (Haight 2010). Another article contended that the earthquake in Chile was "the best case study yet for how a truly catastrophic earthquake could impact the United States" (Haynes 2010). Similarly, an article in the Vancouver Sun stated that Canada should learn lessons as it is a vulnerable country to earthquakes, and that it was) 
a long way from being prepared for an earthquake like Chile's (Sinoski and Cohen 2010).

While the coverage of the Turkey earthquake also featured lessons that could be learned, the Seattle Times focused more on insights gained from the earthquake by American scientists. The Vancouver Sun coverage of the Turkey earthquake acknowledged the potential for a similar event at home, but it centred more on the controversy surrounding the Canadian government's refusal to send the Vancouver urban search and rescue team to Turkey. This was exemplified by opinion pieces which criticized this decision considering their own vulnerabilities to earthquakes and the fact that they may be required closer to home in the future:

"The earthquake that shattered Turkey last week and took thousands of lives offers a shocking glimpse of what Lower Mainlanders might face when the long-predicted big one hits here. The clear lessons of Turkey's experience for us makes Ottawa's failure to send Canada's only earthquake-trained team quite baffling...Team members could only watch the action on television, frustrated at not getting the real-life experience they want and need...Vancouver's rescue team fails to get needed experience and Canada arrives tardily at the disaster" (Editorial 1999a).

"Turkey has suffered one of the worst disasters of the century, but our federal government refused to send B.C.'s earthquake response team to assist in the rescue, on the grounds that European teams were closer. This is irresponsible for a government whose own citizens are at risk from a similar catastrophe." (Boucher 1999). 
The communalisation was also evident in discussions of the third person communities' preparedness after the earthquakes in Japan, Chile and Turkey. Both newspapers used their coverage of the Japan earthquake to comment on their locality's own measures of preparedness. For instance, a day after the Japanese earthquake, one Seattle Times article headline asked, “Are you prepared for when a quake hits?" (Anon. 1995). The article goes on to list a series of pre-emptive measures that can be undertaken at home to lessen the effects of an earthquake (Anon. 1995a).

Similarly, the Chilean earthquake prompted Vancouver Sun articles suggesting that Vancouver or Canada in general was not adequately prepared for a disaster event. There was a difference in the coverage of notions of preparedness following the Turkish earthquake, with both Vancouver Sun articles discussing local governance. For example, one article stated that "natural disasters have a way of exposing official pretensions even in the wealthiest regions of the world; one dreads to imagine what Canadians might discover in the wake of 'the big one' on the West Coast" (Sajoo 1999). An editorial in the newspaper also argued that "when the big one hits in the Vancouver/Seattle corridor, citizens of Greater Vancouver and Vancouver Island will be on their own" because of cutbacks in the Canadian military forces (Crone 1999).

Allusions to methods of construction were another indicator of communalisation in the newspaper coverage of overseas earthquakes. Again, this occurred after the same three earthquakes, but the vast majority of these were in the coverage of the Chilean earthquake. This is somewhat surprising given the expected expertise of Japanese engineering to mitigate the risks presented by earthquakes. However, it could also reflect Chile's relatively small loss of life compared to these other two disaster events. 
One Seattle Times article discussed how well Seattle is prepared for an earthquake compared to Japan following the Kobe earthquake (Simon 1995c). However, there was much more localisation of vulnerabilities following the Chilean earthquake. Another Seattle Times article referred to the fact that "Washington's building codes were updated to international seismic standards in recent years, but Chile has shown that great standards on paper do nothing when a city is full of older buildings that were grandfathered in" (Haynes 2010). Similarly, a Vancouver Sun article repeated the comparison between communities as "the country [Chile] has many modern buildings and bridges similar to ours" (Adebar 2011). They found that "the majority of modern highrise buildings, which are constructed of concrete similar to those here, did very well” (Adebar 2011). Interestingly, he specifically pointed out that:

"Most modern highrise buildings in B.C. have thick concrete shear walls located around a central core containing elevator and stair shafts; however, in some B.C. buildings, the shear walls are partitions between rooms as they commonly are in Chile." (Adebar 2011).

The coverage of the Turkey earthquake featured less depth and fewer comparisons between communities, with one Seattle Times article after an earthquake in Taiwan only mentioning the disaster by referring to the fact that Turkey has a modern building code equivalent to those in the United States.

Another significant indicator of communalisation through the localisation of vulnerabilities was evident in the coverage in direct comparisons between the stricken community and the third person community, but only after the earthquakes in Japan, Chile and Turkey. Surprisingly, this communalisation was most evident following the 
Chilean earthquake. The direct comparisons primarily came in the descriptions of common hazards. For example, the Seattle Times compared Kobe and Seattle:

\begin{abstract}
"Both cities are about the same distance from offshore trenches that mark the collision boundary between two plates. Both are on inland waters and have large areas of filled tidelands...The last major shallow quake in Kobe was in 600 A.D., and the last one in Seattle big enough to leave evidence was about 900 A.D." (Dietrich 1995a).
\end{abstract}

Likewise, there was communalisation in the direct comparisons between communities in the coverage of the Chile earthquake. The Seattle Times outlined how "the two regions are similar geographically and have similar coastal development" (Haight 2010), while other articles explicitly compared the seismic processes of the Chilean earthquake with the hazards in the Pacific Northwest:

"Chile and the Pacific Northwest are part of several seismic hotspots around the globe where plates of the Earth's crust grind and dive...At some point, centuries of pent-up stress in the Cascadia subduction zone will cause the plates to slip. Scientists cannot predict when a quake will occur, only that one will happen" (Chang 2010b).

"Like Chile, off our coast there is the possibility of a huge megathrust earthquake on the Cascadia subduction zone - the interface between the Juan de Fuca and North American plates, which extends from Cape Mendocino in Northern California to the northern tip of Vancouver Island" (Le Duc, Schelling, and Ash 2010). 
After the Turkey earthquake there were some comparisons between communities, but many of these were tenuous and featured either local scientists conducting research on that earthquake or controversy about the Vancouver search and rescue team's absence.

One unexpected indication of communalisation was the discussion of the third person community's relationship to the stricken community as part of their coverage of the overseas earthquake. This practice occurred five times in the sample, with the common link between them being the importance of the stricken community as a geopolitical ally. This was especially the case with the coverage of the Pakistani earthquake in 2005 with their strategic importance as an ally in the United States-led War on Terror being mentioned in three articles.

\section{$\underline{\text { Partial Communalisation }}$}

There were instances of partial communalisation through the description of shared vulnerabilities following the earthquakes in Japan, Chile and Turkey. This occurred through the description of vulnerabilities in the stricken community which were in common with those faced in the third person community, although this comparison may not have been explicitly stated. For instance a Seattle Times article spoke of how the earthquake in Japan meant that "life in a high-tech country was suddenly reduced to the most basic level" (Associated Press 1995a). The article went on to state how "despite Japan's highly regarded earthquake-resistant architecture, some of the 12,000 buildings toppled by the quake were modern structures" (Associated Press 1995a). An article in the Vancouver Sun went so far as to use the Kobe earthquake as a catalyst to highlight the importance of local citizens creating a living will on the assumption that a similar event could take place in their own locale (Anon. 1995i). These articles all imply that 
the same risks are shared by their own locality and could potentially happen to them, despite being technologically-advanced, developed cities.

In an article following the Chilean earthquake, the Seattle Times compared Chile and Haiti and noted that seismologists and earthquake engineers' "advice is heeded by the government in Latin America's wealthiest nation, getting built not just into architects' blueprints and building codes but also into government contingency planning" (Bajak 2010). This sort of comparison could have the effect of the third person community identifying with the Chilean experience and recognise how they have prepared for their own natural hazards in their own community. The articles featuring shared vulnerabilities after the Turkish earthquake related more to their own scientists' research in Turkey, although one article noted that residents can mitigate their risk by "making sure heavy items such as bookshelves and water heaters are securely attached to walls so a quake won't topple them, injuring someone or starting fires" (Schmid 2000). This communalises the vulnerabilities shared by both the stricken community and the third person community, demonstrating that lessons can be learned from the overseas earthquake.

There were also some instances of the earthquake in the stricken community affecting the third person community as well. The earthquake in Japan prompted most of these occurrences, with the economic reactions to the earthquake benefitting the third person economy. For instance, the economic effects of the Kobe earthquake on the local economy were examined by the Vancouver Sun. One article noted that funds were being moved to North America from Japan in the aftermath of the earthquake; another pointed out the investment opportunities for investing in their construction industry for the 
rebuild; while yet another pondered the effects of a future Japanese earthquake on international markets, suggesting that it could "raise interest rates around the world" (Beauchesne 1995; McGill and Reid 1995; Yoshikawa 1996). An article in the Seattle Times suggested that the Italy earthquake could have an effect on the world economy, while the Vancouver Sun had a similar focus after the Chilean earthquake which noted that the copper and oil industries in Chile were unscathed by the earthquake something which could again have had consequences for the local economy (Barry 2009; Anon. 2010b).

The Turkish earthquake only prompted a note that no Americans were killed in one Seattle Times article, while another Seattle Times article spoke of the scientific research conducted by U.S. scientists in Turkey which could "have repercussions for earthquake prediction in the U.S.” (Seattle Times News Services 1999; Verrengia 1999). The effects of the earthquake in Pakistan on the third person community were economicallyfocussed, with the opportunity for a British Columbia construction company to produce wood houses for victims of the earthquake highlighted in the Vancouver Sun (Leung 2006). This constitutes an important difference in the coverage of the economic effects on the third person community after the six earthquakes. The economic effects described after the Japanese and Chilean earthquakes were as equal trading partners in a global economy, while the only opportunities outlined for local businesses following the Pakistan earthquake was in the immediate disaster reconstruction efforts.

\section{Neutral Localisation}

There were some limited instances of neutral localisation in the newspaper sample. There were 15 articles which featured people from the third person community who 
were in the stricken community after their earthquake. There were also ten instances where there was some involvement in the stricken communities by the third person community prior to the earthquakes. For example, it was reported in the Seattle Times that "a U.S. diplomat was among the dead" after the Haiti earthquake, while the Vancouver Sun stated that there were up to 6,000 Canadian residents in the country before the earthquake (Susman, Wilkinson, and Mozingo 2010; Cayo 2010b).

A further seven stories involved citizens living in the third person community with friends or relatives in the stricken community, such as when the Seattle Times told the story of Turabi Topal, a Turkish resident of Seattle, who "was scheduled to fly to Turkey on Monday for business and a short vacation, but decided Friday to wait until next week because of a mix-up with his tickets," thus avoiding the earthquake (Burkitt, and Fries 1999). Another two articles featured citizens of the stricken community who were living in a third person community at the time of the earthquake. These stories featured neither communalisation nor othering, but instead localised the earthquake without describing the relationship between the communities. These stories illuminate the extent to which local news media cover non-local events in a manner to make it meaningful for their citizens. However, as these stories do not feature communalisation or othering they neither allow nor prevent discussions of DRR from appearing on the public agenda, so they do not contribute meaningfully to the exploration of Van Belle's model.

\section{Partial Othering}

Partial othering occurred in the newspaper coverage of all of the earthquakes through either descriptions of the poor government decision-making, inefficient measures of 
response and recovery, poor construction, or the emphasising of cultural differences. However, the affected countries with the higher HDI rankings were generally criticised less frequently and less severely than those with lower HDI rankings.

Throughout all six earthquakes there was othering through the descriptions of poor government responses to the earthquake, with each nation's leaders suffering from the newspapers' scrutiny of their decision-making and the reporting of victims' anger at slow or ineffective responses. Curiously, articles featuring this form of othering were more prevalent following the earthquakes in Japan and Haiti - the countries occupying opposite positions on the HDI table. There were differences in the tone of the coverage between the nations affected however.

Much of the criticism of the Japanese government stemmed from the fact that they were meant to be well-prepared, but their planning and measures of response were exposed to some extent by the Kobe earthquake. It appears that the Japanese government were criticised against a tougher benchmark than the poorer countries - the government took criticism for not being as responsive was expected, but it was still expected to be able to govern effectively. For the governments of Turkey, Pakistan and Haiti, the criticisms were aimed at a complete lack of governance and an absence of any institutional response to the earthquakes. This double standard in expectations of government is evident in a Vancouver Sun article which contended that Prime Minister Murayama's response was inadequate, and the government was culpable in "the bungling of the management of traffic on roads, which was preventing relief supplies from being delivered" which "showed officialdom's inability to look after their people after the quake" (Jameson 1995). Another Vancouver Sun article accused the Japanese 
government of not having a clear plan after the disaster, while the Kobe city government allegedly had no emergency food provisions (Anon. 1995h).

Interestingly, the descriptions of poor governance following the Italy earthquake were directed at local government instead of the national government, which received positive press following Silvio Berlusconi's decisive response to the earthquake. For instance, it was implied that local officials should not have silenced a local scientist for having warned of an impending earthquake while the rescue efforts overseen by Berlusconi "won praise from his rivals, in an unusual display of unity" (de Cristofaro and Chu 2009; Rizzo 2009a). President Michelle Bachelet was criticised in the newspapers following the Chilean earthquake for slow delivery of aid and not restoring order soon enough while looting was occurring. One article published the results of a poll by a Chilean newspaper that found that " 72 per cent believe the government responded late and inefficiently to re-establish order after the earthquake, and 48 per cent believe it was because Bachelet did not want to end her term sending soldiers into the streets" (Vergara and Sequera 2010).

Significantly, the newspapers' descriptions of poor government actions changed for the coverage of the earthquakes in Turkey, Pakistan and Haiti. Instead of criticisms aimed at specific leaders, the coverage detailed government failures in a more general fashion, perhaps reflecting their ineffectiveness and lack of accountability even before the disaster. For instance, one article following the Turkey earthquake stated that "even under normal circumstances, the bloated Turkish bureaucracy is moribund" and that after the earthquake it "barely staggers along" (Hastings 1999). An example of the absence of accountability in the government is that one piece described how an Indian 
plane with 25 tonnes of aid was initially turned away by "Pakistani authorities" but it was noted that "Pakistan later agreed to accept" the aid offered by the Indian government (Jan 2005a). Similarly general in its description of the people involved, a Seattle Times article stated after the Haiti earthquake that "the government has a large, messy task ahead, against a historical backdrop of corruption and mismanagement" (Lush 2010). There is a clear distinction here between the expectation of the government of the more developed nations, and Japan in particular, and the governments of Turkey, Pakistan and Haiti.

Poor construction was another indicator of othering that was consistently evident after all six earthquakes in both newspapers. Again however there were differences in how this was done depending on the level of development of the stricken country. The discussion of the ineffective construction methods of Japan was contrasted against the previously-held expectation that Japan would be more resilient in an earthquake and "that one of the world's most technologically advanced nations could insulate itself from nature's power and cope with the aftermath" (Thurber 1995). Although this constituted othering according to the framework developed for this investigation, it is possible that this discussion could help the third person communities learn lessons from this disaster. Because it is likely that the third person communities consider themselves as similarly developed and advanced, it is possible that this kind of description could prompt the realisation that they could be similarly susceptible despite their own advances in technology and engineering.

Chile's earthquake prompted comparisons between the construction methods in the stricken country and the third person community, with the thin shear walls of Chile a 
point of comparison where it was not expected that the Pacific Northwest would be as vulnerable. Conversely, the poor construction methods of Italy and Turkey were framed against the backdrop of possible corruption and organised crime, with allegations published in the newspapers that the criminal addition of sand to concrete may have taken place during the building of the collapsed buildings. For example, a Seattle Times article about the Italy earthquake alleged that "there are fears that work done by companies with links to organized crime could use inferior materials" and that "Firefighters clearing rubble in the Abruzzo quake had alleged that poor quality cement and insufficient rods or joints were used in some buildings (D'Emilio 2009a). Furthermore, a Turkish rescue worker was quoted in a Seattle Times article bemoaning the state of the construction industry and the general lack of regard for human life in Turkey:

"There are no rules, and there are very cheap materials. The foundations are just one or two meters deep instead of four or five meters...I'd guess there won't be any new rules because the value of human life isn't high here, as in any Third World country. If you want to make something cheap, Turkey is the place" (Tunc Findik quoted in Hockstader 1999).

In contrast to the coverage in other countries affected by earthquakes, the reporting of poor construction following the Pakistan and Haiti earthquakes reflected assumptions that because of their immense poverty, the derisory standard of buildings was almost inevitable. This idea was perhaps expressed best by an Seattle Times article which paraphrased Mark Merritt stating that "one problem is the poor quality of buildings" and that "Haiti doesn't have building codes and even if it did, people who make on average \$2 a day can't afford to build something that can withstand earthquakes and 
hurricanes" (Borenstein 2010b). There is an element of class vulnerability evident in this analysis, where it is apparently inevitable that those in poverty will suffer the consequences of natural disaster events disproportionately due to their already-poor living conditions.

Another consistent indicator of othering in the sample of newspaper articles was the description of insufficient measures of response and recovery in the stricken communities. The earthquake in Italy was the only country to not have this feature in the coverage of their earthquake, probably due to the fact that Silvio Berlusconi managed to appear authoritative, decisive and urgent in his response to the earthquake in his country in the newspaper coverage. Berlusconi was said to have "snapped into action immediately" while it was noted that he "flew to the disaster area on three consecutive days, rattling off rescue statistics to reporters" (Rizzo 2009a). The nature of the coverage of the inefficient response and recovery was again different depending on the country.

Following the earthquakes in Japan and Chile, the criticisms of poor measures of response and recovery were largely centred on the belated responses of those nations' respective governments. Again, these criticisms were based on the presumption that their respective governments should be able to act decisively and swiftly in response to their earthquakes, where this was not expected of the other nations. For instance, the Turkish government's response was criticised, but rather than responding to particular grievances being aired, more emotive criticisms of the institution of government were expressed. An example of this is Washington Institute for Near East Policy analyst Alan 
Makovsky complaining that for the Turkish government, the victims of the quake "are an afterthought" (Meixler 2000).

In the coverage of the Pakistan and Haiti earthquakes, the burden of the response and recovery was thrust on NGOs and foreign governments as well due to the apparent complete inability of the state governments to cope with the disaster. For instance, one Seattle Times article outlined the fact that a year after the quake, "international aid agencies had completed fewer than 32,000 of the more than 124,000 transitional shelters scheduled for construction" amid a lack of planning and coordination among NGOs, the Haitian government and land owners (Bernton 2011). Accordingly, criticisms were made of NGOs as well as those governments - an interesting indication of othering where the state governments were so poor that they were perhaps not expected to be able to do anything in response to a disaster event.

Another significant indicator of othering shared across most of the countries was where cultural differences between the third person community and the stricken community were emphasised during the coverage of their earthquakes. Interestingly, this only occurred once after the earthquake in Chile, and not at all following the Turkish earthquake. Following the earthquake in Japan, cultural differences were sometimes explained in a positive light, with the alleged patience and stoicism of the Japanese people praised. For instance, one article in the Seattle Times said:

\footnotetext{
“The many stories about Japanese stoicism risk becoming an ethnic cliché. Yet it’s difficult not to marvel at the people's orderliness after the disaster. Kobe residents wait in mammoth lines for everything: to take buses, use public baths erected by the
} 
army, draw drinking water or get money from a bank. With so many dead, they even wait to conduct proper funerals for loved ones" (Simon 1995b).

Other articles drew attention to an alleged Japanese 'fetish' for cleanliness, while deference to power was also noted as being a cultural trait but these differences were described in an admiring fashion as though it was worth replicating those traits in the third person communities. There were minor cultural differences noted in the articles following the Italian earthquake, such as references to the Catholic faith of the victims. Following the Pakistan and Haiti earthquake, major cultural differences were criticised according to Western values. For instance, multiple articles in the Seattle Times addressed the different role of women in the patriarchal society of Pakistan, as well as the poor treatment of the disabled, with one declaring that following a child suffered an amputation, "Gulnaz is not only an amputee, but a likely orphan, and a girl, three strikes against her in a poor, conservative society where a disabled person with little prospect of getting married, or supporting herself, is a burden few can afford" (Watson 2005). Both newspapers also addressed differences in the culture of Haiti in the treatment of children and the disabled. For instance, a Vancouver Sun article wrote of how:

\footnotetext{
"Ruth Zimmerman had been horrified to find disabled children left to die in a shed behind the city's main hospital by parents who couldn't pay their medical bills. She learned that disabled children are particularly prone to abandonment" (Cayo 2010a).
}

These kinds of attitudes and cultural differences were repeated across numerous articles following the earthquakes in Pakistan and Haiti. 


\section{Othering}

Othering featuring the third person community in the provision of aid and the response and recovery efforts in the stricken community was much more prevalent in the countries towards the bottom of the HDI table. A clear change in the nature of the coverage occurred as the level of development changed. Japan, Italy and Chile were portrayed as relatively self-sufficient, but the coverage of the earthquakes in Turkey, Pakistan and Haiti prompted most of the articles featuring the local community's own involvement. A saviour-victim relationship was established in the newspaper coverage of the earthquakes in those lesser-developed countries, where the burden was perceived to fall on the local community to provide for the stricken communities because of their patent inability to cope with the earthquakes by themselves. As the newspapers localised their coverage to focus on local involvement in the provision of aid, the implication was that the poorer nations could not cope without this assistance. This is a significant finding as it demonstrates that even if the news coverage is localised for the local audience, it can other the stricken community. The third person community's involvement in assisting the stricken community occurred through their national government, armed forces, local community groups, non-governmental organisations and the actions of private individuals.

Most of the local community's involvement in the provision of aid in the stricken community came from central government, with the political leaders of the respective nations of the United States of America and Canada pledging aid to the affected countries. Following the earthquakes in Chile and Turkey there were government pledges of aid and donations of supplies to assist the stricken community. However, it was after the earthquakes in Pakistan and Haiti that most of the articles featuring 
othering through the provision of aid by the national government occurred. Rather than simply assisting the stricken country in their recovery efforts, the coverage following the earthquakes in Pakistan and Haiti implied that the government was compelled to intervene as those countries were helpless without that aid.

After initial pledges of up to $\$ 50$ million in aid, the US government ended up pledging $\$ 510$ million following the Pakistan earthquake in the form of relief and reconstruction (The Associated Press, and Bloomberg News 2005; Tu 2005a; Lancaster 2006). The Canadian government contributed too, with a pledge of $\$ 20.3$ million following that earthquake in addition to matching any private donations to the relief effort (Edwards 2005; Woods 2005). It was also reported that President Obama had made "an initial $\$ 100$ million relief effort" which later climbed to $\$ 1.15$ billion after the Haiti earthquake (Higgins 2010a; Katz 2011). Likewise, the Canadian government was reported to have contributed $\$ 400$ million to the aid effort after an initial pledge of " $\$ 5$ million for immediate disaster aid" (Bruemmer 2010; Iype, Barrera, and Cross 2010). The coverage of these earthquakes implied that those countries were helpless without the governmental aid as these substantial sums were implied to have been pledged out of necessity to help the victims of the earthquakes.

There was a similar shift in emphasis in the newspaper reports of the fundraising of local community groups following the overseas earthquakes. After the earthquakes in Italy and Turkey, there were reports of local fundraising efforts and the subsequent provision of aid. However, the people of Seattle and Vancouver were much more proactive following the earthquakes in Pakistan and Haiti. There were reports of the adoption of Pakistani villages by local community groups in Seattle, while other local 
organisations donated products and even their own labour as one Vancouver sawmill worked a full shift on a Saturday and donated their wages to the relief efforts in Pakistan. This shift in the nature of the coverage suggested that the poorer nations were helpless without this assistance, effectively othering the stricken community and marking them as different to the third person communities.

Following the earthquakes in Turkey, Haiti and Pakistan there were articles in both newspapers demonstrating othering by highlighting the provision of aid by nongovernmental organisations. They were major contributors to the aid effort, especially in the dispersion of federal funds in the stricken community. A local connection was made in the articles describing the actions of the NGOs by indicating their location. For instance, they were referred to as being Portland-based Northwest Medical Teams International, Seattle-based World Concern, Federal Way-based World Vision, and Portland-based Mercy Corps. This was indicative of an attempt to emphasise the fact that some of these charities had local bases, with a possible intention being to make their actions more meaningful to the communities where they are located.

There were also reports of actions from private individuals following the earthquakes in Italy and Turkey. Again however, there was a greater obligation placed on citizens to assist the stricken countries of Pakistan and Haiti in the newspaper coverage of those earthquakes. Following the Pakistan quake, for instance, there was coverage of "calamity fatigue" to explain the lack of aid raised compared to the Boxing Day tsunami the previous year (Bernton and Turnbull 2005). A Vancouver Sun editorial implored the people in their local area to give generously to the relief effort following the earthquake there, acknowledging the lack of support immediately following the 
quake before claiming that the victims desperately needed their support and if aid was not forthcoming, "blood will be on our hands" (2005a). The strong editorial attempted to localise the effects of the earthquake by implying that those local people who do not contribute to the relief effort are guilty.

This coverage effectively turns the provision of aid into a local issue for the citizens of the third person community. This form of localisation is based around the burden of supporting the stricken communities of Pakistan and Haiti as victims, rather than being a more equal relationship where the third person community as evidenced in the response to the earthquakes in Japan, Italy, Chile and Turkey. Although this coverage localised their content for the local audience, it served to other the stricken communities and highlight their inability to cope for themselves following the earthquakes.

There were further instances of othering in the newspaper coverage, which generally occurred more frequently following the earthquakes in those countries at the bottom of the HDI table. These occurred in the descriptions of social disorder, troubled history of the country, the perception of the country's inability to cope with the disaster by themselves and poverty. This could have been a result of the very real economic, social, political and cultural differences between the third person communities and the poorer stricken countries in the sample. Nevertheless, these distinctions make it difficult for the coverage to prompt a discussion of DRR in the third person community. Instead, this othering differentiates the stricken community from the third person community, a process which is likely to prevent the likelihood of any lessons from being learned from the earthquakes in Pakistan and Haiti in the third person communities of Seattle and 
Vancouver. These findings may suggest that it is simply unrealistic to expect that to occur between such different communities.

Social disorder following the earthquakes was highlighted as a point of difference between the third person community and the stricken communities following the earthquakes in Chile, Turkey, Haiti and Pakistan. The newspapers covered the looting in Chile following their earthquake, with President Bachelet slow to act to restore order. There was also one article featuring reports of looting following the Turkey earthquake in the Seattle Times. However the majority of the reports of social disorder followed the earthquakes in Pakistan and Haiti. Following the Pakistan earthquake, there were reports of chaotic scrambles for goods whenever a relief truck pulled into a village. One Vancouver Sun article quoted a resident stating that "people have become terrorists over here...when the vehicles approach, they fight" with the author alleging that "this scene has played out countless times here since last Saturday's earthquake" (Blanchfield 2005d). Similarly, there were many reports of a complete lack of law and order in Haiti following the earthquake, with no law enforcement in the camps or in pre-existing settlements. One article in the Seattle Times ventured far enough to say that "mugging, robbery and rape became facts of life" in post-earthquake Haiti (Katz 2011). This impression contributed to the othering of the stricken community, but it is possible that this was somewhat justified by what was occurring in Haiti at the time.

One interesting indicator of othering found in the sample was the perception of a lack of preparedness on the part of the stricken communities. This was especially evident in the coverage of the Japanese earthquake, potentially because they were expected to be as well prepared for an earthquake as a country could reasonably expect to be. However, 
their failings were described in detail in the newspaper reports. One Seattle Times article highlighted how their earthquake shelters in Kobe were short of the necessities needed to provide for its inhabitants (Thurber 1995). Another Seattle Times article spoke of a "barrage of complaints against government relief efforts, which despite Japan's reputation for earthquake preparedness have bogged down” (The Associated Press and the Washington Post 1995b). Reinforcing this idea, the article went on to describe how there was a "growing body of evidence that Japan was considerably less ready to cope with a major seismic disaster than it had long claimed" (The Associated Press, and the Washington Post 1995b). Instead of being well-prepared, a Vancouver Sun article spoke of how the "elevated roads and bridges that Japanese engineers had boasted were quake-proof were broken at crazy angles, flung to the earth by the force of nature" (Anon. 1995h).

There were also reports of complacency among the residents of Kobe, as "safety drills that are common elsewhere throughout the country were largely ignored here, and few residents took the trouble to prepare emergency kits" (Anon. 1995f). A key idea to note here is that the criticisms were aimed at the performance of Japan against the expectation that they would be prepared. The criticisms are of the inadequacy of their pre-existing measures of preparedness for earthquakes, but at least an attempt at risk mitigation was made. Even though this others the stricken community in this instance, there is the opportunity for lessons to be learned in the third person communities following this earthquake as even a highly developed, technologically advanced nation could not comprehensively prepare for an earthquake. 
In contrast to these descriptions of Japanese failure to prepare well enough, measures of preparedness are discussed in the coverage of Italy and Haiti due to the complete absence of any effort to prepare for an earthquake. For example, after the Italy earthquake, a report cited in the Seattle Times "lamented that Italy lags behind other industrial nations in prevention measures for its quake zones" (D'Emilio 2009b). Enzo Boschi was quoted as saying that "it's not in our culture to construct buildings the right way in a quake zone - that is, build buildings that can resist (quakes) and retrofit old ones...This has never been done" (Falconi and D'Emilio 2009). This is reflected in the statistic cited in a Seattle Times article which claimed that "only 14 per cent of buildings in that vulnerable swath (in Central Italy) meet seismic-safety standards (Falconi and D'Emilio 2009).

Similarly, Haiti was referred to as lacking any measures of preparedness for a seismic event. A Vancouver Sun article claimed that the earthquake "was a disaster waiting to happen" because "Haiti is a nation of poorly built structures sitting on a major fault line" (Bruemmer 2010). A Seattle Times article notes that Haiti has had 15 disasters since 2001 which have led to $\$ 16$ million in aid being sent from the U.S. even prior to the 2010 earthquake (Borenstein 2010b). Despite this, Haiti is described as exhibiting "the inability to prepare for and cope with disaster" (Borenstein 2010b). Where Japan's measures of preparedness came under scrutiny for not being comprehensive enough to deal with the 1995 earthquake, the absence of any preparedness measures at all are highlighted in the news coverage following the Italy and Haiti earthquakes.

Another indicator of othering which distinguished the third person communities from the stricken communities was the description of the troubled histories of the country 
struck by the earthquake. Two articles in the Seattle Times referenced the brutal military dictatorship of Augusto Pinochet, citing that memory as a reason for an initial unwillingness to deploy the armed forces to restore order and halt looting in the aftermath of the earthquake. Many more descriptions of the stricken country's troubled history followed the earthquake in Haiti. Many of these mentioned the civil wars, historical inequalities and shambolic governance which allegedly characterise the country's history. One Seattle Times article referred to "Haiti's history of slavery, occupation and upheaval" in an attempt to put the post-earthquake plight of the country into context (Katz 2010b). Other articles implied the country was at fault for the situation given its reliance on overseas donors. One article contended that "for decades, and especially since the Jan. 12 earthquake, Haiti has depended on foreign governments, aid groups and the U.N. for everything from rebuilding to basic services" (Katz 2010c).

Indeed, there were a few instances where the newspaper articles indicated that the stricken community had no ability to cope with the aftermath of their earthquake by themselves, but this was particularly prevalent following the earthquake in Haiti. This indicator of othering was evident following the Chilean earthquake where it was implied that some officials were incompetent after "disaster officials announced they had double-counted at least 27 as dead" (Warren and Vergara 2010c). The nature of the coverage of the inability to cope changed with the Turkey earthquake, where victims of the earthquake were vociferously criticising the rescue efforts - their lack of rescuers and equipment especially. One Seattle Times article described the inability of the Turks to help themselves following their earthquake: 
"There were too few rescuers, and many had only the rudest equipment. The city has too few cranes and not enough rescue equipment, officials said" (Hockstader 1999).

This was even more pronounced following the Pakistan and Haiti earthquakes, where the people of the communities were characterised in one Vancouver Sun editorial as "needy quake victims," which summarised the approach to the people of these countries (2005b). The situation in Haiti was described by one Seattle Times article as being particularly desperate:

"Roads full of hungry, homeless people. An estimated 50,000 dead. A ruined port and an overwhelmed airport. Hundreds of crumpled buildings and little heavy machinery. Few working phones" (Higgins 2010a).

This characterised the coverage, where the situation was described as dire with Haiti portrayed as being a failed state with no ability to help itself either before or after the earthquake.

Another significant indicator of othering which differentiated the third person community from the stricken communities towards the lower end of the HDI table was the descriptions of extreme poverty. This was mentioned just once following the Pakistan earthquake and fifteen times following the Haiti earthquake. Interestingly, it did not register at all after other earthquakes, despite Chile and Turkey having 15.1 per cent and 18.1 per cent of the people in their respective countries living below the poverty line (UNDP 2011, 143). Similarly, it was interesting to note Pakistan's singular 
mention considering the fact that 22.3 per cent of the country lives under the national poverty line (UNDP 2011, 144).

However, the poverty of Haiti was mentioned consistently in the coverage of both newspapers following their earthquake. One article put the disaster into perspective by writing that Haiti was "the poorest country in the Western hemisphere" (Higgins 2010a). Another Seattle Times article explained the particular vulnerability of Haiti to natural disasters simply: "It starts with poverty, includes deforestation, unstable governments, poor building standards, low literacy rates and then comes back to poverty" (Borenstein 2010b)._These descriptions other the stricken community, preventing the opportunity for DRR to become on the public agenda in the third person community. Instead, the vulnerabilities appear to be exclusively burdened by the stricken community, as they can more easily be dismissed as belonging to the impoverished country rather than the First World cities of the newspapers. This is understandable given the differences in the levels of development between the communities, but it is significant in indicating that there may need to be some preexisting identification between them for the localisation of vulnerabilities to occur. This suggests identification with the stricken community in the third person community needs to be present or there will not be any localisation of vulnerabilities. This investigation has suggested that the identification between communities may depend on their respective levels of development.

\section{$\underline{\text { A Comparison of Localisation between the Third Person Communities }}$}

One unexpected result of the investigation was that the number of articles featuring localisation in the Seattle Times significantly outnumbered those in the Vancouver Sun. 
This could suggest that there are differences between the newspapers in their production of the news, although further research is required in order to ascertain why the differences have occurred.

The extent of the communalisation through the explicit localisation of vulnerabilities and direct comparisons with the stricken community was similar between the two newspapers. There were only slight discrepancies between the newspapers in the discussions of similar methods of construction with the stricken community. However, there was a significant shift in the explicit localisation of vulnerabilities in hazards in the Seattle Times after 2001, when an earthquake struck Nisqually. Although this earthquake did not lead to any fatalities, 400 people were injured and it may have prompted a shift in the nature of the coverage of overseas earthquakes in the Seattle Times. This is potentially indicative of the fact that the nature of localisation may change if an earthquake has recently affected the community. This could potentially explain a similar trend in the spate of articles in Wellington's Dominion Post about the city's own earthquake resilience following the 2011 Christchurch earthquake as the relationship between the location and their potential hazards has changed (Anon. 2012a; Anon. 2012b; Chapman 2011; Chapman 2012; Hubbard 2013; Hunt 2011).

A considerable difference between the two newspapers occurred in the othering of all six stricken communities. Othering through the third person community's involvement in the provision of aid and the efforts in response and recovery in the stricken community were relatively similar between the two newspapers. Although the Seattle Times featured more articles that featured this othering, the two newspapers were still broadly similar in the amount of articles for each form of localisation. Interestingly, the 
ratio of stories featuring each indicator of localisation did not significantly change after 2001, with the exception of the localisation of hazards in the Seattle Times. However, it could simply be because there were a greater number of articles from the Seattle Times during initial searches, so that in the twenty articles selected for the sample, there was a stronger likelihood that there would be localisation in their stories. Future research could help to explain the differences between the two newspapers and uncover why the Seattle Times featured more instances of localisation than the Vancouver Sun did in this analysis.

\section{What the Findings Suggest}

The exploratory analysis conducted in this investigation has identified a broad trend, with the majority of the articles in the sample demonstrating some type of localisation. The findings suggest that the level of development of the stricken community affects the processes of communalisation and othering, even though the pattern was not as clear as hypothesised.

The single most surprising finding was that the Chilean earthquake prompted far more communalisation in the research sample than was expected, both quantitatively and qualitatively. This could have been the result of the 2001 Nisqually earthquake, which could have prompted more communalisation in the Seattle Times than what could have been the case ordinarily. This could also explain why the Chilean earthquake prompted much of the explicit localisation - if the Nisqually quake was still on the minds of the Seattle Times especially, this could have prompted more localisation than usual following that earthquake. 
However, a number of different factors may have influenced the nature of this coverage. It is possible that the timing of the Chilean earthquake will have affected how that disaster was covered. After the catastrophic earthquake in Haiti just over a month previously, the coverage of the Chilean earthquake may have been communalised more because the stricken community was more similar than Haiti. As outlined earlier, disasters are inherently newsworthy events, and the event of a second large earthquake occurring in the space of a couple of months may have affected how the second earthquake was covered. As there are more similarities between Chile and the Pacific Northwest than between Haiti and the third person communities, it is possible that they communalised their coverage more than the newspapers would have normally done after the Chilean earthquake because the audiences could relate to the stricken community in Chile more than Haiti.

The newspaper coverage of the Italian earthquake was another anomaly, with that disaster event prompting no instances of communalisation at all. This could potentially be the case due to the relatively small number of fatalities in the quake, or a lack of identification with the country among the third person communities. This is particularly interesting because of the large Italian community in the United States of America. The earthquake did not prompt many instances of othering through the third person involvement in the provision of aid or in the response and recovery efforts either, with only four articles featuring coverage of local individuals and private donors providing aid for the stricken community in Italy. This could partly be explained by Silvio Berlusconi's insistence that "no outside help was needed to deal with the country's worst earthquake in three decades" (Nelson and Greenaway 2009). 
However, there were some instances of othering through allusions to poor government decision-making, poor construction and cultural differences by the two newspapers, as indicated earlier. The coverage of the Italian earthquake is interesting in its lack of communalisation especially. This could have occurred because of the small size of the destruction of the earthquake, especially with the stricken community's lack of industry that would have a trading relationship with the communities of the Pacific Northwest. There were also fewer articles about the earthquake in total, so it is likely that the articles in the sample were shorter than the articles following the other earthquakes. It is also possible that they were produced from information derived from news sources outside of the respective newspapers' staff. More research could establish more definitively why the coverage of the Italian earthquake featured no communalisation, but the comparatively small impact of the disaster may have influenced the extent to which disaster was localised in the two third person communities.

\section{Summary}

In spite of the differences between the Seattle Times and the Vancouver Sun's coverage, it is clear from the evidence produced by the analysis of the newspaper articles in the sample that the nature of the localisation is affected to some extent by the level of development of the stricken country. This is arguably a natural result of the processes involved in the production of news. The local newspapers used the coverage of the six earthquakes according to their own set of news values in order to make it meaningful for their audiences. Significantly, communalisation through the localisation of vulnerabilities and the direct comparisons between communities after the earthquakes in Japan and Chile included specific references to the hazards of the Pacific Northwest. This focused the coverage of those overseas events on to what it meant for their own 
audience. At the same time, the coverage of the Turkey earthquake focused much more on the more general scientific knowledge gained from the earthquake and the experience that could have been gained by the deployment of the Vancouver search and rescue team.

Similarly, the nature of the othering in the involvement of the third person community in the provision of aid and the response and recovery of the overseas earthquake changed according to the wealth of the stricken country. Following the earthquakes in Japan, Italy and Chile, there was little discussion of fundraising for the victims of the quake. However, the earthquakes in Turkey, and especially Pakistan and Haiti prompted a flurry of campaigns urging the donation of money, while national governments were compelled to donate large amounts of money and expertise to assist these countries. A dynamic was established where it appeared that without this assistance from countries such as Canada and the United States of America, an even greater catastrophe would occur as the stricken countries were unable to help themselves.

Some indicators of othering occurred after all of the earthquakes in the sample, but the tone of the coverage still changed according to the level of development of the stricken country. The stricken countries with higher rankings in the HDI table generally had specific criticisms levelled at specific individuals or organisations decrying inefficiencies following the earthquake. These critiques were potentially the result of higher expectations of those in government in those nations compared to those in the lesser developed stricken countries. A much more general despair characterised the indicators of othering in the coverage of the earthquakes in Pakistan and Haiti especially, where the suffering of the people in those countries appeared to be inevitable 
in the aftermath of the earthquakes. This is a different distinction in the nature of the othering. Where elements of human error were frequently mentioned in the articles covering the earthquakes in the more developed countries, structural problems were more frequently present in the coverage of the earthquakes in the poorer countries. This could be because the human error component was perceived as avoidable, while the structural problems are more difficult to resolve and the consequences of the earthquakes were determined by the newspapers to be somewhat inevitable.

There were different indicators of othering which were much more prominent among the countries at the bottom of the HDI table. Social disorder was much more prominent following the earthquakes in Pakistan and Haiti, potentially reflecting an identifiable lack of law and order and the desperation of the victims of the quakes. Similarly, these two countries were portrayed as especially vulnerable to disasters because of their poverty and troubled histories, which contributed to the projection that these countries simply lacked any ability to cope with the earthquakes by themselves. This discourse could potentially prevent any lessons being learned in a third person community following these earthquakes. It is important to discuss what these findings mean in the context of existing disaster risk reduction literature, and what the implications are for disaster risk reduction policy. It is also important to acknowledge the consistent communalising of the overseas events in terms of the two third person communities' vulnerabilities, and how this contributes to the knowledge of the patterns of news production. 


\section{CHAPTER FIVE}

\section{DISCUSSION}

Both communalisation and othering were evident in the localisation of the six overseas earthquakes in the Seattle Times and the Vancouver Sun. Both the quantitative data and the qualitative content analysis suggest that the nature of the localisation changed broadly according to the level of development of the stricken community. The findings add an additional perspective to the field of literature surrounding disaster risk reduction, where the localisation of vulnerabilities is apparent in the coverage of overseas disasters in the third person communities. However, this comparison between communities depended on a level of identification with the stricken community, and there was almost no localisation of vulnerabilities following the earthquakes in Pakistan and Haiti.

Van Belle's model for the successful implementation of disaster risk reduction depends on the communalisation of an overseas disaster event in the news coverage of a third person community. This occurred in some instances, but not in others in the investigation. The findings from this investigation suggest that it will be more difficult to successfully campaign for DRR after all overseas disaster events as the coverage will not put DRR on the public agenda after all disasters. Instead, this will only happen following disasters which occurred in countries that the third person community identifies with to the extent that they construct the news coverage of the event in terms of their own risks to a similar hazard. This constitutes a refinement of Van Belle's model, and suggests that advocates of DRR need to be selective in their use of news coverage to campaign for DRR in a third person community. The establishment of the 
typology of localisation is also a significant development of Van Belle's model, identifying the different forms of localisation in news coverage.

This chapter focuses the findings into a coherent discussion, suggesting how this investigation fits alongside existing theory and how the results build on previous knowledge to illustrate the nature of localisation in the news media. The findings add to the field of disaster risk reduction as they suggest opportunities are available for news coverage of overseas events in third person communities to be turned into disaster risk reduction policy. The findings also have implications for news theory as they add to the understanding of international news flows. There are several areas for future research worth exploring, where further investigations can build on the findings to add to the understanding of localisation and policy entrepreneurship in the pursuit of more effective implementation of DRR in third person communities.

\section{Implications for Disaster Risk Reduction}

This investigation uncovered patterns of both communalisation and othering in the coverage of the six overseas earthquakes in the Seattle Times and the Vancouver Sun, which changed according to the level of development of the stricken community. This knowledge contributes to the understanding of the news media's coverage of disasters because while there has been previous research into the amount of disaster coverage itself according to a variety of variables, the content of the coverage itself has not been the subject of previous enquiry. A better understanding of how news is produced in atrisk communities following disasters is important in understanding how DRR may become on the public agenda. 
The differences in coverage of the overseas earthquakes were most evident in the communalisation of vulnerabilities. This occurred in the newspapers following the earthquakes in the more developed countries, with the notable exception of Italy. The Chilean earthquake prompted most of this communalisation though, which was not predicted at the outset of the investigation. The third person communities did localise overseas disasters to the risks they face themselves, but this depends on the level of development of the stricken country. However, this pattern was not as clear as was expected and the distribution of the localisation did not simply reflect development in a linear fashion. The existence of communalisation does suggest that news coverage of non-local disasters can reflect domestic priorities and that it can be used to propel DRR onto the public agenda. This presents opportunities for policy entrepreneurs to exploit to campaign for DRR in their own rational self-interest as Van Belle's model suggests. This is significant in the suggestion that lessons do not have to be learned first-hand and that there is the capacity to capitalise on overseas disasters to lessen the risks faced in communities yet unscarred from their own hazards. However, if this depends on a particular affinity between communities, this will limit the number of opportunities available for public discussions of DRR in third person communities.

Therefore, the opportunities for discussions of disaster resilience in the third person community are not always going to be readily available. The othering in the provision of aid and the involvement in the response and recovery in this investigation demonstrated this, where the coverage focused on their community's role in providing aid and resources for the stricken community rather than imagining that they could suffer from a similar event. The coverage was constructed in a way that implied that these nations would not be able to cope without this support in the aftermath of these 
earthquakes. This effectively established a victim-saviour relationship between the two communities. These judgements were not made following the earthquakes in Japan, Italy and Chile, where these countries were generally portrayed as being much more self-sufficient, despite some governmental failures. This suggests that this type of coverage of overseas disasters is unlikely to produce discussions of DRR in the third person community. However, this finding does have significant implications for the understanding of third person communities' humanitarian response to overseas disasters and their contribution to the relief efforts. The findings suggest that fundraising efforts are likely to be most widely covered in the news following earthquakes in lesserdeveloped countries. There is the possibility if the necessary conditions are met, for this type of news coverage to lead to humanitarian intervention by the governments of third person communities through the CNN Effect if its necessary preconditions are met, such as policy uncertainty and elite dissensus.

Even though all six earthquakes prompted othering in the research sample, the nature of this was again found to have changed according to the level of development of the stricken country. Each government was liable for criticism according to the different expectations of their ability to prepare and respond to the earthquakes. Poor construction was also relative. For instance, where Japanese failings were outlined because they were unexpected, the earthquakes in Italy and Turkey prompted allegations of illegality in the construction industry, and the coverage of Pakistan and Haiti focused on their poverty as an explanation for their buildings' poor performance in the earthquakes. Japanese cultural traits were admiringly described, even if it was patronising, but the coverage of the Pakistani and Haitian earthquakes criticised their treatment of women, children and the disabled. Social disorder was present after the 
earthquakes in Chile, Pakistan and Haiti especially, while Haiti was responsible for a great deal of the coverage which featured details of a country's troubled history, poverty and a general lack of ability to cope by themselves.

This othering suggests that differences between communities may preclude the third person community's news media from acknowledging that they are susceptible to the same risks. This presents a development to Van Belle's model as this finding suggests that not all overseas disasters present an opportunity for news media to propel DRR onto the public agenda. Instead, it may only be possible following disasters in similarly developed countries, with which the third person community can establish an affinity. This is a significant because it may help to avoid wasting DRR aid on communities who are presently unwilling to face the social, political and economic costs of implementing it. This knowledge could inform those organisations currently promoting and funding the implementation of DRR in at-risk communities, and lead to more efficient use of the limited resources available. If aid is only given to those communities with news media that are already communalising overseas disasters to prompt a public discussion off DRR, it could potentially lead to the more efficient use of scarce resources.

\section{$\underline{\text { Implications for News theory }}$}

The findings contribute to the understanding of international news flows and the production of news. Although it is logical that a news outlet would interpret overseas events by covering them in a fashion that makes them relevant to their local audience, this investigation has confirmed that this does happen. Previous research has suggested that the level of identification between communities affects the frequency of coverage of overseas disaster events. This investigation has demonstrated that the level of 
identification between the stricken community and the third person community also affects the nature of the coverage of the disaster event, adding to the understanding of the production of the news.

These findings have significant implications for news theory. Firstly, they demonstrate that the inclusion of news stories for publication is selective, evidenced in the fact that the coverage of the overseas earthquakes was different across the six stricken countries. The gatekeeping practices of the two newspapers determined that the overseas earthquakes were newsworthy enough to be included in their bulletins, although what made the event newsworthy differed depending on the level of development of the stricken community. Significantly, the nature of the localisation in the news coverage changed according to the level of development of the affected country, reflecting the news values of the respective newsrooms, where different aspects of the earthquakes demanded coverage for different reasons. The practical application of Galtung and Ruge's news values of meaningfulness and personalisation resulted in the localisation of the overseas earthquakes, where the events were constructed by the newspapers in a manner which interpreted those events as affecting their own locality. More importantly, the presence of communalisation and othering augments their news values, and this presents an additional perspective to theoretical discussions of how the news is produced.

The typology of localisation constitutes a significant theoretical development of Van Belle's model. The typology of communalisation, partial communalisation, neutral localisation, partial othering, and othering can be applied to analyse other news events. The findings also suggest several meaningful additions to the understanding of 
communalisation and othering. The findings uncovered evidence that localisation is not only present in the news coverage of overseas disasters, but its nature is affected by factors other than the damage caused by the earthquake. While the pattern of the communalisation and othering across stricken communities did not perfectly match expectation, the findings do suggest that development is a very significant factor in influencing the nature of the coverage.

The findings demonstrate that localisation is worthy of further scrutiny as the news is packaged to meet its audience's needs as best as possible, interpreting events in a framework that best fits the expectations and the needs of that community. Local news outlets maintain an audience through this practice, especially in their coverage of events from outside their locality - where those events must be localised for them to be worthy of inclusion in their bulletin. The findings confirm the presence of localisation in the news coverage of non-local disaster events, and that the level of development affects how this localisation is evident in this coverage. It would be useful to examine other types of news events and investigate whether similar patterns of localisation are apparent in the resulting news coverage there.

\section{Suggestions for Future Research}

This investigation hypothesised that disaster events in lesser-developed countries would rarely prompt communalisation. The othering found in the investigation suggests it is unlikely for third person communities to identify with the disasters experienced by stricken communities in developing countries and for their news media to respond to those events by interpreting that event in terms of their own vulnerabilities. It could be unrealistic to assume that the people of the third person community can identify with 
the people of the stricken community to the extent where they can see themselves as potential victims of a similar event. If this were true of all third person communities, this would be important for DRR as the more targeted use of scarce resources could help to implement DRR in communities where it is already on the public agenda.

Future research could be conducted to determine whether the same patterns of communalisation and othering are found in the analysis of the news media of developing countries in their overseas disaster coverage. This research could examine whether the third person communities repeat the same practices of identifying with the wealthier countries and differentiating themselves from the poorer countries. It is possible that a different set of third person communities would identify more with the poorer nations and localise their vulnerabilities more than what the newspapers of Seattle and Vancouver did in this investigation. It would be useful to examine whether at-risk cities like Dhaka [Bangladesh], New Delhi [India], Kingston [Jamaica], Lima [Peru], and Manila [Philippines] feature similar patterns of communalisation and othering as the Seattle Times and the Vancouver Sun after the same six overseas earthquakes.

This future research would build on the understanding of international news flows and help determine how the news media in developing countries identify themselves. The investigation could reveal who they identify themselves with through the nature of the localisation in the news coverage of overseas disasters - whether the third person communities identify with similarly-developed countries or whether they communalise more after the developed countries they may be aspiring to be. This research could also be useful for discussions of DRR by providing insights into the interpretation of hazards 
in at-risk communities in developing countries. It is possible there could be some cultural or philosophical differences between third person communities in their interpretation of disaster events and the risks these hazards present to their own locality.

Alternatively, the research methodology could be applied to communities who have been affected by an earthquake in living memory, and whether the same trends of were evident or whether they approached overseas earthquakes entirely differently. The Seattle Times coverage after 2001 hints at the fact that there may be some difference in the way overseas disasters are localised by a recently-stricken community. It could be informative to analyse the news media in cities struck by natural disasters in living memory and assess how the nature of their coverage compared to the findings in this investigation. For example, it would be interesting to examine the coverage of hurricanes in the New York Times before and after Hurricane Sandy. Similarly, it would be interesting to examine the news media of communities which were not directly affected by the disaster event but were close enough to have some connections with the community which was affected. For instance, it could be useful to examine the San Francisco Chronicle's coverage of overseas disasters following the 1994 Northridge earthquake in Southern California. This could further contribute to the understanding of how the news media interpret disaster events in terms of their own vulnerabilities.

It is also important to investigate policy entrepreneurship as outlined in Van Belle's model. He proposed that a disaster event could be a catalyst for the implementation of DRR if political actors use the opportunity presented by the news coverage of that event to promote DRR in their own community. There are some indications that policy entrepreneurship does follow disasters. For instance, Birkland identified Senator Alan 
Cranston, H. Guyford Stever and Frank Press as political actors who were active in pursuing policy change following earthquakes, and the San Fernando earthquake in 1971 in particular $(1997,66-73)$. Further research should seek to establish whether it is possible for political actors to successfully exploit communalisation between communities to promote disaster risk reduction policies as predicted in Van Belle's model. This could involve analysing if policy entrepreneurship is present in the news coverage of overseas events. The research should evaluate their success in establishing measures of disaster risk reduction, and why they were successful or why they failed. It is perhaps even more important to identify whether the pursuit of DRR policies were politically successful and led to any increases in popularity among the policy entrepreneurs as this could encourage policy entrepreneurs to become active in campaigning for DRR following non-local disasters. This is particularly significant because the research could confirm that disaster risk reduction can become a political issue in the aftermath of an overseas disaster, and that it can be prudent for political actors to pursue disaster risk reduction in their own rational self-interest.

Olson and Gawronksi established a framework to account for how the political response to catastrophic events can become a 'political crisis' in the aftermath of a disaster (2010). However, Healy and Malhotra found that "myopic voters" in the United States "do not significantly reward governors for federal relief or preparedness spending" (2009, 392). If DRR became an issue on the public agenda through the communalisation between communities in the news coverage, it is possible that there would be greater reward for politicians who invest in preparedness spending and greater consequences for political actors who do not embrace DRR measures. However, avoiding a crisis is not necessarily newsworthy as it is difficult for policy entrepreneurs 
to claim credit for an event which does not happen, so pursuing DRR following a distant event remains the best opportunity for policy entrepreneurs to be successful.

Future research could help to confirm a model from which the news media, NGOs and policymakers could act together to implement disaster risk reduction in their community following an overseas earthquake. This has implications for disaster preparedness in at-risk communities all over the world in informing discussions of how to better achieve disaster risk reduction and establish more efficient uses of resources to mitigate against the risks of natural hazards. This could also be useful in influencing how aid is donated, with efforts focused on providing aid to those communities which are ready and willing to implement disaster risk reduction. This could ultimately lead to the successful implementation of disaster risk reduction if the preconditions of DRR in Van Belle's model are met.

This research could have significant consequences for DRR policy, but it also represents a dramatic departure from the prevailing ways of thinking about disaster risk reduction. If further evidence suggests that the preconditions in Van Belle's model have to be met for disaster risk reduction to be implemented, this could lead to more effective efforts at fomenting DRR policy in third person communities and more efficient use of money spent on DRR aid. Most importantly, it could result in disaster events causing fewer casualties in at-risk communities. Lessons can be learned from overseas disaster events in third person communities. It is important that more research is conducted to determine how at-risk communities all around the world can seize the opportunities presented by distant disasters to prepare for when disaster strikes closer to home. 


\section{APPENDIX \\ THE NEWSPAPER ARTICLES IN THE SAMPLE}

\section{The Seattle Times}

Japan earthquake

Anonymous. 1995. “Are You Prepared for When a Quake Hits?" The Seattle Times, January 18.

The Associated Press. 1995a. "The Survivors Seek Refuge: Hundreds of Thousands Homeless; Quake Toll Passes 2,500." The Seattle Times, January 18.

- 1995b. "The Survivors Seek Refuge: Quake Forces Kobe Rescuers to Leave Dead, Save the Living: Hundreds of Thousands Homeless; Death Toll Passes 3,000.” The Seattle Times, January 18.

The Associated Press, and the Washington Post. "1995a. "Death Toll Past 4,000: Kobe Relief Operation Can't Meet Basic Needs of Survivors." The Seattle Times, January 19.

- 1995b. "Kobe Quietly Mourns: Relief Operation Lags Behind Needs of Japanese." The Seattle Times, January 19.

Benkoil, Dorian. 1995. "Six Months After Quake, Kobe Struggles to Rebuild." The Seattle Times, July 17.

Boardman, David. 1996. "One year ago, Kobe was rocked by quake: Kobe rebuilds, but first images can be deceptive." The Seattle Times, January 16.

Dietrich, Bill. 1995a. “"Everyone is Spooked': Mild Quake has Similarities to Kobe's Disastrous One, Showing Area's Vulnerability." The Seattle Times, January 30.

—. 1995b. "Seattle Built to Withstand Quake Better than Kobe." The Seattle Times, January 24.

Eliason, Marcus. 1995. "A Year After Quake, Kobe's Residents are Still Suffering." The Seattle Times, December 31.

Farrey, Tom. 1995. “A Kingdome-size Dilemma on Earthquake Safety: Tough Choices Ahead on Safeguards." The Seattle Times, May 16.

Friedman, David. 1995. "Assessing Kobe's Psychic Aftershocks." The Seattle Times, January 26.

Martens, Carole. 1995. "Pro/Con: On Tuesday Seattle Voters Will Decide the Fate of a \$330 Million Levy to Renovate and Rebuild 19 Seattle Schools." The Seattle Times, February 3.

Simon, Jim. 1995a. "City Hall in Kobe is Now a Huge Homeless Shelter: Quake Survivors Putting Lives Back Together as Best they Can.” The Seattle Times, January 24.

1995b. "Kobe: Reporter Sketches Scenes from Shattered City." The Seattle Times, January 29.

1995c. "Kobe Slowly Returning to Life: Electricity, Water Being Restored; Subway Starts Up.” The Seattle Times, January 23. 
1995d. "Kobe's Elderly Stoically Endure Pain and Loss: 'You Cannot Expect Government to Help Much,' Says One.” The Seattle Times, January 27.

Talmadge, Eric. 1995. "Newsmen See Devastation in a Walk through Hell." The Seattle Times, January 18.

Thurber, David. 1995. "Cold, Disease, Hunger Now Threaten Kobe: Survivors Face Quake Aftermath." The Seattle Times, January 20.

Yamaguchi, Mari. 1995. "For Self-reliant Japanese, Help is Hard to Give or Take." The Seattle Times, January 20.

\section{Italy earthquake}

Barry, Colleen. 2009. "Italy's Shaky Finances Jolted by Quake." The Seattle Times, April 8.

Chong, Jia-Rui. 2009. "Despite Forecast, Quake Predictions on Shaky Ground." The Seattle Times, April 7.

D’Emilio, Frances. 2009a. "Italy Fears Mobsters Ready to Profit from Quake." The Seattle Times, April 19.

2009b. "Quake-proof Italy Lags in Quake-proofing Buildings." The Seattle Times, April 7.

David, Ariel. 2009a. "Italian Jews Aid World War II Saviors Hit by Quake." The Seattle Times, April 13.

- 2009b. "Italy Seeks to Move G-8 Summit to Quake-hit City." The Seattle Times, April 23.

de Cristofaro, Maria, and Henry Chu. 2009. "6.3 Quake in Italy Wrecks Historic Area's Past, Future." The Seattle Times, April 7.

Donadio, Rachel. 2009. "Funeral for 205 Victims of Quake in Italy." The Seattle Times, April 11.

Falconi, Marta. 2009. "Quake Survivors Face Hard Start in Tent Camps." The Seattle Times, April 9.

Falconi, Marta, and Frances D'Emilio. 2009. "Italy Especially Vulnerable to Quake Damage.” The Seattle Times, April 7.

Gera, Vanessa. 2009a. "Quake Brings Hardship to Italy's Immigrants." The Seattle Times, April 14.

2009b. "Some Quake Survivors Expect to Live in Tents for 6 Months." The Seattle Times, April 12.

Gera, Vanessa, and Marta Falconi. 2009. "Italy Outraged by Crumbling of Hospital in Quake." The Seattle Times, April 17.

Kole, William J. 2009a. "Buildings, Onna's Soul Destroyed Following Earthquake in Italy." The Seattle Times, April 8.

- 2009b. "Death of a Village: Losses Devastate Italian Town." The Seattle Times, April 7.

- 2009c. "Death of a Village: Losses Devastate Italian Town." The Seattle Times, April 7.

2009d. "Italy's Quake-stricken Cling to Faith for Comfort." The Seattle Times, April 8.

Rizzo, Alessandra. 2009a. "Berlusconi Wins Praise at the Quake Scene." The Seattle Times, April 10.

2009b. "Italy Readies Evacuation Plan for G8. The Seattle Times, July 7.

Winfield, Nicole. 2009. "Pope Demands Soul-searching After Italy Quake." The Seattle Times, April 28. 


\section{Chile earthquake}

Achenbach, Joel. 2010. "Urban Areas, Earthquakes a Lethal Combination." The Seattle Times, February 28.

Bajak, Frank. 2010. "Chile was Ready for Quake, Haiti Wasn't." The Seattle Times, February 27.

Borenstein, Seth. 2010a. "Not More Quakes, Just More People in Quake Zones." The Seattle Times, March 8.

Chang, Alicia. 2010a. "Northwest at Risk of Earthquake Like One in Chile." The Seattle Times, March 2.

2010b. "Northwest at Risk of Earthquake Like One in Chile." The Seattle Times, March 2.

Doughton, Sandi. 2010. "Tsunami-forecast Model Developed by Seattle Scientists Passes First Big Test." The Seattle Times, March 1.

2011a. "Dangerous Ground: Hard Lessons Learned Since the 2001 Nisqually Quake." The Seattle Times, February 26.

2011b. "Monday Marks 10 Years Since Big Nisqually Quake." The Seattle Times, February 27.

Ervin, Keith. 2011. "After Nisqually Quake, Need to Shore Up Buildings Persists.” The Seattle Times, February 26.

Haight, Abby. 2010. "Cannon Beach Plans Tsunami-resistant Building." The Seattle Times, May 31.

Haynes, Brad. 2010. "Chile Quake Offers Tough Lessons for US Coast." The Seattle Times, April 6.

Le Duc, Andre, John D. Schelling, and Cale Ash. 2010. "Puget Sound Must Not Be Complacent in the Face of an Earthquake Threat." The Seattle Times, March 4.

Talmadge, Eric. 2010. "Tsunami Warning Lifted; Waves Reach Japan, Russia." The Seattle Times, February 27.

Vergara, Eva, and Vivian Sequera. 2010. "Chile Quake Survivors Suffer Cold, Rainy Night." The Seattle Times, March 7.

Warren, Michael, and Eva Vergara. 2010a. "Chile Quake Death Toll Over 700 as Rescue Ramps Up.” The Seattle Times, February 28.

- 2010b. "Chile Says Rebuilding After Quake Could Take Years." The Seattle Times, March 4.

- 2010c. "Doctors Warn of Health Threat from Chile Wreckage." The Seattle Times, March 5.

Warren, Michael. 2010a. "Chile Pres. Faces Conflicts in Quake Recovery Plan.” The Seattle Times, June 13.

2010b. "Disaster Experts Praise Chile Quake Response." The Seattle Times, March 10.

—. 2010c. "Post-quake Chaos, Looting Wound Chile's Pride." The Seattle Times, March 2.

\section{Turkey earthquake}

Anonymous. 1999. "Quake Notebook: Turkish Airlines 737 will Transport Aid from Seattle Tonight." The Seattle Times, August 19.

Burkitt, Janet, and Jacob Fries. 1999. "Turkey Relief Flight Planned with Boeing Jet." The Seattle Times, August 18.

Burns, Robert. 1999. "Clinton Meets with Quake Victims." The Seattle Times, November 16. 
Fordahl, Matthew. 1999. "Engineers Eager to Examine Why Structures Fell." The Seattle Times, September 22.

Geitner, Paul. 1999. "Islamic Party May Thrive in Earthquake's Aftermath." The Seattle Times, August 26.

Hastings, Deborah. 1999. "Doctor Saves Lives with his People Skills." The Seattle Times, August 29.

Hockstader, Lee. 1999. "Earthquake Aftermath: Fast Growth Led to Flimsy Homes." The Seattle Times, August 19.

The Los Angeles Times, and the Associated Press. 1999. "Quake Crisis: Find Housing for Homeless." The Seattle Times, August 23.

Meixler, Loius. 2000. "26,000 Turks in Tents a Year After Quake.” The Seattle Times, August 16.

Murphy, Brian. 1999. "World Rushes to Turkey: Aid Teams Still Seeking Survivors of Quake." The Seattle Times, August 18.

Quinn, Patrick. 1999a. "Lessons from Turkey May Save Lives in Calif." The Seattle Times, August 27.

1999b. "Turkey Grapples with Sheltering Quake Survivors: Hundreds of Thousands Camp Outdoors." The Seattle Times, August 22.

Schmid, Randolph E. 2000. "Quakes Left Istanbul on Shaky Ground, Scientists Say." The Seattle Times, April 28.

Seattle Times News Services. 1999. "Rescuers Have Few Victories in Search for Quake Survivors: Death Count Surpasses 6,000; Anger Over Slow Response Grows." The Seattle Times, August 19.

Sheridan, Mary Beth, and Dexter Filkins. 1999. "Turks Leaving Shattered Cities." The Seattle Times, August 24.

Sorensen, Eric. 1999. "On Shaky Ground.” The Seattle Times, September 28.

Struck, Doug. 1999. "Tokyo Braces for Monster Quake Predicted by Experts." The Seattle Times, November 26.

Turner, Dale. 1999. "Disasters Remind US True Power Lies Within." The Seattle Times, September 11.

Verrengia, Joseph B. 1999. "Scientists Had Predicted Quake in Broad Time Frame." The Seattle Times, August 18.

Wilkinson, Tracy. 1999. "Survivors Recall their Prisons of Rubble." The Seattle Times, August 24.

\section{Pakistan earthquake}

The Associated Press, and Bloomberg News. 2005. "US Rushing Equipment, Supplies to Stricken Region." The Seattle Times, October 11.

Bernton, Hal, and Lornet Turnbull. 2005. "Latest Disaster Tests Stamina of Donors." The Seattle Times, October 11.

Glionna, John M. 2005a. "Earthquake Toll Pushes Pakistani Doctors to their Limits." The Seattle Times, November 8. 2005b. "Pakistani Bankrolls Earthquake Recovery." The Seattle Times, December 4.

Herman, Burt. 2006. "A Day in the Life of Quake Survivors." The Seattle Times, January 10.

Jan, Sadaqat. 2005a. "Girl, 5, Found Alive Amid Quake Ruins." The Seattle Times, October 12.

2005b. "Rain Halts Some Aid Flights to Quake Victims." The Seattle Times, October 11. 
2005c. "Rescuers Struggle to Reach Survivors as Quake Death Toll Kills More than 20,000." The Seattle Times, October 9.

Lancaster, John. 2005. "As Winter Looms, Quake Victims Resist Evacuation." The Seattle Times, November 6.

- 2006. "Pakistanis Spared Second Wave of Deaths from Record Quake." The Seattle Times, March 3.

Rosenberg, Matthew. 2005. "Kashmiri Separatists Dispense Quake Aid, a Move that could Boost their Cause." The Seattle Times, October 11.

Seattle Times News Services. 2005a. "Many Pakistanis Wait in Vain for Relief After Earthquake." The Seattle Times, October 15.

2005b. "Quake Victims' Frustration Boils Over as Relief Trickles in." The Seattle Times, October 11.

Tanner, Robert. 2005. "After the Quake, Kashmiri Family Keeps Grip on Old Ways." The Seattle Times, October 25.

Tu, Janet I. 2005a. "Embracing a Sister Village in Need." The Seattle Times, December 18.

2005b. "Teaching, Learning Amid the Rubble." The Seattle Times, December 19.

- 2006. "Infusion of Help, Hope to Villagers in Pakistan." The Seattle Times, August 27.

Watson, Paul. 2005. "Shining Promise Goes Dark." The Seattle Times, October 19.

Williams, Carol J. 2005. "Quake Victims' Plea: 'We Need Shelter'." The Seattle Times, October 16.

Ziadi, Mubashir, Paul Watson, and Shankhadeep Choudhury. 2005. "Pakistan Pleads for Help in Race to Rescue Victims." The Seattle Times, October 10.

\section{Haiti earthquake}

Bernton, Hal. 2010. "Two Months After the Quake, Many Haitians Still Wonder Where they Will Live." The Seattle Times, March 15.

2011. "Haiti's Quake Recovery Proves Painfully Slow." The Seattle Times, January 3.

Borenstein, Seth. 2010b. "Why Haiti Keeps Getting Hammered by Disasters." The Seattle Times, January 14.

Callimachi, Rukmini. 2010a. "Child Rescued from Haiti Rubble is Orphaned Again." The Seattle Times, June 19.

2010b. "Facebook Page Leads Search for Loved Ones in Haiti." The Seattle Times, September 1.

Crary, David. 2010. "Haitian Orphans Settling in with Adoptive Families." The Seattle Times, December 25.

Hanley, Charles J. 2010. "Looking for Lessons in Haiti's Epic Tragedy." The Seattle Times, March 1.

Higgins, Alexander G. 2010a. "Aid Workers in Haiti Face 'Logistical Nightmare'." The Seattle Times, January 14.

2010b. "Divisions Arise over Push for Adoptions from Haiti." The Seattle Times, April 11.

Katz, Jonathan M. 2010a. "Fights over Land Stall Haiti Earthquake Recovery." The Seattle Times, July 11.

2010b. "Haiti Recovery Bogged Down 6 Months After Quake." The Seattle Times, July 10. 
2010c. "UN Worries its Troops Caused Cholera in Haiti." The Seattle Times, November 19.

2011. "Haiti Suffers Year of Crisis with Nobody in Charge." The Seattle Times, January 8.

Lush, Tamara. 2010. "Retired Florida Teacher Rebuilds School in Haiti." The Seattle Times, August 29.

Mendoza, Martha. 2010. "Haiti Flight Logs Detail Early Chaos." The Seattle Times, February 18.

Mozingo, Joe, and Tracy Wilkinson. 2010. "With Slow Response and Few Tools, Haitian Bodies Pile Up." The Seattle Times, January 14.

Susman, Tina, Tracy Wilkinson, and Joe Mozingo. 2010. "Desperation Grips Haiti as Aid Struggles to Get In." The Seattle Times, January 14.

Tanner, Lindsey. 2010. "Haiti Quake Survivor Returns Home After 6 Months." The Seattle Times, September 6.

Thompson, Lynn. 2010. "Out of Haiti's Earthquake Chaos Comes an Adoption Miracle." The Seattle Times, January 29.

Viglucci, Andres, and Scott Hiaasen. 2010. "Starting from Scratch in Haiti's Port-auPrince Ruins." The Seattle Times, January 24.

\section{The Vancouver Sun}

\section{Japan earthquake}

Anonymous. 1995a. "Dogs Aid Rescues as Many Residents Flee Kobe on Foot." The Vancouver Sun, January 20, A10.

1995b. "First Flu, Now Depression Spread Among Survivors." The Vancouver Sun, January 27, A13.

1995c. "Horror Not Meant to Happen to Kobe: Massive Earthquake Comes Knocking at God's Door." The Vancouver Sun, January 18, A8.

1995d. "Japanese Government Admits Confusion in Wake of Huge Quake: Attention Now Shifting to 310,000 Left Homeless." The Vancouver Sun, January 21, A16.

1995e. "Japanese Quake Toll Tops 300: 400 People Still Trapped in Rubble, Officials Believe: Quake: Hundred Trapped in Rubble." The Vancouver Sun, January 17, A1.

1995f. "Japanese Quake Toll Tops 400: Apartment Buildings, Roads Collapse Trapping Hundreds." The Vancouver Sun, January 17, A1.

1995g. "Kobe Quake Toll Climbs as Cleanup Begins: Freezing Temperatures, Rain Add to Survivors' Misery." The Vancouver Sun, January 23, A6.

1995h. "Rescuers Claw for Survivors in Kobe's Debris." The Vancouver Sun, January 18, A1.

-. 1995i. "Your Insurance May Need to Withstand an Earthquake." The Vancouver Sun, February 6, D7.

Beauchesne, Eric. 1995. "Financial Markets from Earthquake Aftershocks." The Vancouver Sun, January 24, A1.

Cannata, Rosetta. 1995. "It Wasn't The Big One, but Quake was a Warning, Seismologist Says." The Vancouver Sun, January 30, B2.

Hamilton, Gordon. 1995. "B.C. Project Survives Quake with Flying Colors." The Vancouver Sun, February 4, C1.

Jameson, Sam. 1995. "PM 'Politically Responsible' for Deaths." The Vancouver Sun, February 10, A12. 
Kristof, Nicholas D. 1995. "Survivors Happy as Clams, Steaming in Warm Waters." The Vancouver Sun, January 26, A15.

McGill, Peter, and T.R. Reid. 1995. “Japan's Catastrophic Lesson: Quake: Japan's Disastrous Lesson: With Thousands Dead and More Missing, a Nation at Risk Takes a Chilling Second Look at its Quake-proofing Measures: And Wonders: What if it had Been Tokyo?" The Vancouver Sun, January 21, B1.

Munro, Margaret. 1995. "Earthquake at the Height of Rush Hour in Lower Mainland 'Would be Deadly'." The Vancouver Sun, March 9, B4.

Peterson, Leslie. 1995. "Simple Devices will Help Hold Houses Together when the Big One Hits." The Vancouver Sun, April 8, E12.

Sarti, Robert. 1995. "Student Awaiting Call from her Grandmother in Japan: and the Effects are Felt Halfway Around the World." The Vancouver Sun, January 18, A9.

Watanabe, Teresa. 1995. "Officials Accused of Saving Face, Not Lives: Kobe: Leaders Scramble." The Vancouver Sun, January 25, A1.

Yoshikawa, Miho. 1996. "Thousands Remain in Shelters Nearly Year After Kobe Quake: Some Victims Have Given Up Hope of Ever Owning a Home Again because they Cannot Pay for the one they Lost." The Vancouver Sun, January 15, A7.

\section{Italy earthquake}

Aloisi, Silvia, and Antonella Cinelli. 2009. "Earthquake Rescuers Hit by Aftershocks; 17,000 Homeless Sleeping in Tent Villages." The Vancouver Sun, April 9, B5.

Anonymous. 2009a. "Earthquake Kills At Least 16 in Central Italy; Rescuers Race to Find People Trapped in Rubble After Quake that Measured 5.8 on the Richter Scale." The Vancouver Sun, April 6, B4.

2009b. "Quake Exacts Heavy Toll on Historical Architecture." The Vancouver Sun, April 8, B3.

2009c. "Relief Turns to Anxiety for Earthquake Survivors." The Vancouver Sun, May 4, B4.

2009d. "State Funeral Slated for Earthquake Victims." The Vancouver Sun, April 10, B5.

2009e. "Woman, 98, Knitted Until her Rescue from Rubble." The Vancouver Sun, April 8, B3.

2009f. "Woman Mourns Loss of Daughter, Grandsons." The Vancouver Sun, April 8, B3.

De Souza, Mike, and Irwin Block. 2009. "Canadians Respond to Quake with Fundraising Campaigns; Outpouring of Support 'a Powerful Thing to View'." The Vancouver Sun, April 8, B3.

Dolmadjian, Katia. 2009. "Earthquake Leaves At Least 150 Dead." The Vancouver Sun, April 7, B1.

Nelson, Tara, and Mike De Souza. 2009. "Earthquake Forces Thousands into Tent Cities: Focus is on Medical Care for Survivors, and Security." The Vancouver Sun, April 9, B5.

Nelson, Tara, and Norma Greenaway. 2009. “'We Need a Miracle,' Rescuer Says as Hope Fades for Finding More People Alive; Terrified by a String of Aftershocks, Survivors Take Shelter in a Hastily Erected Tent City." The Vancouver Sun, April 8, B3.

Rayner, Gordon. 2009. "Geologist Called Scaremonger When he Predicted Quake; Giampaolo Giulani Told Locals to Evacuate Their Houses and Posted a Video 
Warning on YouTube, but Authorities Reported Him to Police." The Vancouver Sun, April 7, B5.

Rayner, Gordon, and Nick Squires. 2009. “'There's Nothing Left to Recover'; Powerful Quake Struck in Middle of the Night, Sending Tens of Thousands Running for Their Lives." The Vancouver Sun, April 7, B5.

Squires, Nick. 2009. "10,000 Grieve at Open-air Mass; Outpouring of Grief and Anger as 205 Coffins are Lined Up on a Field at a Police Barracks Outside the Devastated City of L'Aquila: the Only Place Judged Safe Enough to Hold a State Funeral for Earthquake Victims.” The Vancouver Sun, April 11, B5.

\section{Chile earthquake}

Adebar, Perry. 2011. "Earthquake Alert: How Safe are the Highrise Buildings in B.C.?" The Vancouver Sun, February 5, C5.

Almendras, Graciela. 2010. "Billionaire President's Administration Gets Off to Shaky Start; Pinera Sworn in as Aftershocks, Tsunami Alert Cause Panic Among Heads of State and in the Streets of Coastal City of Valparaiso." The Vancouver Sun, March 12, B7.

Andrews, Marke. 2010. "Banking on The Big One: Store Specializing in Emergency Survival Kits Opens its Doors at City Square Mall." The Vancouver Sun, August 30, B6.

Anonymous. 2010a. "Country Plans to Dip into its 'Rainy Day' Billions." The Vancouver Sun, March 19, B6.

— 2010b. "Experts Warn of More Strong Tremors Months After Quake." The Vancouver Sun, July 15, B8.

- 2011. "Chilean Mega-quake Felt in California Temblors." The Vancouver Sun, January 15, B7.

Cohen, Tobi. 2010. "Vancouver, Victoria are Most Vulnerable Canadian Cities: Report." The Vancouver Sun, December 2, B3.

Dimassa, Cara Mia. 2010. "Scientists Want Your Laptop to Sound Earthquake Alarm; Network of Volunteer 'Quake Catchers' Provides More, Faster and Better Data for Seismic Investigators.” The Vancouver Sun, March 17, B5.

Favennec, Gael. 2010. "Sounds of Life Emanate from Building Ruins; Rescue Teams Employ Cameras and Search Dogs to Find Survivors Amid Quake-strewn Rubble." The Vancouver Sun, March 2, B1.

Fowlie, Jonathan. 2010. "B.C. Services Not Equipped to Deal with Major Disaster: Audit." The Vancouver Sun, March 22, A4.

Gardner, Simon. 2010. "Chile's Incoming President Must Focus on Rebuilding; Sebastian Pinera and Opposition Rally on Emergency Aid, Reconstruction Funding Legislation." The Vancouver Sun, March 9, B5.

Gray, Richard. 2010. "Chile's Quake on Ring of Fire Erupted with the Force of Thousands of Atom Bombs; Pressure Built for Centuries on Fault that Encircles Pacific Basin." The Vancouver Sun, March 1, B6.

Hamilton, Gordon. 2010. "Chile Earthquake Boosts Pulp Prices; Canadian Producers Expect Higher Margins." The Vancouver Sun, March 16, C5.

Kraul, Chris. 2010. "Death Toll Rises After Massive Earthquake; 8.8-magnitude Quake Leaves At Least 700 Dead, Untold Numbers Missing, Millions Homeless." The Vancouver Sun, March 1, B1.

Pynn, Larry. 2010. "Effects of Tsunami Go Unnoticed by Tofino Beach Watchers." The Vancouver Sun, March 1, B6. 
Shore, Randy. 2010. “'Monster' Houses, Masonry Buildings at Risk in Quake; Vancouver is a Patchwork of Seismic Risk, Especially the Cheaply Built Structures from the 1980s, Expert Says." The Vancouver Sun, March 4, A11.

Sinoski, Kelly, and Tobi Cohen. 2010. "City Could Go Up in Flames in an Earthquake." The Vancouver Sun, December 15, A4.

Stone, Laura. 2010a. "Search is on for 138 Missing Canadians; Canada's Ambassador Says There are No Confirmed Reports of Casualties from this Country." The Vancouver Sun, March 4, B3.

- 2010b. "Search is on for 250 Missing Canadians; Canada's Ambassador Says There are No Confirmed Reports of Casualties from this Country." The Vancouver Sun, 4 March 4, B3.

Wilkinson, Tracy, and Patrick J. McDonnell. 2010. "Looting Contained, Clearing Way for Aid Shipments." The Vancouver Sun, March 3, B5.

\section{Turkey earthquake}

Anonymous. 1999a. "Daily Specials: Saturday." The Vancouver Sun, August 28, E12. 1999b. "Red Cross: Help Available to Trace Quake Victims." The Vancouver Sun, August 30, B1.

1999c. "Searchers Probe for Earthquake Victims: Some Officials in Turkey Fear as Many as 10,000 People May Be Buried in Debris After the Earthquake that Hit Early Tuesday." The Vancouver Sun, August 18, A3.

1999d. "Travel Advisories." The Vancouver Sun, August 21, H11.

. 1999e. "Travel Advisories." The Vancouver Sun, September 18, H4.

1999f. "Turkey Reduces Earthquake Death Toll: An Official Trying to Attract

More Aid for his Area was Blamed for the Inflated Figure." The Vancouver Sun, August 26, A12.

1999g. "Turkish Toddler Saved After Six Days in Rubble: The Rescue of the Boy Gives Quake Search Teams a Welcome Boost." The Vancouver Sun, August 24, A10.

- 2000. "Probe Can Help Save the Lives of People Trapped After Earthquake: A Richmond Based Company Has Developed a Device - the Rescue Communications Probe - Which Allows Rescuers to Communicate with People Buried Under the Rubble." The Vancouver Sun, March 6, B3.

Boucher, Sandra. 1999. "Ignoring Rescue Teams Costs Lives." The Vancouver Sun, August 24, A12.

Crone, Thomas. 1999. "Falling Behind in Earthquake Readiness." The Vancouver Sun, September 23, A18.

Editorial. 1999a. "Our Team Should Be There to Prepare for the Big One." The Vancouver Sun, August 23, A10.

1999b. "Rescue Team Ready for Duty." The Vancouver Sun, September 23, A18.

Krangle, Karenn. 1999. "Downtown Traffic Chaos Almost Over, City Pledges: The Problem-causing Pender Street Portion of the City's New Firefighting System Will Be Finished Soon and Next Year Traffic Trouble Will Be 'Minimal'." The Vancouver Sun, August 19, A1.

Nutt, Rod. 1999. "Search-and-rescue Leader Dismisses Report that Unit is Not Selfsufficient: After Being Passed Over for the Second Time This Summer, the Highly Trained Rescue Squad Has Lost One of its Leaders, Who Quit in Disgust." The Vancouver Sun, September 25, B7. 
Sajoo, Amyn B. 1999. “The Old Order on Shaky Ground: In the Aftermath of Turkey's Devastating Earthquake, Citizens are Questioning Their Dependence on the State, Their Respect for the Armed Forces and Their Place in Modern Europe." The Vancouver Sun, September 1, A13.

\section{Pakistan earthquake}

Agrell, Siri. 2005a. "Canadian Team Gets Water Flowing." The Vancouver Sun, October 24, A4.

- 2005b. "DART Members Frustrated at Delays: Late Supplies Push Back Hospital Opening in Pakistan." The Vancouver Sun, October 22, A15.

Alberts, Sheldon, and Siri Agrell. 2005. "Global Aid Begins to Arrive Amid Chaos of Pakistan Quake." The Vancouver Sun, October 11, A1.

Anonymous. 2005. "Pakistan Mourns Loss of an 'Entire Generation'; Quake Claimed 'Entire Generation' of Children." The Vancouver Sun, October 17, A6.

Blanchfield, Mike. 2005a. "Canadian Forces Finding Winter Tents for Homeless." The Vancouver Sun, October 18, A14.

2005b. "Canadian Mission Seeks Role for DART." The Vancouver Sun, October 14, A14.

2005c. "Crisis Opens Contentious Border: The Move Allows Quake Victims to Find Family Members." The Vancouver Sun, October 19, A14.

2005d. "Quake Victims Like 'Terrorists' Grabbing for Aid." The Vancouver Sun, October 15, A3.

Editorial, 2005a. "Blood Will Be On Our Hands Unless We Help Desperate Quake Victims." The Vancouver Sun, November 9, A18.

2005b. "Making a Difference." The Vancouver Sun, December 28, A10.

Edwards, Steven. 2005. "Asia Quake Toll May Outstrip Tsunami's: UN Predicts Second Wave of Deaths." The Vancouver Sun, October 21, A1.

Fisher, Matthew. 2005. "Soldiers Honour War Dead Amid Devastation." The Vancouver Sun, November 12, A7.

Glionn, John M. 2005. “Amid Quake's Rubble, Barber Reopens for Business." The Vancouver Sun, November 24, A17.

Hamilton, Gordon. 2005a. "Donations May Bring New Trading Partner." The Vancouver Sun, November 18, D2.

2005b. "Workers Donate Day's Pay to Quake Victims in Pakistan." The Vancouver Sun, November 2, D5.

Lee, Jenny. 2005. "Girls Who Escaped Quake Head for B.C. to Stay with Relatives." The Vancouver Sun, October 15, A3.

Leung, Wency. 2006. "Success Through Disaster: B.C.-made Wood Houses Hold Great Potential for Disaster Relief." The Vancouver Sun, May 15, F1.

Manthorpe, Jonathan. 2005. "China Embarks on Mission to Recover Historic Relics." The Vancouver Sun, October 24, D3.

Skelton, Chad. 2005. "Relatives Cope with Loss After Massive Quake." The Vancouver Sun, October 10, A1.

Woods, Allan. 2005. "Ottawa to Match Quake Donations." The Vancouver Sun, October 12, A1.

\section{Haiti earthquake}

Alberts, Sheldon. 2010a. "Exhausted Haitians Pray for Strength; Six Months After the Earthquake, Little Rebuilding Has Been Done: And Now it's Hurricane Season." The Vancouver Sun, July 10, B7. 
2010b. "Stoic Residents Face Up to the Misery; While Many Have Lost Everything, Haitians Seldom Complain as They Struggle to Rebuild." The Vancouver Sun, January 30, B1.

Allen, Nick, and Bruno Waterfield. 2010. "Child-trafficking Fears Grow as West Looks to Fast-track Adoption Process; Children's Charities Call for Stop on Adoptions until Efforts Made to Reunite Families." The Vancouver Sun, January 23, B7.

Berkow, Jameson. 2010. "Plastic Homes: Canadian Company Thinks it Has an Answer for Haitian Relief." The Vancouver Sun, December 30, C4.

Bruemmer, Rene. 2010. "Rebuilding a Community: Haiti and the World Face an Enormous Challenge in Trying to Rebuild Following a 7.0-magnitude Earthquake that Struck on Jan. 12, Killing More Than 240,000 and Leaving 1.3 Million People Homeless." The Vancouver Sun, April 17, C1.

2011. "Slow Reconstruction Raises Aid Questions; Are the Many NGOs Operating in the Country Helping or are They Slowing Things Down?" The Vancouver Sun, January 8, B6.

Cayo, Don. 2010a. "Heroes or Villains? In Haiti, it is Often Hard to Tell; Haiti's Poverty Makes it Difficult for Families to Provide for Their Children and Opens the Door for Those Who Want to Exploit Them." The Vancouver Sun, February 6, C4.

- 2010b. "Is There Any Hope in the Rubble? Bangladesh, Central America and Southeast Asia Have Managed to Move On After Tragedy." The Vancouver Sun, January 23, C1.

Charles, Jacqueline. 2010. "Deadly Cholera Epidemic Has Country Running Scared; Residents are Stoning Body Collection Teams that Have Nowhere to Bury Corpses." The Vancouver Sun, November 27, B9.

Greenaway, Norma. 2010. "Will a Better Haiti Emerge from the Rubble? Reconstruction Efforts Following Tsunami in Indonesia Demonstrate that 'Impossible' is Achievable." The Vancouver Sun, January 16, B2.

Iype, Mark, Jorge Barrera, and Allison Cross. 2010. "500,000 Feared Dead in Haiti; A Canadian Nurse Among Those Killed as Donors from Around the World Rush to Send Millions of Dollars to Help Battered Nation." The Vancouver Sun, January 14, A1.

Kielburger, Craig. 2010. "Haitians Helping Haitians are the True Heroes in the Recovery; While the World Scrambles to Get its Relief Efforts in Place, Local Residents are Using Their Skills and Resources to Help Their Fellow Citizens." The Vancouver Sun, January 20, B1.

Kielburger, Craig, and Marc Kielburger. 2010. "We Need Alternative Ways of Delivering Aid in Haiti." The Vancouver Sun, January 18, B4.

Kielburger, Craig, Marc Kielburger, and Drew Davidson. 2011. "Haiti's Plight." The Vancouver Sun, January 12, A11.

Landsberg, Mitchell. 2010a. "Life Starts to Take on a Routine; Some Tent Cities Choosing Leaders, Forming Own Security Service and Even Naming Streets in Makeshift Community." The Vancouver Sun, February 1, B5.

2010b. "School Opens After Debate with Squatters; People Living in the Yard Object to Being Told They Will Have to Move While School is in Session." The Vancouver Sun, February 2, B5.

Macintyre, Iain. 2010. "Paying it Forward with Presents, Presence: Defenceman Dan Hamhuis Went to Disaster-struck Haiti to Give it Back: His Life Will Never be the Same." The Vancouver Sun, December 26, D7. 
Mozingo, Joe. 2010a. "Death is Part of Life in Ravaged Country: Jan. 12 Earthquake was Catastrophic, but Cholera Epidemic Underscores Island Nation's Fragility." The Vancouver Sun, November 10, B5.

—. 2010b. "Earthquake's Aftershocks Widen Chasm between Christianity, Voodoo Beliefs; Evangelicals Claim Devastation in Wake of Disaster is 'Warning from God to Those Witch Doctors'." The Vancouver Sun, January 30, B7.

Trenton, Daniel, and Alfonso Chardy. 2010. "Prayer, Music to Remember the Dead; in Haiti, Thousands Take Part in Three-day Service Marking One-month Anniversary of Earthquake." The Vancouver Sun, February 13, B7. 


\section{BIBLIOGRAPHY}

Adams, William C. 1986. "Whose Lives Count? TV Coverage of Natural Disasters." Journal of Communication 36 (2): 113-122.

Alexander, David. 2012. “Our Starting Point." International Journal of Disaster Risk Reduction 1 (1): 1-4.

Allan, Stuart. 2010. "Journalism and the Culture of Othering." Brazilian Journalism Research 6 (2): 26-40.

Allen, Chris W. 2000. "Reporting World War II for the Local Audience: Jack Shelley's Experience as a Local Radio Reporter in the European Theater." American Journalism 17 (1): 35-52.

Anonymous. 2012a. "Capital 'Designed to Cope' with Big Quakes." The Dominion Post, July 24, 5.

2012b. "Earthquake Report Sobering." The Dominion Post, November 15, 12.

The Associated Press, and Seattle Times Business Staff. 2010. "Seattle Times Mirrors National Drop in Newspaper Circulation.” The Seattle Times, October 25.

Babbie, Earl. 2010. The Practice of Social Research. $12^{\text {th }}$ ed. Belmont, CA: Wadsworth.

Baumgartner, Frank R., and Bryan D. Jones. 1993. Agendas and Instability in American Politics. Chicago, IL: University of Chicago Press.

Bennett, W. Lance. 1988. News: The Politics of Illusion. $2^{\text {nd }}$ ed. New York, NY: Longman.

1994. "The Media and the Foreign Policy Process." In The New Politics of American Foreign Policy, edited by David A. Deese, 168-189. New York, NY: St Martin's Press.

- 2007. News: The Politics of Illusion. $7^{\text {th }}$ ed. New York, NY: Pearson Longman.

Bennett, W. Lance, Regina G. Lawrence, and Steven Livingston. 2007. When the Press Fails: Political Power and the News Media from Iraq to Katrina. Chicago, IL: University of Chicago Press.

Bilham, Roger. 1995. "Global Fatalities from Earthquakes in the Past 200 Years: Prognosis for the Next 30." In Reduction and Predictability of Natural Disasters: Proceedings of the Workshop "Reduction and Predictability of Natural Disasters" held January 5-9, 1994 in Santa Fe, New Mexico, edited by John B. Rundle, Donald L. Turcotte, and William Klein, 19-31. Reading, MA: Addison-Wesley.

Birkland, Thomas A. 1997. After Disaster: Agenda Setting, Public Policy, and Focusing Events. Washington, D.C.: Georgetown University Press. 
2006. Lessons of Disaster: Policy Change After Catastrophic Events. Washington, D.C.: Georgetown University Press.

Boin, Arjen, and Paul 't Hart. 2003. "Public Leadership in Times of Crisis: Mission Impossible?" Public Administration Review 63 (5): 544-553.

Boyd-Barrett, Oliver. 1979. "Media Imperialism: Toward an International Framework for the Analysis of Media Systems." In Mass Communication and Society, edited by James Curran, Michael Gurevich, and Janet Woolacoot, 116-141. Beverly Hills, CA: Sage.

Briceño, Sálvano. 2012. "Foreword." In The Routledge Handbook of Hazards and Disaster Risk Reduction, edited by Ben Wisner, J.C. Gaillard and Ilan Kelman, xxvii-xxxi. Abingdon; New York, NY: Routledge.

Chang, Stephanie E. 2010. "Urban Disaster Recovery: A Measurement Framework and its Application to the 1995 Kobe Earthquake." Disasters 34 (2): 303-327.

Chang, Tsan-Kuo. 1998. "All Countries Not Equal to be News: World System and International Communication." Communication Research 25 (5): 528-563.

Chang, Tsan-Kuo, Tuen-yu Lau, and Hao Xiaoming. 2000. "From the United States with News and More: International Flow, Television Coverage and the World System." International Communication Gazette 62 (6): 505-522.

Chapman, Katie. 2011. "Can We Cope with a Big One? Government Report Finds Cracks in Capital's Emergency Management." The Dominion Post, June 2, 1. 2012. "Quake Fear: No Way In or Out." The Dominion Post, February 17, 1.

Cheesman, Tom, Arnd-Michael Nohl, and BBC WS US Elections Study Group. "Many Voices, One BBC World Service? The 2008 US Elections, Gatekeeping and Trans-editing." Journalism 12 (2): 217-233.

Cho, Hiromi, and Stephen Lacy. 2000. "International Conflict Coverage in Japanese Local Daily Newspapers." Journalism and Mass Communication Quarterly 77 (4): 830-845.

Clark, Helen E. 2012. "Building Resilience: The Importance of Prioritising Disaster Risk Reduction: A United Nations Development Programme Perspective." Lecture presented at the annual Hopkins Lecture, University of Canterbury, Christchurch, New Zealand, August 15.

Clausen, Lisbeth. 2004. "Localizing the Global: 'Domestication' Processes in International News Production." Media, Culture and Society 26 (1): 25-44.

Cohen, Bernard C. 1963. The Press and Foreign Policy. Princeton, NJ: Princeton University Press.

Combs, Barbara, and Paul Slovic. 1979. "Newspaper Coverage of Causes of Death." Journalism Quarterly 56 (4): 837-849. 
Cowan, Jodie. 1998. "The Effects of Media Descriptions on Judgements about Earthquakes." Master's thesis, Victoria University of Wellington.

Cowan, Jodie, John McClure, and Marc Wilson. 2002. "What a Difference a Year Makes: How Immediate and Anniversary Media Reports Influence Judgements about Earthquakes." Asian Journal of Social Psychology 5 (3): 169-185.

Dahlgren, Peter and Sumitra Chakrapani. 1982. "The Third World on TV News: Western Ways of Seeing the 'Other'." In Television Coverage of International Affairs, edited by William C. Adams, 45-65. Norwood, NJ: Ablex.

Darling-Wolf, Fabienne. 2008. "Holier than Thou: News of Racial Tensions in a Transnational Context." 9 (3): 357-373.

Davies, Nick. 2009. Flat Earth News: An Award-winning Reporter Exposes Falsehood, Distortion and Propaganda in the Global Media. London: Vintage.

Davis, Aeron. 2007. The Mediation of Power: A Critical Introduction. London; New York, NY: Routledge.

- 2010. Political Communication and Social Theory. Abingdon; New York, NY: Routledge.

Davis, Ian. 1978. Shelter after Disaster. Oxford: Oxford University Press.

de Beer, Arnold S. 2010. "News from and in the 'Dark Continent'." Journalism Studies 11 (4): 596-609.

Dimitrova, Daniela V., Lynda Lee Kaid, Andrew Paul Williams, and Kaye D. Trammell. 2005. "War on the Web: The Immediate News Framing of Gulf War II." The Harvard International Journal of Press/Politics 10 (1): 22-44.

Drury, A. Cooper, Richard S. Olson, and Douglas A. Van Belle. 2005. "The Politics of Humanitarian Aid: U.S. Foreign Disaster Assistance, 1964-1995.” The Journal of Politics 67 (2): 454-473.

Emergency Events Database: The Office of U.S. Foreign Aid Disaster Assistance/Centre for Research on the Epidemiology of Disasters, Universite Catholique de Louvain, Brussels, Belgium. 2009. "The EM-DAT Glossary." Accessed May 30 2012. http://www.emdat.be/glossary/9\#term81.

Emergency Events Database: The Office of U.S. Foreign Aid Disaster Assistance/Centre for Research on the Epidemiology of Disasters, Universite Catholique de Louvain, Brussels, Belgium. 2012. "Result Disaster Profiles." Accessed June 15 2012. http://www.emdat.be/result-disaster-profiles?disgroup $=$ natural\&dis_type=Earthquake(seismicactivity)\&period=1993\$2012.

Enia, Jason. Forthcoming. "The Spotty Record of the Hyogo Framework for Action: Understanding the Incentives of Natural Disaster Politics and Policy Making." The Social Science Journal. 
Ericson, Richard Victor, Patricia M. Baranek, and Janet B.L. Chan. 2009. "Reading the News." In Mass Communication Research Methods: Researching Media Institutions, Organisations, Professionals and Production (continued). Political Economy (Media Institutions). The Political Economy of Communications, edited by Anders Hansen, 129-149. London: Sage.

Fine, Michelle. 1994. "Working the Hyphens: Reinventing Self and Other in Qualitative Research." In Handbook of Qualitative Research, edited by Norman K. Denzin and Yvonna S. Lincoln, 130-155. Newbury Park, CA: Sage.

Galtung, Johan. 1971. “A Structural Theory of Imperialism.” Journal of Peace Research, 8 (2): 81-118.

Galtung, Johan, and Mari H. Ruge. 1965. "The Structure of Foreign News: The Presentation of the Congo, Cuba and Cyprus Crises in Four Norwegian Newspapers." Journal of Peace Research 2 (1): 64-90.

Glaser, Barney G., and Anselm L. Strauss. 1967. The Discovery of Grounded Theory: Strategies for Qualitative Research. Chicago, IL: Aldine.

Global Facility for Disaster Risk Reduction. 2008. Integrating Disaster Risk Reduction into the Fight Against Poverty. Washington, D.C.: Global Facility for Disaster Reduction and Recovery.

Golan, Guy J. 2008. "Where in the World is Africa?: Predicting Coverage of Africa by US Television Networks." The International Communication Gazette 70 (1): 41-57.

Gurevitch, Michael, Mark R. Levy, and Itzhak Roeh. 1991. "The Global Newsroom: Convergences and Diversities in the Globalisation of Television News." In Communications and Citizenship: Journalism and the Public Sphere in the New Media Age, edited by Peter Dahlgren and Colin Sparks, 195-216. London: Routledge.

Hafez, Kai. 2011. "Global Journalism for Global Governance? Theoretical Visions, Practical Constraints." Journalism 12 (4): 483-496.

Hanson, Robin. 2008. "Catastrophe, Social Collapse, and Human Extinction.” In Global Catastrophic Risks, edited by Nick Bostrom and Milan M. Cirkovic, 363-377. Oxford; New York, NY: Oxford University Press.

Hanusch, Folker. 2008. "Valuing Those Close to Us: A comparison of German and Australian quality newspapers' reporting of death in foreign news." Journalism Studies 9 (3): 341-356.

Harcup, Tony, and Deirdre O'Neill. 2001. "What is News? Galtung and Ruge Revisited." Journalism Studies 2 (2): 261-280.

Harrison, Jackie. 2006. News. London; New York, NY: Routledge. 
Healy, Andrew, and Neil Malhotra. 2009. "Myopic Voters and Natural Disaster Policy." The American Political Science Review 103 (3): 387-406.

Hergovich, Andreas, Reinhard Schott, and Christoph Burger. 2010. "Biased Evaluation of Abstracts Depending on Topic and Conclusion: Further Evidence of a Confirmation Bias Within Scientific Psychology." Current Psychology 29 (3): 188-209.

Hubbard, Anthony. 2013. "Talking Up the Issues.” The Dominion Post, January 12, 1.

Hunt, Tom. 2011. "Capital Reliant on Access from Sea and Air if Quake Hits." The Dominion Post, March 9, 1.

Ito, Youichi. 1990. "Mass Communication Theories from a Japanese Perspective." Media, Culture \& Society 12 (4): 423-464.

Iyengar, Shanto, and Donald R. Kinder. 1987. News that Matters: Television and American Opinion. Chicago, IL: University of Chicago Press.

Jamieson, Thomas, and Douglas A. Van Belle. 2013. "Constructing Risks and Hazards Through the Coverage of Foreign Disasters: Implications for Foreign Aid and Other Disaster Risk Reduction Policies." Paper presented at the International Studies Association Annual Convention, San Francisco, California, April 3-6.

Kennan, George F. 1993. "Somalia, Through a Glass Darkly." The New York Times, September 30, A25.

Krøvel, Roy. 2012. "Setting the Agenda on Environmental News in Norway." Journalism Studies 13 (2): 259-276.

Krumer-Nevo, Michal, and Orly Benjamin. 2010. "Critical Poverty Knowledge: Contesting Othering and Social Distancing." Current Sociology 58 (5): 693714.

Krumer-Nevo, Michal, and Mirit Sidi. 2012. "Writing Against Othering." Qualitative Inquiry 18 (4): 299-309.

Lang, Gladys Engel, and Kurt Lang. 1980. "Newspaper and TV Archives: Some Thoughts About Research on Disaster News." In Disasters and the Mass Media: Proceedings of the Committee on Disasters and the Mass Media Workshop, February 1979, edited by the Committee on Disasters and the Mass Media, 269-280. National Academy of Sciences.

Lang, Kurt, and Gladys Engel Lang. 1966. "The Mass Media and Voting." In Reader in Public Opinion and Communication, edited by Bernard Berelson and Morris Janowitz, 2nd ed., 455-472. New York, NY: Free Press.

Lee, Chin-Chuan. 1980. Media Imperialism Reconsidered: The Homogenizing of Television Culture. Beverly Hills, CA: Sage. 
Leung, Christine M., and Yu Huang. 2007. “The Paradox of Journalistic Representation of the Other: The Case of SARS Coverage on China and Vietnam by Westernled English-Language Media in Five Countries." Journalism 8 (6): 675-697.

Livingston, Steven. 1997. "Clarifying the CNN Effect: An Examination of Media Effects According to Type of Military Intervention.” Research Paper R-18. Harvard University.

- 2011. "The CNN Effect Reconsidered (again): Problematizing ICT and Global Governance in the CNN Effect Research Agenda." Media, War and Conflict 4 (1): 20-36.

Livingston, Steven, and Eachus, Todd. 1995. "Humanitarian Crises and U.S. Foreign Policy: Somalia and the CNN Effect Reconsidered." Political Communication 12 (4): 413-429.

Lofland, John, David A. Snow, Leon Anderson, and Lyn H. Lofland. 2006. Analysing Social Settings: A Guide to Qualitative Observation and Analysis. $4^{\text {th }}$ ed. Belmont, CA: Wadsworth.

Lupovici, Amir. Forthcoming. "Me and the Other in International Relations: An Alternative Pluralist International Relations 101." International Studies Perspectives.

Madec, Alain. 1981. "The Political Economy of Information Flows." Intermedia 9 (2): 29-32.

Mathewson, Nicole. 2013. "Pre-quake Christchurch being forgotten." The Press [Christchurch], March 17. Accessed March 25, 2013. http://www.stuff.co.nz/the-press/news/christchurch-earthquake-2011/8436779/ Pre-quake-Christchurch-being-forgotten.

Maxfield, Michael G., and Earl Babbie, 2009. Basics of Research Methods for Criminal Justice and Criminology. $2^{\text {nd }}$ ed. Belmont, CA: Wadsworth.

McClure, John, Robbie M. Sutton, and Chris G. Sibley. 2007. "Listening to Reporters or Engineers?: How Instance-Based Messages about Building Design Affect Earthquake Fatalism." Journal of Applied Social Psychology 37 (9): 19561973.

McClure, John, Robbie M. Sutton, and Marc Wilson. 2007. "How Information about Building Design Influences Causal Attributions for Earthquake Damage." Asian Journal of Social Psychology 10 (4): 233-242.

McCombs, Maxwell E., and Donald L. Shaw. 1972. "The Agenda-Setting Function of Mass Media." The Public Opinion Quarterly 36 (2): 176-187.

McGregor, Judy. 2002. "Terrorism, War, Lions and Sex Symbols: Restating News Values." In What's News? Reclaiming Journalism in New Zealand, edited by 
Judy McGregor and Margie Comrie, 111-125. Palmerston North: Dunmore Press.

McQuail, Denis. 1994. Mass Communication Theory: An Introduction. 3rd ed. London: Sage.

Merrill, John C. 1995. Global Journalism: Topical Issues and Media Systems. 3rd ed. Boston, MA: Pearson.

Meyer, William H. 1989. "Global News Flows: Dependency and Neoimperialism." Comparative Political Studies 22 (3): 243-264.

Molotch, Harvey, and Marilyn Lester. 1974. "News as Purposive Behaviour: On the Strategic Use of Routine Events, Accidents, and Scandals." American Sociological Review 39 (1): 101-112.

Newspapers Canada. 2012. "2011 Daily Newspaper Circulation by Province." Accessed 15 June 2012. http://www.newspaperscanada.ca/sites/default/files/2011-DailyNewspapers_Circulation- Report-05302012.pdf.

Nickerson, Raymond S. 1998. "Confirmation Bias: A Ubiquitous Phenomenon in Many Guises." Review of General Psychology 2 (2): 175-220.

Nossek, Hillel. 2004. "Our News and their News: The Role of National Identity in the Coverage of Foreign News." Journalism 5 (3): 343-368.

Oliver-Smith, Anthony. 1999. “"What is a Disaster?': Anthropological Perspectives on a Persistent Question." In The Angry Earth: Disaster in Anthropological Perspective, edited by Anthony Oliver-Smith and Susanna M. Hoffman, 18-34. New York, NY: Routledge.

Olson, Richard S., and Vincent T. Gawronski. 2010. "From Disaster Event to Political Crisis: A '5C+A' Framework for Analysis." International Studies Perspectives 11 (3): 205-221.

Olson, Richard S., Juan Pablo Sarmiento Prieto, and Gabriela Hoberman. 2010. "Disaster Risk Reduction, Public Accountability, and the Role of the Media: Concepts, Cases, and Conclusions." Background Paper Prepared for the 2011 Global Assessment Report on Disaster Risk Reduction. Geneva: United Nations International Strategy for Disaster Reduction.

—. 2011. "Establishing Public Accountability, Speaking Truth to Power and Inducing Political Will for Disaster Risk Reduction: 'Ocho Rios + 25'." Environmental Hazards 10 (1): 59-68.

Overholser, Geneva. 1999. "In the Age of Public Ownership, the Importance of Being Local." Columbia Journalism Review 38 (4): 64.

Pantti, Mervi, Karin Wahl-Jorgensen, and Simon Cottle. 2012. Disasters and the Media. New York, NY: Peter Lang Publishing. 
Paul, Bimal Kanti, and Rejuan Hossain Bhuiyan. 2010. "Urban Earthquake Hazard: Perceived Seismic Risk and Preparedness in Dhaka City, Bangladesh." Disasters, 34 (2): 337-359.

Pauly, John J., and Melissa Eckert. 2002. "The Myth of 'The Local' in American Journalism." Journalism and Mass Communication Quarterly 79 (2): 310-326.

Podkalicka, Aneta. 2011. "Factory, Dialogue, or Network? Competing Translation Practices in BBC Transcultural Journalism.” Journalism 12 (2): 143-152.

Powell, Plato J. 2011. "Post-disaster Reconstruction: A Current Analysis of Gujarat's Response after the 2001 Earthquake. Environmental Hazards 10 (3): 279-292.

Quarantelli, Enrico L. 1987. "What Should we Study? Questions and Suggestions for Researchers about the Concept of Disasters." International Journal of Mass Emergencies and Disasters 5 (1): 7-32.

Radford, Tim, and Ben Wisner. 2012. "Media, Communication and Disasters." In The Routledge Handbook of Hazards and Disaster Risk Reduction, edited by Ben Wisner, J.C. Gaillard and Ilan Kelman, 761-771. Abingdon; New York, NY: Routledge.

Reese, Stephen D., and Bob Buckalew. 1995. "The Militarism of Local Television: The Routine Framing of the Persian Gulf War." Critical Studies in Mass Communication 12 (1): 40-59.

Robertson, Roland. 1992. Globalisation, Social Theory and Global Culture. London: Sage.

Robinson, Piers. 1999. "The CNN Effect: Can the News Media Drive Foreign Policy?" Review of International Studies 25 (2): 301-309.

Rolston, Bill, and Greg Mclaughlin. 2004. "All News is Local: Covering the War in Iraq in Northern Ireland's Daily Newspapers." Journalism Studies 5 (2): 191202.

Rony, Fatimah Tobing. 1996. The Third Eye: Race, Cinema, and Ethnographic Spectacle. Durham, NC: Duke University Press.

Said, Edward W. (1978) 2003. Orientalism. Reprint, London: Penguin.

Sanderson, David, and Anshu Sharma. 2008. "Winners and Losers from the 2001 Gujarat Earthquake." Environment and Urbanization 20 (1): 177-186.

Schiller, Herbert I. 1969. Mass Communication and American Empire. New York, NY: Killy.

Seattle Office of Intergovernmental Relations. 2011. "Seattle Sister Cities." Accessed June 15 2012. http://www.seattle.gov/oir/sistercities/cities.htm. 
Shoemaker, Pamela J. and Stephen D. Reese. 1996. Mediating the Message: Theories of Influences on Mass Media Content. $2^{\text {nd }}$ ed. New York, NY: Longman.

Simpson-Housley, Paul, and Fred A Curtis. 1983. "Earthquake Occurrence, Experience and Appraisal in Wellington, New Zealand." The Professional Geographer 35 (4): 462-467.

Singhal, Arvind, and Parichart Sthapitanonda. 1996. "The Role of Communication in Development: Lessons Learned from a Critique of the Dominant, Dependency and Alternative Paradigms." Journal of Development Communication 7 (1): $10-25$.

Smith, Conrad. 1992. Media and Apocalypse: News Coverage of the Yellowstone Forest Fires, Exxon Valdez Oil Spill, and Loma Prieta Earthquake. Westport, CT: Greenwood Press.

Stallings, Robert A. 1995. Promoting Risk: Constructing the Earthquake Threat. New York, NY: Aldine de Gruyter.

Strauss, Anselm L., and Juliet M. Corbin. 1994. "Grounded Theory Methodology: An Overview." In Handbook of Qualitative Research, edited by Norman K. Denzin and Yvonna S. Lincoln, 273-285. Newbury Park, CA: Sage.

- 1998. Basics of Qualitative Research: Techniques and Procedures for Developing Grounded Theory. $2^{\text {nd }}$ ed. Thousand Oaks, CA: Sage.

Sunstein, Cass R. 2007. Worst-case Scenarios. Cambridge, MA: Harvard University Press.

Teo, Peter. 2000. "Racism in the News: A Critical Discourse Analysis of News Reporting in two Australian Newspapers." Discourse and Society 11 (1): 7-49.

Tierney, Kathleen J., Michael K. Lindell, and Ronald W. Perry. 2001. Facing the Unexpected Disaster Preparedness and Response in the United States. Washington, D.C.: Joseph Henry Press.

Tierney, Kathleen J., Christine Bevc, and Erica Kuligowski. 2006. "Metaphors Matter: Disaster Myths, Media Frames, and Their Consequences in Hurricane Katrina." Annals of the American Academy of Political and Social Science 604 (1): $57-81$.

Todorov, Tzvetan. 1984. The conquest of America: The Question of the Other Translated by Richard Howard. New York, NY: HarperCollins.

Tomlinson, John. 1991. Cultural Imperialism: A Critical Introduction. London: Pinter.

Tuchman, Gaye. 1978. Making News: A Study in the Construction of Reality. New York, NY: Free Press.

Turner, Ralph H. 1980. "The Mass Media and Preparation for Natural Disaster." In Disasters and the Mass Media: Proceedings of the Committee on Disasters 
and the Mass Media Workshop, February 1979, edited by National Research Council (U.S.). Committee on Disasters and the Mass Media, 281-292. National Academy of Sciences.

Turner, Ralph H., Joanne M. Nigg, and Denise Heller Paz. 1986. Waiting for Disaster: Earthquake Watch in California. Berkeley, CA; Los Angeles, CA; London: University of California Press.

United Nations Development Programme, 2004. Reducing Disaster Risk: A Challenge for Development. Geneva: United Nations Development Programme.

—. 2011. "Human Development Report 2011: Sustainability and Equity: A Better Future for All." Accessed June 15 2012. New York, NY: United Nations Development Programme. http://hdr.undp.org/en/media/HDR_2011_EN_ Complete.pdf.

United Nations International Strategy for Disaster Reduction. 2009a. 2009 Global Assessment Report on Disaster Risk Reduction. Geneva: United Nations International Strategy for Disaster Reduction.

- 2009b. UNISDR Terminology on Disaster Risk Reduction. Geneva: United Nations International Strategy for Disaster Reduction.

2011. 2011 Global Assessment Report on Disaster Risk Reduction. Geneva: United Nations International Strategy for Disaster Reduction.

United States Geological Survey: Earthquake Hazards Program. 2013. "Historic World Earthquakes.” Accessed 22 March 2013. http://earthquake.usgs.gov/earthquake es/world/historical.php.

Van Belle, Douglas A. 2000. "New York Times and Network TV News Coverage of Foreign Disasters: The Significance of the Insignificant Variables.” Journalism and Mass Communication Quarterly 77 (1): 50-70.

- 2008. "Agenda-Setting and Donor Responsiveness to Humanitarian Crisis and Development Aid." Paper presented at the Harvard-World Bank Workshop. Cambridge, Massachusetts, 29-31 May 2008.

—. 2012. "Media's Role in Disaster Risk Reduction: The Third-Person Effect." Paper presented at the International Studies Association Annual Convention, San Diego, California, April 1-4.

Van Belle, Douglas A., Jean-Sébastien Rioux, and David M. Potter. 2004. Media, Bureaucracies and Foreign Aid: A Comparative Analysis of the United States, the United Kingdom, Canada, France and Japan. New York, NY; Basingstoke: Palgrave Macmillan.

Wardle, Claire. 2006. "'It Could Happen to You': The Move towards 'Personal' and 'Societal' Narratives in Newspaper Coverage of Child Murder, 1930-2000." Journalism Studies 7 (4): 515-533.

Weill, Susan, and Laura Castañeda. 2004. “'Empathetic Rejectionism' and Inter-ethnic Agenda Setting: Coverage of Latinos by the Black Press in the American South." Journalism Studies 5 (4): 537-550. 
Wellington City Council. 2013. "Earthquake Risk to Wellington." Accessed March 25 2013. http://wellington.govt.nz/services/rates-and-property/earthquake-pronebuildings/improving-earthquake-resilience/earthquake-risk-to-wellington.

White, David Manning. 1950. "The Gatekeeper: A Case Study in the Selection of News.” Journalism Quarterly 11: 383-396.

Wimmer, Roger D., and Joseph R. Dominick. 1997. Mass Media Research: An Introduction. $5^{\text {th }}$ ed. Belmont, CA: Wadsworth.

Wisner, Ben, J.C Gaillard, and Ilan Kelman. 2012. "Challenging Risk: We Offer the Reader a Left-Foot Book." In The Routledge Handbook of Hazards and Disaster Risk Reduction, edited by Ben Wisner, J.C. Gaillard and Ilan Kelman, 1-7. Abingdon; New York, NY: Routledge.

Woo, Gordon. 2011. Calculating Catastrophe. London; Singapore: Imperial College Press.

The World Bank Group. 2009a. Disaster Risk Management: Managing Natural Hazards, Reducing Risks to Development. Washington, D.C.: World Bank. 2009b. Global Facility for Disaster Risk Reduction Project: Reducing the Risk of Disasters and Climate Variability in the Pacific Islands. Washington, D.C.: World Bank.

—. 2013. "Data: GNI per capita, Atlas Method." Accessed March 252013. http://data.worldbank.org/indicator/NY.GNP.PCAP.CD?order=wbapi_data_va lue_2011+wbapi_data_value+wbapi_data_value-last\&sort=desc.

Wright, Michael. 2012. "Brownlee apologises for 'moaning' comments." The Press [Christchurch]. Last modified April 12 2012. Accessed March 252013. http://www.stuff.co.nz/the-press/news/christchurch-earthquake2011/7663412/ Brownlee-apologises-for-moaning-comments.

Wu, H. Denis. 2000. "Systemic Determinants of International News Coverage: A Comparison of 38 Countries." Journal of Communication 50 (2): 110-130. 